\title{
Establishing and Pushing the Knowledge Boundaries of Electroimmobilization in Fisheries Science
}

\author{
By
}

\author{
Connor H. Reid
}

A thesis submitted to the Faculty of Graduate and

Postdoctoral Affairs in partial fulfillment of

the requirements for the degree of

Master of Science

in

Biology

Carleton University

Ottawa, Ontario

(C)2020

Connor H. Reid 


\begin{abstract}
Researchers and fisheries professionals who must handle fish in field, laboratory, and hatchery settings do so with the safety and welfare of both fish and handler in mind. Pharmaceuticals have long been used during fish handling procedures (e.g. surgeries) and data collection, but have drawbacks such as the inability to immediately release wild fish postexposure given potential of fish to be consumed by humans. The use of electricity to immobilize fish (henceforth "electroimmobilization") is a viable and effective alternative to pharmaceuticals, yet its relatively recent emergence comes with difficulties for electroimmobilization's eventual formal incorporation into animal care guidelines. I provide the first ever review of the electroimmobilization literature in a synthesis of current knowledge, knowledge gaps, and future research needs. I then use an experimental approach to address one of the identified knowledge gaps; namely, whether there is any evidence that pharmaceuticals improve the welfare of electroimmobilized fish. I found that fish electroanesthetized during a short-term surgical procedure did not benefit from the application of lidocaine to the surgery site, failing to generate support for the application of local analgesics to improve the welfare of electroanesthetized fish. Overall, much evidence exists to support the use of electroimmobilization instead of pharmaceuticals, but many questions still remain unanswered.
\end{abstract}




\section{Preface}

Chapter 2 has been reproduced from an original published article, reprinted with permission from Wiley, 2020. The bibliographical details of the original article are:

Reid, C. H., C. S. Vandergoot, J. D. Midwood, E. D. Stevens, J. Bowker, and S. J. Cooke. 2019. On the electroimmobilization of fishes for research and practice: Opportunities, challenges, and research needs. Fisheries 44(12): 576-585.

This article has undergone the following formatting changes in being included in this thesis: (1) Box 1 in the original publication (on electroimmobilization terminology) has been incorporated into the main text (2.1. Introduction; p. 5-6); and (2) the conclusions section has been omitted and incorporated in 4. Conclusions. All coauthors contributed by providing revisions and edits to the manuscript.

Chapter 3 comprises a manuscript that is in preparation. The bibliographical details for Chapter 3 (Does a Local Analgesic Complement Electroanesthesia of a Teleost Fish?) are:

Reid, C. H., E. D. Stevens, J. D. Midwood, T. W. Moon, A. E. I. Abrams, A. J. Zolderdo, and S. J. Cooke. (Manuscript in Preparation). Does a local analgesic complement electroanesthesia of a teleost fish?

Coauthors E. D. Stevens, J. D. Midwood, and S. J. Cooke contributed to the experimental design and have provided revisions and edits to the manuscript as it appears in this thesis. T. W. Moon also provided revisions and edits to the manuscript. A. E. I. Abrams and A. J. Zolderdo provided invaluable assistance with field and laboratory work, and contributed to experimental design in the field. 


\section{Acknowledgements}

The research presented herein was supported by NSERC, the Ocean Tracking Network, the Canada Research Chairs Program, the Great Lakes Fishery Commission, and Fisheries and Oceans Canada. I would first thank my supervisor, Dr. Steven J. Cooke, and the Cooke Lab as a whole, for all of the unparalleled learning opportunities I have had the privilege of sharing in for five great years. My co-supervisor, Dr. Jonathan D. Midwood, and committee members Dr. Thomas W. Moon and Dr. William G. Willmore, have also provided invaluable support over the course of my degree, as have other co-authors on the papers comprising my main thesis chapters (Alice E.I. Abrams, Dr. Jim D. Bowker, Dr. E. Don Stevens, Dr. Christopher S. Vandergoot, and Aaron J. Zolderdo). A number of colleagues assisted significantly with field and laboratory work; I would again thank Alice Abrams and Aaron Zolderdo, as well as gratefully acknowledge the support and contributions of Carol Best, Auston Chhor, Brooke Etherington, Dr. Kathleen Gilmour, Daniel Glassman, Ben Hlina, Peter Holder, Amanda Jeanson, Jon Kubelka, Liane Nowell, Shuhong Shi, Isabelle Tooker, Alexandria Trahan, and Adam Williamson to the work presented here. I am further indebted to I. Tooker, who has been (and remains) an unending source of motivation and support. 


\section{Table of Contents}

Abstract $\quad$ ii

Preface $\quad$ iii

Acknowledgements $\quad$ iv

Lists of Tables, Illustrations, and Appendices vi

1. Introduction: Sedation and Anesthesia in Humans and Other Animals 1

2. On the Electroimmobilization of Fishes for Research and Practice:

Opportunities, Challenges, and Research Needs 4

2.1. Introduction 4

2.2. Insight from Human and Non-Fish Vertebrate Applications 6

2.3. Background and Theory of Electroimmobilization 7

2.4. Current Knowledge and Gaps 9

2.5. Current and Potential Applications 23

2.6. Specific Acknowledgements

3. Does a Local Analgesic Complement Electroanesthesia of a

Teleost Fish? $\quad 29$

3.1. Introduction 29

3.2. Methods $\quad 32$

3.3. Results 45

3.4. Discussion

4. Conclusions

$\begin{array}{ll}\text { References } & 68\end{array}$ 


\section{List of Tables}

Table 1: Benefits and challenges of electroimmobilization

\section{List of Illustrations}

Figure 1: Electroimmobilization equipment examples

Figure 2: Experimental treatment summary

Figure 3: Surgical setup $\quad 38$

Figure 4: Voluntary escape attempts during surgery 48

Figure 5: Line cross counts post-surgery 449

$\begin{array}{ll}\text { Figure 6: Plasma cortisol results } & 60\end{array}$

$\begin{array}{ll}\text { Figure 7: Blood glucose results } & 61\end{array}$

Figure 8: Blood lactate results $\quad 62$

Figure 9: Plasma osmolality results

$\begin{array}{ll}\text { Figure 10: Haematocrit results } & 64\end{array}$

\section{List of Appendices}

$\begin{array}{ll}\text { Appendix I } & 78\end{array}$

$\begin{array}{ll}\text { Statistical Analysis Outputs } & 78\end{array}$

Model Selection Outputs $\quad 92$ 


\section{Introduction: Sedation and Anesthesia in Humans and Other Animals}

At the Battle of Shrewsbury in 1403 CE, sixteen-year-old Prince Henry (later Henry V of England) had the misfortune of getting shot in the face with an arrow. Having survived this typically fatal occurrence, the Prince then experienced the ordeal of extracting said arrow, which struck next to his nose and embedded about six inches deep into his skull (Lang 1992). The arrow was removed by the capable hands of court surgeon John Bradmore, who had to invent a forceps-like tool to get the job done ${ }^{1}$. The operation, while successful, was apparently conducted with no described sedatives or anesthetics, and must have been traumatic for the young Prince.

Thus, while the list of unpleasant medical procedures that one might experience today is certainly long and varied, the great advances in health and sanitation, surgical techniques, tools/technologies, and anesthesia over time have brought us to a point where an experience like that of Henry V is virtually unfathomable. Although human sedation for medical purposes can be traced back into antiquity, with examples of plant-based substances such as mandrake root in ancient Rome (Chidiac et al. 2012) and opium in Sumer (Brownstein 1993), this was clearly not practiced in all places at all times. The eventual discovery of anesthesia by chloroform (Wawersik 1997), diethyl ether (Connor 2004), and nitrous oxide (Grimm et al. 2015) in the 1840s were milestones in humanity's search for safer and more ethically sound methods for numerous medical procedures.

Recent ( $\sim 1800$ onward) advances in human anesthesiology were often applicable in veterinary contexts, including anesthetic substances as well as techniques such as intravenous anesthesia, local infiltrations, and regional (e.g. epidural) anesthesia (Grimm et al. 2015). Despite

\footnotetext{
${ }^{1}$ Harley MS 1736, folio 48. British Library, London, U.K.
} 
this, adoption of many of these techniques in veterinary medicine was much slower than in human medicine, and also inconsistent across different domesticated taxa (Grimm et al. 2015). It was once popular belief that animals did not need anesthesia as humans do; today, however, the standards and care of veterinary medicine (at least for terrestrial vertebrates) are largely comparable to those of human medicine (Steffey 2014). Concerning aquatic animals, including fish, the picture is less clear.

Browman and Skiftesvik (2011) found the aquatic animal welfare literature to be clouded by several issues also present throughout scientific literature in general, including disregard of null results and so-called "faith-based" research. The literature on aquatic animal welfare holds much debate on whether fish (or other taxa) are "sentient" and/or can "feel pain", concepts that are frequently left poorly or not at all defined (Browman et al. 2019). While debate continues, the fact that fish welfare can be impacted by human activities, including in field and laboratory research, recreational and commercial activities, and indirect human influence (e.g. pollution), is undisputed (Rose et al. 2014). Human interactions with fish should be guided by evidence-based policies, especially for fisheries researchers and professionals. To that end, the use of sedatives and anesthetics on fish is extensive and frequently mandatory (e.g. Ackerman et al. 2005), but these substances all have drawbacks with implications for fish welfare and we must continue to refine both our body of knowledge and handling practices. This thesis focuses on the use of electricity for safe and effective fish immobilization (henceforth "electroimmobilization"). Specifically, the goal of my thesis is to summarize the current literature on electroimmobilization (including establishing appropriate terminology, knowledge and knowledge gaps, and major future directions), and then experimentally address the question of whether electroimmobilization should be complemented with the simultaneous use of pharmaceuticals. 
There is a significant body of available (albeit unorganized) literature on this topic, which is reviewed and summarized below (Chapter 2). Then, an experiment is presented (Chapter 3) wherein behavioural and physiological changes were measured in fish that had undergone electroimmobilization with and without a local analgesic applied to the surgery site, to test the hypothesis that the welfare of electroanesthetized fish is ameliorated by the additional application of a local analgesic. I close by generating a series of conclusions and identifying future research needs and opportunities (Chapter 4). 


\section{On the Electroimmobilization of Fishes for Research and Practice: $\underline{\text { Opportunities, Challenges, and Research Needs }}^{2}$}

\subsection{Introduction}

Data collection in fisheries science frequently requires the safe acquisition and handling of live fish as well as the use of both invasive (e.g. surgical implantation of transmitters, nonlethal tissue sampling) and non-invasive sampling procedures (e.g. measuring body size). These activities can induce stress (e.g. from capture and/or handling) and cause injury (e.g. if a fish is dropped), which individually or collectively can have negative consequences for the physiology, health, and welfare of fish (e.g. Barton and Iwama 1991). Immobilization techniques (prevention of movement, typically utilizing various chemical compounds) are frequently employed to help minimize the negative consequences of handling fish (Trushenski et al. 2013) and ensure researcher safety (particularly when working with large fishes).

Traditionally, chemical sedatives/anesthetics such as MS222 (tricaine methanesulfonate), carbon dioxide, or clove oil have been used to facilitate fish handling (reviewed in Ross and Ross 2008). These techniques are still frequently used, despite the assorted logistical challenges associated with their use, which include: lengthy handling times while waiting for drugs to take effect; stress on experimental subjects associated with the metabolic effects of anesthetics; enforcement of proper chemical handling practices; lack of clarity or understanding regarding the legal status of use; and extended post-exposure recovery and substance withdrawal periods (Trushenski et al. 2012b, 2013). In recent years there has been increased demand for immediate-

\footnotetext{
${ }^{2}$ Please note that this chapter has been peer-reviewed and published (see Preface on page iii). The list of coauthors on the publication is as follows:

C. H. Reid, C. S. Vandergoot, J. D. Midwood, E. D. Stevens, J. D. Bowker, and S. J. Cooke
} 
release approaches that allow fish to be safely released or consumed immediately following recovery (i.e. also referred to as "zero withdrawal”; Schnick 2006; Trushenski et al. 2013). Electroimmobilization techniques are an appealing substitute with potential advantages over chemical sedatives that will be explored here in further detail.

In fisheries science the terms "sedation", "anesthesia", and "narcosis" have occasionally been used synonymously and/or inconsistently (Trushenski and Bowker 2012), and explicitly stated definitions for these terms are often not provided. The terminology recommended in this review is roughly based on symptomatic definitions supplied by Ross and Ross (2008), wherein anesthesia is defined as, "a reversible, generalized loss of sensory perception accompanied by a sleep-like state induced by drugs or by physical means," and sedation as, "a preliminary level of anesthesia, in which the response to stimulation is greatly reduced and some analgesia is achieved but sensory abilities are generally intact and loss of equilibrium does not occur." The terms "narcosis" and "anesthesia" have been considered synonymous. This review will use the terms electrosedation and electroanesthesia (as with the respective terms from Ross and Ross 2008; the former may be considered to be a lesser or preliminary stage of the latter).

Electrosedation is a state of immobility from muscle relaxation due to low-voltage electricity, characterized by partial loss of equilibrium and reactivity to other stimuli. At higher voltages, full loss of equilibrium and reactivity to other stimuli is observed; this I refer to as electroanesthesia. Further increases in voltage may induce electrotetany, a state of immobility from contracted muscles. Electrosedation, electroanesthesia, and electrotetany are typically associated with very fast recovery times. Alternatively, fish may be immobilized for a prolonged period with initial tetany and a delayed, sleep-like recovery period potentially spanning several minutes (Cowx and Lamarque 1990). This non-instantaneous recovery from tetany distinguishes 
this more intense form of immobilization from electrotetany, and so I refer to it herein as electrostunning. In short, electrosedation, electroanesthesia, electrotetany, and electrostunning are all forms of electroimmobilization that occur along an increasing gradient of voltage (though depend on current type/parameters as well).

Electroimmobilization has been considered a potential alternative to chemical anesthesia

for many years (e.g. Kynard and Lonsdale 1975). However, a review of the efficacy and safety of electroimmobilization, as well as an effort to summarize current knowledge and identify knowledge gaps on this topic, has not been previously conducted. The purpose of this review is to: (1) assess the effectiveness of electroimmobilization techniques for the safe handling of live fish in fisheries science; (2) compare the behavioural, physiological, and fitness impacts as well as the logistics of electroimmobilization techniques with those of chemical sedation; and (3) summarize current available research on electroimmobilization techniques while identifying knowledge gaps and areas of future research. I begin by providing a brief overview of how low doses of electricity have been used in humans and non-fish vertebrates to emphasize the work on the topic and precedence for using such tools in clinical and therapeutic contexts. I acknowledge that the terminology associated with research in this area has been inconsistent, so I also define and differentiate key terms.

\subsection{Insight from Human and Non-Fish Vertebrate Applications}

Electrosedation, electroanesthesia, and electrotetany have been used in humans and other non-fish vertebrates for medicinal purposes and in the farming of livestock. Research on the use of electrosedation on humans as replacements for chemical anesthetics during surgeries and as therapeutic treatments was common throughout much of the 20th century, but declined in the 
1970s and 1980s due to major developments in chemical anesthetics (Francis and Dingley 2015). The electrical stimulation of nerves for analgesia ("pain" relief) is seen in modern physiotherapy with mixed results using devices such as transcutaneous electrical nerve stimulation (TENS) units (DeSantana et al. 2008; Vance et al. 2014; available from pharmacies without prescription) and in dentistry for pain management and muscle spasm relief (Quarnstrom 1992). There are also procedures such as deep brain stimulation (Arsenault et al. 2015) that attempt to use electricity for the treatment of various neurological disorders. Beyond use in humans, electricity of various forms has also been used in veterinary practices for both pain management and therapeutic applications, though this has also seen mixed results in part due to lack of knowledge of appropriate electrotherapy parameters and protocols across a wide array of real-life scenarios (Baxter and McDonough 2007). Complete immobilization via electricity has been used to facilitate the slaughter of livestock (Grandin 2013) although its use in mammals remains controversial (see American Veterinary Medical Association 2008). In other words, while many people tend to view electricity as a hazardous or noxious stimulus, this is not always the case, and there is no reason to believe that humans or non-human mammals are the only animals capable of experiencing beneficial effects from the safe application of electricity in a controlled setting and for specific purposes.

\subsection{Background and Theory of Electroimmobilization}

Electricity in its various forms has been used for many decades on wild fishes and at aquaculture facilities. Aquaculturists use electroimmobilization to stun (i.e. to induce unconsciousness; Robb and Roth 2003) fish prior to slaughter or spawning, whereas field biologists typically use it to temporarily immobilize fish during handling procedures. Despite its 
widespread use, the exact means by which various forms and strengths of electricity affect fish are not well-understood. The biological mechanisms by which electric currents can sedate, tetanize, or stun fishes is presumably based on the same mechanisms underlying electrofishing. However, no recent work has been conducted in this area. The following is a brief summary of the relevant physiology as examined in detail by Cowx and Lamarque (1990). This information is often cited in the electroimmobilization literature, however some of the physiological explanations offered by research cited therein (e.g. Vibert 1963) are erroneous and merit reevaluation by modern experts. When exposed to constant direct current (cDC; constant polarity), the nerve elements are facilitated ("activated") if the anode (+) is positioned at the body cell end of a fish's nerves (i.e. head facing the anode) or inhibited if the cathode (-) is positioned at the body cell end of a fish's nerves (in general, taxonomic- and orientation-dependent effects of electric currents on neurons seem to exist more broadly in animal nervous systems; Müller 1970). When a fish faces the anode, electricity will induce (in order of increasing voltage) electrosedation, electroanesthesia, electrotetany, and then electrostunning. When a fish faces the cathode, electrosedation is not observed, and electrotetany and electrostunning occur at lower voltages than when the fish faces the anode (n.b., author observations corroborate the existence of some orientation-dependent variation in responses to $\mathrm{cDC}$, though the full extent of this phenomenon should be elucidated in future work). Exposing a fish to pulsed direct current (pDC) may yield less predictable outcomes because of the immense variation in potential pDC settings (e.g. waveform, pulse frequency, and pulse duration). Electrosedation and electroanesthesia are unachievable with this pulsed current due to the intermittent nature of $\mathrm{pDC}$ that precludes chronic muscle relaxation. Instead, pDC induces electrotetany (at much lower voltages than those required by $\mathrm{cDC}$ ) and, through more intense exposure, prolonged incapacitation, probably 
through synaptic fatigue and post-tetanic potentiation (lowered activation threshold lasting for a variable but prolonged time after the current ceases). Alternating current (AC) will induce electrostunning at sufficiently high voltages, but, because of the continuous anode/cathode switching, will not yield any polarity-induced effects (e.g. anodic/cathodic galvanotaxis).

A summary of the known benefits and challenges of electroimmobilization has been provided in Table 1. Currently, pDC and cDC are the most commonly employed current types for electroimmobilization. Once commonplace, use of AC has been largely abandoned after being found to be more hazardous towards fish than direct current (Ackerman et al. 2005).

\subsection{Current Knowledge and Gaps}

\subsubsection{Known effects of electroimmobilization on fish}

$\underline{\text { Physiological Alterations }}$

Most investigations of the physiological alterations of electroimmobilization concern blood chemistry and stress physiology. Plasma cortisol was not shown to differ significantly from a control when Bluegill Lepomis macrochirus were exposed to electroanesthesia (cDC) or electrostunning (pDC), though in Largemouth Bass Micropterus salmoides plasma cortisol was significantly higher among electroanesthetized individuals (Abrams et al. 2018). This suggests that taxonomic variation does not necessarily permit extrapolating cortisol responses from one species to another, even within the same family. Grass Carp Ctenopharyngodon idella

electrostunned (pDC) at different voltages and durations of current exhibited quick, short-lived increases in plasma cortisol and lactate, a gradual net increase in glucose, and mild variations in haematocrit and osmolality (Bowzer et al. 2012); similar findings were reported in Sunshine Bass Morone chrysops $\times$ M. saxatilis (Trushenski and Bowker 2012). Electric fish handling 
gloves designed for low-voltage electrosedation or electroanesthesia (cDC) yielded no significant differences in blood glucose, lactate, $\mathrm{pH}$, or haematocrit compared with non-electric handling or control groups (Ward et al. 2017).

Side-by-side comparisons of blood chemistry profiles between electroimmobilized and chemically sedated fish have been conducted for a number of species, though there are visible inconsistencies across these studies' results. A decrease of plasma cortisol and increase in blood glucose relative to a control group was detected in Crucian Carp Carassius carassius that either underwent prolonged electroanesthesia (cDC; 1 h) or were anesthetized with MS-222 (100 or $200 \mathrm{mg} / \mathrm{L}$ for $1 \mathrm{~h}$ ), though the decrease in cortisol was greater in the fish treated with MS-222 (Gao et al. 2014). On the other hand, an experiment on electroanesthetized (cDC) juvenile Atlantic Sturgeon Acipenser oxyrinchus found no significant differences in plasma cortisol levels between electroanesthetized and MS222-sedated individuals (Balazik et al. 2013). This may be attributable to the difference in exposure time; the 1-h exposure in Gao et al. (2014) being much longer than what would be required in virtually any field procedure. Interestingly, Japanese Eels Anguilla japonica electrostunned (AC or $\mathrm{pDC}$ ) at high ( $\geq 240 \mathrm{~V})$ voltages exhibited lower plasma cortisol within 3 min of immobilization than conspecifics sedated with MS-222 or 2phenoxyethanol (Chiba et al. 2006). It is unclear whether this apparent reversal in relative plasma cortisol trends between electroimmobilized and chemically sedated fish is due to the type of current or level of electroimmobilization used, the species tested, environmental factors, or an interaction of these variables. A comparison of Sunshine Bass that were electrostunned $(\mathrm{pDC})$ or sedated with $\mathrm{CO} 2$, benzocaine, eugenol, or MS-222 found that all treatments exhibited a generalized stress response visible in haematological profiles, and the observed blood chemistry changes subsided within $6 \mathrm{~h}$ (Trushenski et al. 2012a). Johnson et al. (2016) reported higher 
plasma osmolality (associated with stress responses) in electrostunned (pDC) Pallid Sturgeon Scaphirhynchus albus than conspecifics sedated with MS-222 or eugenol, but, as with Trushenski et al. (2012a), most variation in tested individuals' haematological profiles dissipated within $6 \mathrm{~h}$. Therefore, while the haematological response to electrostunning via $\mathrm{pDC}$ is typically consistent with that of a generalized stress response, the same response may not be elicited through electrosedation or electroanesthesia via cDC. Ward et al. (2017) failed to detect an effect of electroanesthesia (cDC) on secondary stress markers (blood glucose, lactate, $\mathrm{pH}$, and haematocrit) in Largemouth Bass, whereas higher haematocrit levels (associated with stress responses) were observed in clove oil-sedated Common Carp Cyprinus carpio compared to electroanesthetized (cDC) individuals (Monsef Rad et al. 2016). Variation in the relative physiological effects of electroimmobilization compared with chemical sedatives therefore appears to be influenced by a number of factors including species and the form of electroimmobilization used, as well as the concentration of employed chemical sedatives.

Fewer studies have been conducted on the physiological effects of electroimmobilization using non-haematological metrics. The prolonged electroanesthesia (cDC) of Crucian Carp resulted in oxidative stress detected through elevated gene expression for several mitochondrial respiratory chain genes, antioxidant enzymes, and heat shock proteins (Gao et al. 2014). Conversely, electrostunned (pDC) adult Zebrafish Danio rerio did not exhibit symptoms of oxidative stress or significant differences in metabolic rate and mitochondrial performance with respect to a control group (Teulier et al. 2018). Because of the differences between these two experiments (species, electroimmobilization type, metrics used), it is difficult to pinpoint the exact cause of this apparent contradiction. Duryea (2014) investigated healing rates of a ventral 
incision in Gopher Rockfish Sebastes carnatus, which did not significantly differ between electrostunned (pDC) and chemically sedated fish.

\section{Behavioral Impairments}

Arguably the most commonly studied behavioural effects of electroimmobilization concern induction and recovery times. As the time required to induce immobilization and allow for recovery of fish is critically important from an animal welfare perspective, this is understandable. The diverse representation of fish taxa, life history stages, and electroimmobilization parameters in studies on induction and recovery times can make direct comparisons across studies difficult. It is generally agreed that induction of immobilization appears to occur immediately in fish at all levels of electroimmobilization (i.e. sedation, anesthesia, tetany, and stunning; e.g. Balazik et al. 2013; Keep et al. 2015; Abrams et al. 2018). Recovery times are less predictable, varying with species and electrical parameters (pulse, voltage, exposure time, etc.). For instance, higher voltages and longer exposure times were associated with longer recovery times in juvenile Sunshine Bass (Trushenski and Bowker 2012), but this relationship was not visible in Grass Carp tested using similar testing protocols and exposed to the same voltages and similar exposure times (Bowzer et al. 2012). The recovery times of Crucian Carp from low-voltage electroanesthesia (cDC) observed by Gao et al. (2014) were non-instantaneous (ranging from 3-7 s), possibly due to the fact that the fish experienced chronic symptoms from exposure to the electric current for $1 \mathrm{~h}$ (again, a much longer time than necessary or relevant for virtually any field procedure).

A relatively large body of research in electroimmobilization either focuses on or includes comparisons of induction and recovery times between electroimmobilization techniques and fish 
drugs. This body of research clearly establishes superior induction and recovery times as one of the primary advantages of electroimmobilization over chemical sedation. Faster induction and recovery times for electroimmobilized fish have been documented in Pallid Sturgeon (electrostunned [pDC]; Johnson et al. 2016), Atlantic Sturgeon (electroanesthetized [cDC]; Balazik et al. 2013), Gopher Rockfish (electrostunned [pDC]; Duryea 2014), Striped Bass M. saxatilis (electroanesthetized [cDC]; Jennings and Looney 1998), and Walleye Sander vitreus (electroanesthetized [cDC]; Vandergoot et al. 2011). It should be noted that recovery times may not differ significantly between electroimmobilized and chemically sedated fish in cases where electrostunning is induced at high voltages (e.g. Vandergoot et al. 2011 [pDC]; Prystay et al. $2017[\mathrm{pDC}])$.

The six stages of anesthesia defined by Summerfelt and Smith (1990) currently serve as the primary reference for determining the desired level of "anesthesia" (typically Stage IV; total loss of equilibrium, muscle tone, spinal reflexes with slowed opercular rate) in many studies involving electroimmobilization (e.g. Vandergoot et al. 2011; Bowzer et al. 2012; Balazik et al. 2013; Kim et al. 2017). As a result, many electroimmobilization studies report induction times that are not instantaneous because the authors defined "induction time" to mean the time taken to reach Stage IV anesthesia rather than the time required to immobilize the fish. For example, the Grass Carp electrostunned (pDC) by Bowzer et al. (2012) were immobilized immediately; however, because induction criteria were based on the stages of anesthesia described by Summerfelt and Smith (1990) the reported induction times are described as averaging $0.6 \mathrm{~min}$ before "Stage IV" anesthesia was visually confirmed.

The effects of electroimmobilization on other behaviours are not as well documented, though there has been some focus towards impacts on migratory behaviours. The time required 
for electroanesthetized (cDC) Lake Sturgeon A. fulvescens and Shortnose Sturgeon

A. brevirostrum to exhibit positive rheotaxis did not differ significantly from non-immobilized individuals (Henyey et al. 2002). Similarly, spawning migrations of Atlantic Sturgeon were not significantly affected or delayed by electroanesthesia and surgical telemetry tag implantations (Balazik 2015), nor were migrations of electroanesthetized Chinook Salmon Oncorhynchus tshawytscha and Coho Salmon O. kisutch significantly different from conspecifics sedated with CO2 (Keep et al. 2015). A study of the effects of intracoelomic telemetry tagging with electrostunning $(\mathrm{pDC})$ on migratory behaviour in Walleye found a significant increase in downstream travel time in more recently tagged fish, but this difference was not determined to be ecologically relevant nor was it specifically attributable to capture (electrofishing), electrostunning, or the surgical procedure (Wilson et al. 2017). It therefore appears that electroanesthesia is at least as safe as other techniques used in research on anadromous fish during their migrations. It is, however, important to validate the effects higher levels of electroimmobilization on these and other migratory species and to conduct further field evaluations of post-recovery behaviour to assess electroimmobilization's safety in conducting field research on migratory fishes. 
Table 1. Identified benefits and challenges of electroimmobilization based on the available literature. Much of the benefits concern advantages over chemical sedation, while the challenges may be shared with chemical sedation (e.g. "dosage" concerns) or may be unique (e.g. positioning). Adapted from Reid et al. (2019); reprinted with permission from Wiley, 2020.

\begin{tabular}{ll}
\hline \multicolumn{1}{c}{ Benefits } & \multicolumn{1}{c}{ Challenges } \\
\hline $\begin{array}{l}\text { Unlike chemical sedatives, no concerns over } \\
\text { expiration/degradation or proper handling and } \\
\text { disposal protocols }\end{array}$ & $\begin{array}{l}\text { Failure to maintain equipment in proper } \\
\text { working condition may lead to failure or risk } \\
\text { of injury/death for fish and humans }\end{array}$ \\
$\begin{array}{l}\text { Significantly shorter induction and recovery } \\
\text { times than chemical sedatives; fish may be } \\
\text { released immediately following removal from } \\
\text { electric stimulus }\end{array}$ & $\begin{array}{l}\text { Inappropriate application of electricity may } \\
\text { result in insufficient electricity for desired } \\
\text { effect, or internal injuries (e.g. spinal damage, } \\
\text { hemorrhaging) }\end{array}$ \\
$\begin{array}{l}\text { Better real-time control over application of } \\
\text { electricity compared to chemical methods } \\
\text { (easy to adjust "dosage") }\end{array}$ & $\begin{array}{l}\text { Fish must be positioned properly in } \\
\text { electroimmobilization apparati (i.e. proper } \\
\text { orientation, facing anode, adequate distance } \\
\text { from electrodes, etc.) }\end{array}$ \\
$\begin{array}{l}\text { May significantly reduce fish handling times, } \\
\text { particularly during short (<5 min) sampling } \\
\text { procedures }\end{array}$ & $\begin{array}{l}\text { Lacking knowledge of appropriate electrical } \\
\text { settings (e.g. current, voltage) for different } \\
\text { fish species, life history stages, etc. and } \\
\text { environmental variables (e.g. temperature, } \\
\text { salinity) }\end{array}$ \\
$\begin{array}{l}\text { A single electroimmobilization device is } \\
\text { reusable many times over (as opposed to } \\
\text { regularly) }\end{array}$ & $\begin{array}{l}\text { Certain electroimmobilization devices (e.g. } \\
\text { electrostunning units) have greater initial } \\
\text { "start-up" costs relative to chemical sedatives. }\end{array}$ \\
\hline
\end{tabular}




\section{Injury, Growth, and Survival}

The risk of injury when exposing fish to electric current depends on current type and intensity, fish species and life history stage, and environmental (i.e. water quality) variables (Henyey et al. 2002; Ackerman et al. 2005; Zydlewski et al. 2008). Injuries (e.g. fractured vertebrae, haemorrhaging) tend to occur more often and more severely with AC (Ackerman et al. 2005), and in larger fish that move with greater body oscillations (Duryea 2014). Electrotetany and electrostunning are more likely than electrosedation and electroanesthesia to result in injury (Dolan and Miranda 2004). Overall, reported rates of injury from electroimmobilization are inconclusive and need to be investigated further. No injuries attributable to electric current were observed in the application of electrostunning (pDC) or electrotetany ( $\mathrm{cDC}$ ) to Walleye (Vandergoot et al. 2011) or in the application of electrostunning (pDC) to Lake Trout Salvelinus namaycush (Faust et al. 2017). Conversely, higher electricity-induced injury rates have been reported in electrostunned (pDC) Chinook Salmon (e.g. Zydlewski et al. 2008). In a simulated electrofishing experiment where fish were exposed to similar risk of injuries, significant differences in haemorrhaging and spinal injury across different taxa were observed (Dolan and Miranda 2004). Therefore, care should be used to select appropriate settings to minimize the risk of injury from electroimmobilization, particularly in those taxa sensitive to injury due to strong muscles and high body undulations (e.g. eels and salmonids).

Fewer studies have monitored the long-term effects of electroimmobilization on growth and there is insufficient long-term information to make any conclusive arguments. Short-term growth (i.e. 1 month post-treatment) of juvenile Rainbow Trout $O$. mykiss was not affected by electrosedation (cDC; Kynard and Lonsdale 1975), however the presence or absence of vertebral injuries that could have impeded growth was not evaluated. The growth of the offspring of 
migrating adult Chinook Salmon was found to be uninfluenced by their electrostunned (pDC) parents (Zydlewski et al. 2008). One approach to better assess the potential effects of electroimmobilization on growth would be to conduct long-term monitoring (e.g. analyzing lateral radiographs from x-rays; Duryea 2014) on injured and non-injured juvenile fish as they grow into adulthood, an effort that might be best conducted under controlled laboratory conditions.

When appropriate protocols are used, short-term $(\sim 24 \mathrm{~h})$ survival after electroimmobilization is high. $100 \%$ survival rates post-immobilization were observed in electrostunned (pDC) Common Carp, Bluegill, and Brown Bullhead Ameiurus nebulosus (Kim et al. 2017), Largemouth Bass (Trushenski et al. 2012b; Kim et al. 2017), Gopher Rockfish (Duryea 2014), Walleye (though one mortality was observed during the application of pDC; Vandergoot et al. 2011), and Grass Carp (minor injuries reported; Bowzer et al. 2012). One mortality was observed out of 90 electrostunned (pDC) Sunshine Bass (Trushenski and Bowker 2012). Long-term survival is rarely monitored, though a $100 \%$ survival rate after 22 days was reported in two-stage (i.e. two different currents applied consecutively) electrostunned (pDC) Lake Trout (Faust et al. 2017). Jennings and Looney (1998) also report 100\% survival during a 14-day period post-electroanesthesia (cDC) in Striped Bass.

\subsubsection{Variation in instrumental parameters, fish, and environmental effects}

Variation in voltage and duration of exposure is necessary and dependent on the nature of the experimental subject (i.e. species, size, etc.). Proper immobilization of fish with $\mathrm{pDC}$ requires a thorough understanding of the appropriate pulse frequency, duration, and duty cycle (fraction of time that pulses are being emitted, given as a percentage; calculated as 
$100 \times$ frequency $\times$ duration/1000 ms with frequency and duration given in $\mathrm{Hz}$ and $\mathrm{ms}$, respectively; Miranda and Dolan 2004). Higher duty cycles have been recommended for safer, less injurious electrofishing (Dolan and Miranda 2004) but information concerning the effects of duty cycles in other applications of electroimmobilization is lacking. Similarly, there is a need for an improved understanding of the short- and long-term lethal and sublethal effects of pulse frequency and duration (Vandergoot et al. 2011).

Fish size may affect the success and times of induction and recovery, though the ability to detect significant effects of fish size may depend on the metric used. For example, effects of fish size may be found to be a factor when measured as length (e.g. Prystay et al. 2017) or mass (e.g. Trushenski et al. 2012a). Fish volume, however, is a better predictor of required power to induce tetany than size or length (Dolan and Miranda 2004), and so might be a more appropriate size metric for variables such as induction and recovery times. Fish orientation is also important when electrostunning fish situated between an anode and cathode plate, with optimal induction achieved when the fish is oriented perpendicular to the plates (Rous et al. 2015). Tetanus appears to be observed at lower voltages when the fish is oriented facing the cathode compared to if the fish were facing the anode (Lamarque 1989). It is therefore recommended that fish be oriented facing the anode during electroimmobilization, allowing for increased versatility and control over immobilization.

Environmental parameters such as water conductivity and temperature will influence the efficacy of electroimmobilization (Ackerman et al. 2005). Salinity may prevent adequate or successful electroimmobilization, depending on the equipment used (Balazik et al. 2013). More studies examining the effects of water quality variables at finer scales (e.g. conductivity, temperature, salinity, $\mathrm{pH}$ ) on various electroimmobilization apparati at fixed settings are 
required. This type of assessment would be greatly facilitated by reporting the exact electroimmobilization settings (e.g. current type, voltage; when applicable, duty cycle and pulse frequency/duration). Other relevant parameters that are reported in electrofishing surveys (e.g. water temperature, conductivity) should also be provided.

\subsubsection{Other knowledge gaps/identified questions}

To help direct future work, I have identified key research questions or topics that have yet to be addressed comprehensively in the literature. Knowledge gaps exist throughout the topics of policy, theory, applications, and impacts of electroimmobilization. To attempt to cover this diverse array of problems in brief, the identified questions/topics have been divided into two general categories: (1) the "human" perspective (encompassing theory and applicability), and (2) the "fish" perspective (primarily concerning the effects of electroimmobilization). Insofar as I know, few jurisdictions have explicit policies regarding electroimmobilization procedures and essentially all will permit its use in field studies for collecting wild fishes.

\section{The Human Perspective}

As mentioned, the list of stages of anesthesia given in Summerfelt and Smith (1990) is the reference of choice for nearly all electroimmobilization studies when describing the desired level of effect. These stages are based on the typical symptoms elicited by chemical sedatives; problematically, other symptoms caused by electrical currents (e.g. tetany) are absent despite their obvious relevance. I therefore propose that a similar table be designed to reflect the "stages of electroimmobilization" that can combine the unique symptoms of electrical exposure with symptoms common to both (e.g. muscle relaxation, changes in opercular rate). Ideally, this will 
also be able to reflect which responses are available with different types of current. A preliminary attempt to develop such a table has been provided (Table 2).

The efficacy of electroimmobilization is negatively influenced by saline water (Balazik et al. 2013). Russian scientists have claimed success in the use of marine electrotrawling in immobilizing fish and increasing catching success, but these claims are highly questionable, often based on anecdotal observations and reporting raw data without statistical analyses (e.g. Maksimov et al. 1987). Though controversial, electric trawling is being considered for shrimp harvesting in the North Sea despite major remaining knowledge gaps concerning broader impacts on marine animals (Soetaert et al. 2015). Electroimmobilization would likely only occur in marine waters if the fish come into contact with the electrodes, and if differences did exist between catch rates of electric and normal trawls, they would sooner be attributable to electrotaxis rather than electroimmobilization. Future work is needed to pinpoint any thresholds in salinity, water temperature, $\mathrm{pH}$, and other environmental parameters that make electroimmobilization ineffective. In addition, determining potential options for circumventing these limitations such as using low-voltage electrodes in direct contact with the fish or temporarily introducing marine fish to freshwater for immobilization, would be beneficial for species from saline waters. 
Table 2. A preliminary list of the "Stages of Electroimmobilization," describing the permitting currents, general characteristics and injury risk of each stage (ordered by increasing voltage), and a comparison with Summerfelt and Smith's (1990) stages of anesthesia.

Adapted from Reid et al. (2019); reprinted with permission from Wiley, 2020.

\begin{tabular}{|c|c|c|c|c|}
\hline Stage & $\begin{array}{l}\text { Permitting } \\
\text { Currents }\end{array}$ & General Description & $\begin{array}{c}\text { Overall } \\
\text { Injury Risk }\end{array}$ & $\begin{array}{l}\text { Versus Summerfelt and Smith's (1990) } \\
\text { Stages of Anesthesia }\end{array}$ \\
\hline 0. No Effect & All & $\begin{array}{l}\text { Normal equilibrium and reactivity to other } \\
\text { stimuli }\end{array}$ & NA & "Normal" stage - identical \\
\hline 1. Electrosedation & $\begin{array}{l}\mathrm{AC} \\
\mathrm{cDC}\end{array}$ & $\begin{array}{l}\text { Muscles relaxed, normal opercular } \\
\text { movements; slight loss of equilibrium and } \\
\text { reactivity to other stimuli; very fast recovery }\end{array}$ & Low & $\begin{array}{l}\text { "Light sedation" - slight loss of reactivity but } \\
\text { normal equilibrium }\end{array}$ \\
\hline 2. Electroanesthesia & $\begin{array}{l}\mathrm{AC} \\
\mathrm{cDC}\end{array}$ & $\begin{array}{l}\text { Muscles relaxed, normal opercular } \\
\text { movements; full loss of equilibrium and } \\
\text { reactivity to other stimuli; very fast recovery }\end{array}$ & Low & $\begin{array}{l}\text { "Deep sedation" - near-total loss of reactivity but } \\
\text { equilibrium is still normal }\end{array}$ \\
\hline 3. Electrotetany & $\begin{array}{l}\mathrm{AC} \\
\mathrm{cDC} \\
\mathrm{pDC}\end{array}$ & $\begin{array}{l}\text { Muscles relaxed or contracting weakly, } \\
\text { opercular movements may be irregular; full } \\
\text { equilibrium and reactivity loss; fast recovery }\end{array}$ & Moderate & $\begin{array}{l}\text { "Partial loss of equilibrium" - erratic swimming, } \\
\text { near-total loss of reactivity, still some equilibrium }\end{array}$ \\
\hline 4. Electrostunning & $\begin{array}{l}\mathrm{AC} \\
\mathrm{cDC} \\
\mathrm{pDC}\end{array}$ & $\begin{array}{l}\text { Muscles contracting, opercular movements } \\
\text { cease; prolonged full loss of equilibrium and } \\
\text { reactivity to other stimuli; prolonged } \\
\text { recovery }\end{array}$ & $\begin{array}{l}\text { Moderate to } \\
\text { high chance of } \\
\text { spinal injury, } \\
\text { haemorrhaging }\end{array}$ & $\begin{array}{l}\text { "Total loss of equilibrium" - total loss of spinal } \\
\text { reflex, muscle tone, equilibrium } \\
\text { "Loss of reflex reactivity" - total reactivity loss, } \\
\text { very slow opercular movements and heart rate }\end{array}$ \\
\hline 5. Adverse Effects & All & $\begin{array}{l}\text { Intense muscle contractions, injuries, } \\
\text { respiratory failure, and death; full loss of } \\
\text { equilibrium and reactivity to other stimuli }\end{array}$ & Certain & $\begin{array}{l}\text { "Medullary collapse" - opercular movement } \\
\text { ceases, followed by cardiac arrest }\end{array}$ \\
\hline
\end{tabular}




\section{The Fish Perspective}

I have described electrosedation, electroanesthesia, electrotetany, and electrostunning as different levels of electroimmobilization, though determining exactly where the boundaries lie between each stage would greatly enhance the accuracy and utility of this classification. Controlled studies with individual gradients in voltage and current (type and intensity) for different species could provide valuable, policy-relevant insight on predicting appropriate settings to use in a given research effort. As an immediate-release technique, electroimmobilization can be more appealing than drugs when handling fish during or shortly before spawning periods (especially in migratory species). Quantitative comparisons concerning the reproductive success between fish exposed to electroimmobilization or chemical anesthetics prior to spawning are currently lacking despite the clear value of this knowledge to selecting the most appropriate handling protocol in spawning or pre-spawning fish.

All of the research discussed herein has examined ray-finned fish (Actinopterygii). The efficacy and value in using electroimmobilization to facilitate handling procedures on other fishes (i.e. lobe-finned [Sarcopterygii], cartilaginous [Chondrichthyes], and jawless [Agnatha] fish) should be evaluated in future work. In line with the above note on salinity, a better understanding is needed on the effects of moving a marine species briefly into freshwater for electroimmobilization (Balazik 2015) and whether or not any induced stress response is detectable over that associated with general handling. It would also be interesting to examine the efficacy of electroimmobilization on electric fishes (e.g. Electrophorus electricus) and their posthandling physiological and behavioural responses.

The underlying physiology of the different stages of electroimmobilization deserves further exploration, especially from an institutional animal care and use committee (IACUC) 
welfare perspective on how electric currents of various types and intensities may influence nociception in fish. For example, is there any evidence of analgesia/sensory loss or, conversely, increased nociception as a result of electroimmobilization? Due to established evidence of nocifensive responses (behavioural responses to noxious stimuli) in fishes (Chatigny et al. 2018), is there any evidence that chemical anesthetics/analgesics alter behavioural responses during and after electroimmobilization-facilitated surgical procedures? Furthermore, although studies have demonstrated electroimmobilization's association with a typical generalized stress response (Bowzer et al. 2012; Trushenski and Bowker 2012), is it possible to differentiate between the physiological stress attributable to general handling procedure as compared with the stress induced from the electric stimulus itself? These are the types of questions that are being asked of researchers by IACUCs and thus need to be addressed with some expediency. The Canadian Council on Animal Care follows a precautionary approach in assigning categories of invasiveness to various procedures, and it is recommended that electrofishing be considered "Category D" invasiveness ("Experiments that cause moderate to severe distress or discomfort;" Griffin et al. 2007). There is no recommendation for other examples of electroimmobilization, but these would presumably fall into the same category. Given the evidence for rapid recovery and high survival of electroimmobilization, however, this assignment may need revision.

\subsection{Current and Potential Applications}

\subsubsection{Electroimmobilization equipment}

Electroimmobilization units may be uniquely designed and built by researchers (e.g. Jennings and Looney 1998; Hudson et al. 2011) or adapt gear such as TENS units, which typically cost less than US\$50 (2019; see Vandergoot et al. 2011). The procedure requires the 
basic necessities for delivering current (i.e. power supply, anode/cathode plates, holding tank) in addition to personal protective equipment and adequate knowledge of the appropriate physical dimensions and electricity settings for different species, life history stages, and environmental conditions. Alternatively, such units can be found commercially made and designed (e.g. Portable Electroanesthesia System [PES] or low-voltage Fish Handling Gloves [FHG], both developed by Smith-Root [Vancouver, Washington]). The PES can emit cDC or pDC for all levels of electroimmobilization but is most commonly used to induce electrostunning with pDC. The FHG emit cDC for low-voltage electrosedation or electroanesthesia and have modified the anode and cathode plates of traditional apparati into mesh gloves for direct contact of the electrodes on the fish. Larger, industrial scale units have recently been developed for mass processing in fisheries such as the Humane Stunner Universal developed by Ace Aquatec (Dundee, Scotland). Figure 1 shows the active use of both the FHG (A) and PES (B). Regardless of the how the unit is built or designed, an understanding of the potential effects and relative efficacy of the equipment (as well as suitable equipment and protocol for operator safety) is critical to its appropriate application. Another potential setback is start-up cost; a 48-quart cooler PES unit costs roughly $\$ 9,500$ (2019).

\subsubsection{Current applications}

Electrostunning from $\mathrm{pDC}$ is used for lasting immobilization for an extended length of time following the cessation of exposure to the electric current (often referred to as the "recovery period"). Surgeries and other data collection procedures are frequently performed during the recovery period of electrostunned fishes. Alternatively, cDC may be used to subdue fish through electrosedation or electroanesthesia during less invasive sampling procedures while allowing for 
a nearly instantaneous recovery once the fish is removed from the electric current. Given current evidence suggesting that low-voltage electrosedation and electroanesthesia do not appear to result in ecologically relevant changes in post-release behaviour (e.g. Henyey et al. 2002; Wilson et al. 2017) or physiological alterations that differ significantly from a generalized stress response (which is also exhibited in chemically sedated fish; e.g. Ward et al. 2017; Abrams et al. 2018), invasive procedures may be safely undertaken while cDC is actively passing through the fish, provided that handlers follow appropriate safety protocols. This distinction could make cDC more suitable for procedures demanding precise duration times and immediate recovery. Recent work has begun to examine the potential for multi-stage electroimmobilization, involving the successive application of several different electric waveforms (e.g. Faust et al. 2017). 


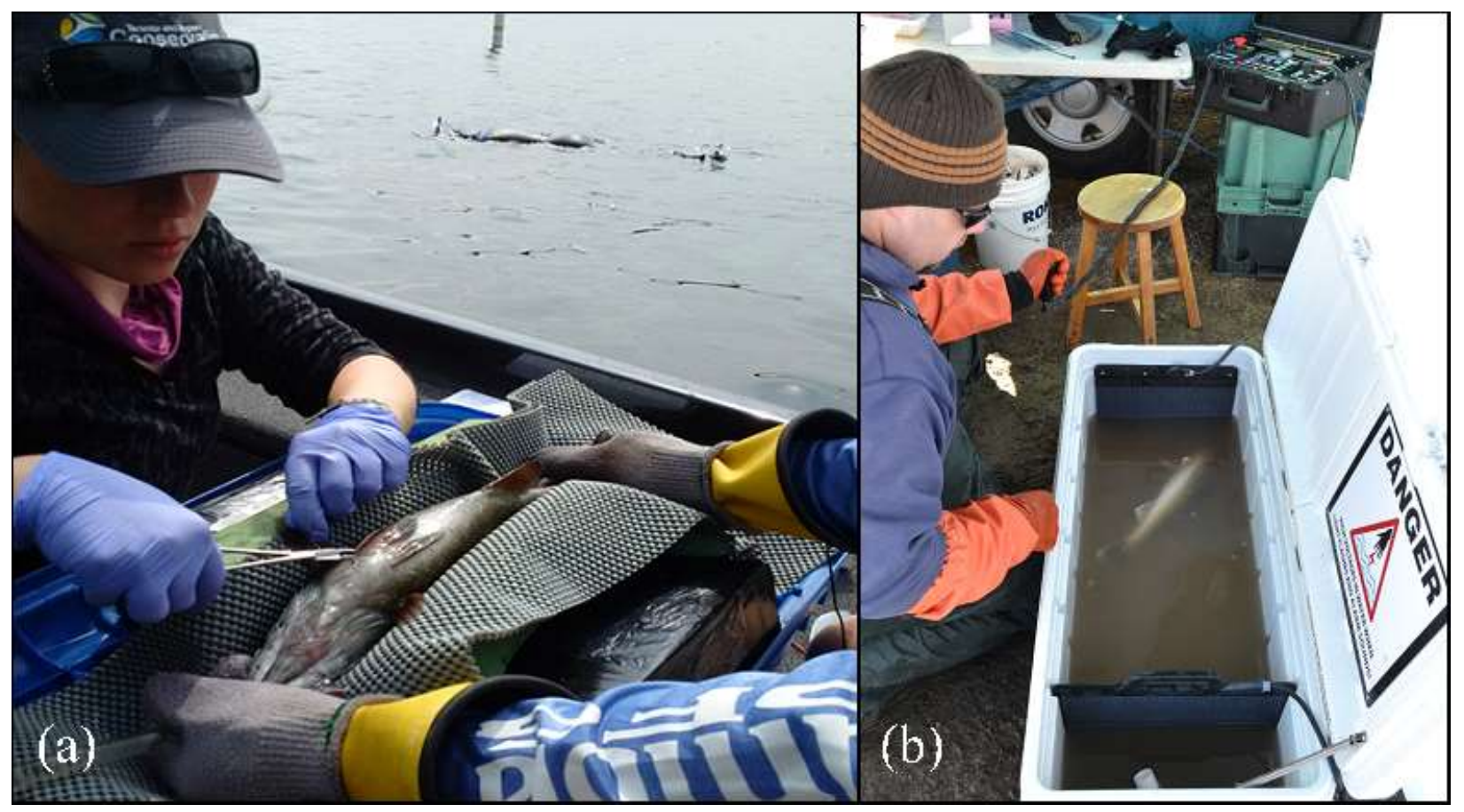

Figure 1. (a) A Smallmouth Bass Micropterus dolomieu is immobilized using low-voltage electric (constant direct current) gloves. The Smallmouth Bass was angled from a nest and put in supine position on a surgery table. A water hose was inserted into its mouth and then electricity was applied to immobilize the fish for surgical implantation of a biologging tag (procedure time $=5 \mathrm{~min})$. The fish was released immediately following the procedure and resumed parental care duties within 1 min (the background snorkeller defended the nest in the nesting male's absence) and subsequently raised its brood successfully (see Prystay 2018). (b) A Walleye Sander vitreus is immobilized using a portable electrostunning unit. The fish was exposed to $35 \mathrm{~V}$ pulsed direct current for $3 \mathrm{~s}$ prior to being placed on a surgery table for implantation of an acoustic telemetry transmitter. The mean duration of the surgical procedure was $142 \mathrm{~s}$ at which time fish were held for $\sim 5 \mathrm{~min}$ in individual water-filled totes prior to release and subsequent tracking as per Hayden et al. (2014). Adapted from Reid et al. (2019); reprinted with permission from Wiley, 2020. 


\subsubsection{Additional applications}

With rapid induction and recovery times, electrosedation, electroanesthesia, and electrotetany may be used to facilitate handling fish for unpredictable/extended times without the dosage and safety issues associated with chemical sedatives. This could be particularly useful in testing novel methods designed to provide non-lethal means of collecting data that traditionally necessitated intensive surgeries or lethal sampling (e.g. sex determination in many nonreproductive stage fishes). For example, Matsche (2013) used electroanesthesia to assist with a non-lethal method of sex determination of sexually immature and developing Largemouth Bass.

In Canada, MS-222 is the only approved chemical sedative for fish and requires that treated fish be held for a minimum of 5 days in water temperatures above $10^{\circ} \mathrm{C}$ (Health Canada 2010); in the United States, where MS-222 is the only FDA-approved anesthetic for field applications on fish, this holding period is extended to 21 days (Trushenski et al. 2013). AQUIS ${ }^{2} 20 \mathrm{E}$ (10\% eugenol), available as an Investigational New Animal Drug with U.S. Fish and Wildlife Service approval, allows for immediate release under certain conditions but has a 3day holding period for hatchery fish (Trushenski et al. 2012b; Silbernagel and Yochem 2016). Because electroimmobilization allows for immediate release (e.g. Jennings and Looney 1998), it can prove a superior alternative to chemical sedatives in cases where immediate release is critical to the wellbeing of treated fish and/or soundness of experimental methodology (e.g. telemetry tag implantation in migrating fish).

\subsection{Specific Acknowledgements}

Any use of trade, firm, or product names is for descriptive purposes only and does not imply endorsement by the U.S. Government. Cooke is supported by NSERC, the Ocean 
Tracking Network, and the Canada Research Chairs Program. This work was partially funded by the Great Lakes Fishery Commission by way of Great Lakes Restoration Initiative appropriations (GL-00E23010). This paper is Contribution 65 of the Great Lakes Acoustic Telemetry

Observation System (GLATOS). I would like to thank an anonymous reviewer for providing feedback during manuscript preparation. 


\section{$\underline{\text { 3. Does a Local Analgesic Complement Electroanesthesia of a Teleost Fish? }}{ }^{3}$}

\subsection{Introduction}

Chemical sedatives and anesthetics are commonly used in fisheries science in order to calm fish during handling and improve fish welfare (Ross and Ross 2008). Despite their prevalence, there are a number of issues associated with pharmaceuticals that make them inconvenient or inappropriate in various scenarios. For work with food fish that are to be released alive, the only approved pharmaceutical for sedation/anesthesia in North America is tricaine methanesulfonate (MS-222). In Canada, fish treated with MS-222 must be held in water above $10^{\circ} \mathrm{C}$ for a minimum of 5 days before being released into the wild (Health Canada 2010); this holding period is extended to 21 days in the United States (Trushenski et al. 2013). Metomidate, though costly and associated with long recovery times, is also approved in Canada for veterinary use but only for fish not being released with the possibility of human consumption (Ackerman et al. 2005). A few other drugs, such as benzocaine and eugenol, can be used with government approval in investigatory research (e.g. in the U.S., Investigational New Animal Drugs [INADs]), but these too have pre-release holding periods of multiple days (Trushenski et al. 2013).

To address the need for "immediate-release" sedation techniques (i.e. techniques that allow for the immediate release of treated food fish into the wild or allow for treated fish to be harvested immediately for consumption), researchers have been exploring the use of electricity

\footnotetext{
${ }^{3}$ Please note that this material has been co-authored (see Preface on page iii). The list of coauthors on the manuscript is as follows:

C. H. Reid, E. D. Stevens, J. D. Midwood, T. W. Moon, A. E. I. Abrams, A. J. Zolderdo, and S. J. Cooke
} 
to immobilize fish for short-term handling procedures (e.g. Henyey et al. 2002; Matsche 2013; Balazik 2015; Faust et al. 2017). Many have also conducted direct comparisons of the behavioural and/or physiological impacts of drugs and electroimmobilization techniques, with a number of studies recommending the latter due to rapid induction and short recovery times (e.g. Balazik et al. 2013, Keep et al. 2015; Abrams et al. 2018), normal recovery from typical stress responses (e.g. Trushenski et al. 2012a; Johnson et al. 2016), and high survival rates (e.g. Jennings and Looney 1998; Faust et al. 2017; Kim et al. 2017). Standardized definitions of the different forms of electroimmobilization (e.g. electrosedation vs. electroanesthesia) have recently been published (see Chapter 2; Reid et al. 2019). Here I use "electroanesthesia" to refer to immobilization induced by low-voltage, low-current electricity that induces responses similar to chemical sedation (i.e. steady opercular rate and relaxed muscles). Electroanesthesia is associated with rapid to near-instantaneous induction and recovery times (Balazik et al. 2013; Abrams et al. 2018) and therefore has high potential to facilitate time-sensitive handling procedures in fisheries research. Unlike chemical anesthetics, however, the capacity for electroanesthesia to elicit analgesia (defined by the Canadian Council on Animal Care [CCAC] as a "decrease in response to noxious stimuli"; CCAC 2005) is still equivocal.

Whether or not fish feel "pain" is controversial, hard to assess experimentally, and further complicated by the need to differentiate between the general capacity for nociception and the conscious awareness of "pain" in a sense that approximates the human experience (Rose et al. 2014; Browman et al. 2019). As a precaution, analgesics and/or anesthetics producing analgesia are required by various guidelines and authorities (e.g., CCAC, Institutional Animal Care and Use Committees [IACUCs]) during experimental manipulation of fish and especially when conducting invasive procedures (Ackerman et al. 2005). By extension, animal care committees 
may require the application of chemical anesthetics or analgesics when performing electroimmobilization on fishes. One of the main advantages of electroimmobilization is that it permits food fish to be safely released into the wild or harvested for consumption immediately after handling procedures; this is nullified by the application of drugs, necessitating otherwiseavoidable post-handling holding times or euthanasia.

The purpose of this experiment was to evaluate whether or not analgesics improve fish welfare during the electroanesthesia of a teleost fish. Specifically, I tested the hypothesis that the welfare of electroanesthetized fish is improved by the additional application of a local analgesic (lidocaine), by quantifying behavioural and physiological endpoints during and following a standardized electronic tag implantation-type surgery in electroanesthetized Largemouth Bass Micropterus salmoides. A relatively large predatory species, Largemouth Bass are important in recreational fisheries and are often stocked outside of their natural habitat (Quinn and Paukert 2009). They are also frequently studied throughout their life history and for a wide variety of research topics (e.g. Savino and Stein 1982; Oberdörster 2004; Hasler et al. 2016; Twardek et al. 2017). I used primary (i.e. plasma cortisol) and secondary (i.e. blood glucose, blood lactate, plasma osmolality, and haematocrit) metrics to evaluate physiological stress. Cortisol is the main glucocorticoid hormone associated with stress in teleost fish, and elevations in plasma cortisol may be followed by increases in blood glucose (to provide energy for responding to stress) and blood lactate (with higher, stress-induced activity changes; Raposo de Magalhães et al. 2020). In freshwater teleosts, cortisol may play a role in osmoregulation by augmenting ion uptake in the gills (McCormick 2001), therefore increases in plasma cortisol could be associated with higher plasma osmolality levels. Haematocrit can increase in response to stress either through the swelling of red blood cells (erythrocytes) following adrenaline release (e.g. Nascimento et al. 
2012), or the release of new erythrocytes from the spleen (e.g. Houston et al. 1996). I also measured a number of behaviours and reflex indicators during surgical procedures to assess how adequately fish were immobilized across treatments, and after surgeries to evaluate fish recovery and behavioural impacts associated with each treatment. Reflex action mortality predictor (RAMP; e.g. Raby et al. 2012) scores can act as a predictor of short-term mortality. In an arena, refuge emergence may be a useful predictor of shyness/boldness and willingness to take risks (e.g. Brown and Braithwaite 2004), and changes in swimming activity could indicate a flight response following exposure to an acute stressor (if activity increases) or decrease to dedicate leftover energy towards metabolic recovery (McFarlane et al. 2004). I predicted that the levels of haematological responses would increase (as a sign of stress) in response to handling relative to baseline levels, but would not differ among handled treatments. I also predicted that during surgeries, fish would remain "calmer" (i.e. exhibit fewer lateral thrashes) in all electroanesthetized treatments relative to the handling control, and that the post-handling behaviour would differ from typical baseline responses but would not differ among handled treatments.

\subsection{Methods}

\subsubsection{Study site, experimental subjects, and treatments overview}

This experiment was conducted from 14 July to 24 August 2019 at Queen's University Biological Station (QUBS; Elgin, ON). 172 adult Largemouth Bass (total length $=288-405 \mathrm{~mm}$ ) were angled from Lake Opinicon $\left(44.5590^{\circ} \mathrm{N}, 76.3280^{\circ} \mathrm{W}\right)$ after surface water temperatures stabilized at about $24{ }^{\circ} \mathrm{C}$ ( $\sim$ mid-late June). Fish were held in sensory deprivation chambers (blackened Perspex boxes) for 24-48 $\mathrm{h}$ to permit acclimatization and to control for stress 
associated with capture and captivity (Prystay et al. 2017). The sensory deprivation chambers were placed in a large circular tank (inner diameter $=3.5 \mathrm{~m}$ ) filled with lake water to an approximate depth of $110 \mathrm{~cm}$, with each chamber sitting on a rack roughly $30 \mathrm{~cm}$ from the water's surface. New water was circulated in the tank during experimental trials, and an air stone bubbler ran constantly in each chamber to ensure adequate oxygen saturation. An oxygen probe (Handy Polaris; OxyGuard, Farum, Denmark) was used to monitor oxygen concentrations in the holding tank, which remained above $85 \%$ saturation, and in the behavioural arenas (see below) where oxygen concentrations remained above $83 \%$ saturation. Validation of oxygen concentrations in the sensory deprivation chambers themselves (post-removal of fish) showed oxygen concentrations above $92 \%$ saturation.

Fish were divided into either a behavioural experimental protocol or a physiological protocol (henceforth "behaviour track" and "physiology track", respectively). Each track comprised 6 treatment groups: handling control (HC), electroanesthesia (E), surgery with electroanesthesia (SE), surgery with electroanesthesia and lidocaine (SEL), surgery with electroanesthesia and a saline sham (SEH), and a baseline group (BB for behaviour-track fish and BP for physiology track-fish; Figure 2). Detailed treatment descriptions follow in the next subsection, "Surgical Setup and Protocol". Fish size across treatments did not differ from one another for either the behaviour track (though unequal variances were observed; Welch's $F=$ $1.589 ; \mathrm{DF}=41.22 ; P=0.185)$ or the physiology track (ANOVA $F=0.335 ; \mathrm{DF}=5 ; P=0.890)$. 


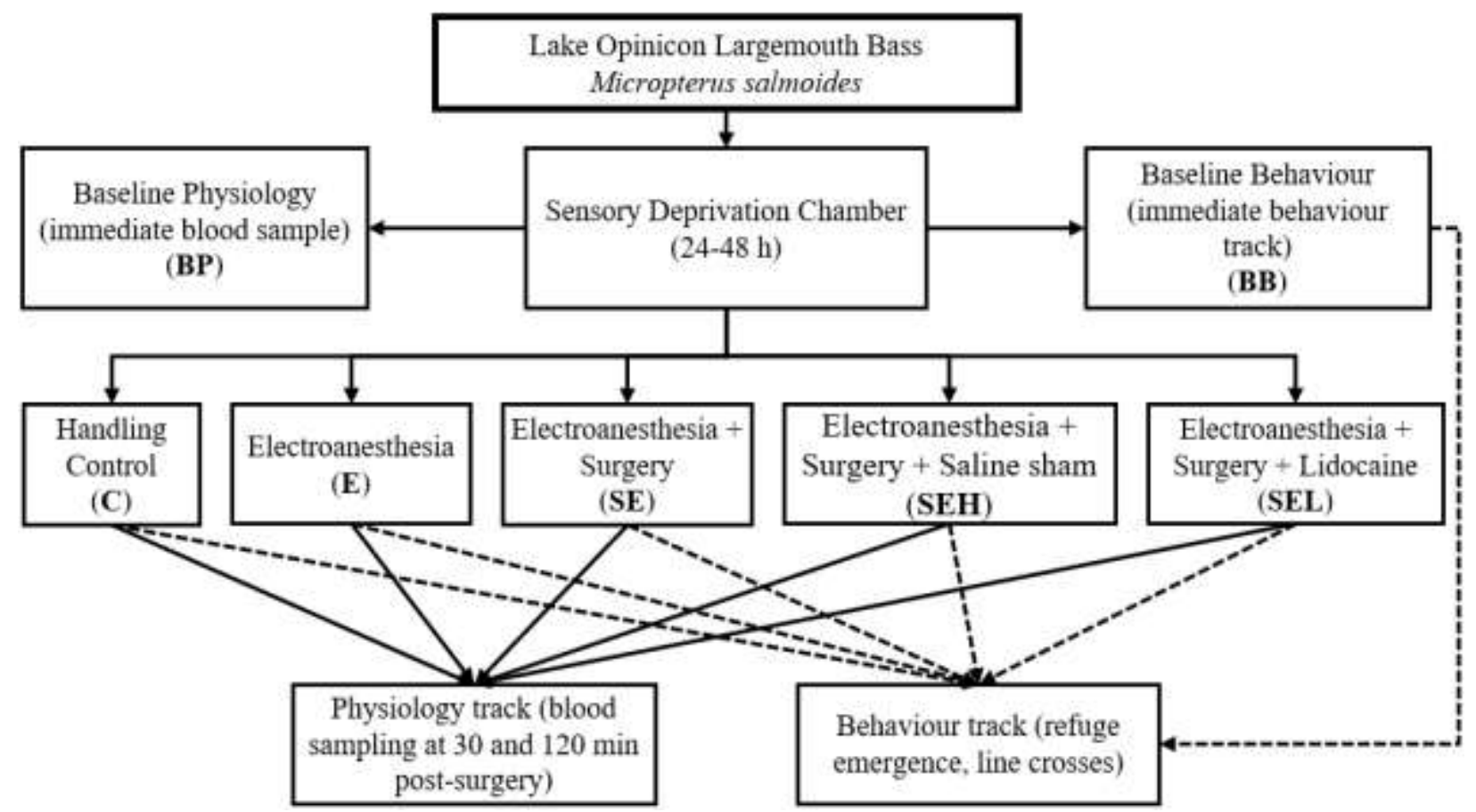

Figure 2. Summary of experimental treatment groups. Arrows denote the paths followed by fish in each treatment, with treatment letter codes included in bold letters. Electroanesthesia refers to immobilization induced by low-voltage, low-current electricity that induces responses similar to chemical sedation (i.e. steady opercular rate and relaxed muscles). 


\subsubsection{Surgical setup and protocol}

Surgeries were conducted on the inverted lid atop a $\sim 50 \mathrm{~L}$ plastic bin filled with fresh lake water from the holding tank. Fish were placed on top of the lid, between two bricks covered by a soft mesh mat in a trough-like shape for stability. A recirculation pump was placed inside the bin and connected to tubing that extended to the fish's mouth, permitting water to flush over the gills during the procedure (Figure 3). New water was used for each fish, and water temperature and conductivity were recorded once per fish using a digital water quality meter (Aquapro AP-2; HM Digital, Redondo Beach, California, USA). Across treatments, no differences were found between surgery temperatures for either the behaviour-track $(F=0.863$; $\mathrm{DF}=66 ; P=0.491)$ or physiology-track $(F=1.848 ; \mathrm{DF}=61 ; P=0.132)$ fish, or between water conductivities for the behaviour-track $(F=0.613 ; \mathrm{DF}=66 ; P=0.655)$ and physiology-track $(F=$ $0.352 ; \mathrm{DF}=61 ; P=0.842)$ fish. Mean $\pm \mathrm{SD}$ water conductivity throughout this experiment was $193.2 \pm 8.2 \mu \mathrm{S}$. Mean $\pm \mathrm{SD}$ water temperatures were $22.6 \pm 1.6^{\circ} \mathrm{C}$ during surgeries, and $22.9 \pm$ $1.7^{\circ} \mathrm{C}$ in the behavioural arena.

Regardless of track, fish in group $\mathrm{HC}$ were removed from the sensory deprivation chambers, measured in a plastic ruled trough full of water, placed on the surgery setup, and held upside down for $240 \mathrm{~s}$ during which time a mock surgery was conducted (consisting of a pretend "incision" with a bladeless scalpel and "suturing" simulated by pinching the skin where sutures would seal the wound). Fish in group E were put through the same procedure, but with the application of an electric current. All fish on the surgery table were held by an assistant wearing a pair of electric Fish Handling Gloves (FHGs) with a standard voltage output of $\sim 32 \mathrm{~V}$ and 5 current settings (4, 6.3, 10, 16, and 25 mA; Smith-Root, 2016). As in Abrams et al. (2018), current setting was selected by beginning at the lowest setting, increasing the current strength 
until full body spasms (tetany) were observed and then returning one setting lower, achieving electroanesthesia (muscle relaxation, normal opercular movement, complete loss of equilibrium and reactivity; see Reid et al. 2019 for a prototypical list of stages of electroimmobilization). Fish in groups SE, SEL, and SEH received both an electric current as well as a $\sim 2 \mathrm{~cm}$ incision in the ventral body wall that was closed with three 3-0 sutures (PDS II; Ethicon, Somerville, New Jersey, USA). In addition, fish in groups SEH and SEL were given a $0.25 \mathrm{~mL}$ infiltration of sterile saline (eyesaline; Honeywell, Charlotte, North Carolina, USA) or lidocaine (Lidocaine $\mathrm{HCl}$ Injection (2\%) with Preservative; Teligent, Mississauga, Ontario, Canada) diluted in sterile saline, respectively. In an infiltration, the solution is gradually expelled as the needle is withdrawn as opposed to an injection where solution is injected at the deepest point of needle puncture. To give the lidocaine time to take effect, SEL fish were held for 5 min (e.g. Oswald 1978) in a 45 L cooler full of lake water. SEH fish were also held for $5 \mathrm{~min}$ in the same conditions to control for the drug administration process. Four diluted lidocaine stock solutions were mixed such that one solution each would provide an approximate dose of $1 \mathrm{mg}$ per $\mathrm{kg}$ body mass for fish with total lengths 300-325, 326-350, 351-375, and 376-400 mm; the masses used in the dose calculations were estimated from those size ranges based on the length-weight relationships provided in Schneider et al (2000). Two SEL fish (one behaviour-track and one physiology-track) had total lengths slightly under $300 \mathrm{~mm}$, and received the stock solution for 300-325 mm fish. The use of stock solutions and estimated masses reflects the reality of many field scenarios where it may not be feasible to record the mass of every captured fish and prepare a dose tailored to each individual (Chatigny et al. 2018). Since tricaine methanesulfonate and metomidate are the only registered anesthetics for veterinary use in fish in Canada (Ackerman et al. 2005), no clear or established safe withdrawal times for lidocaine exist. As these fish were 
being released during the active angling season and could end up being consumed by humans, SEL fish had to be euthanized via cerebral percussion and disposed of on land at the end of experimental protocols. All lidocaine/saline infiltrations were administered using new $1 \mathrm{~mL}$ plastic syringes with 23-gauge needles (i.e. no needles or syringes were re-used). When not in use, all surgical tools (scalpel, haemostat, sutures) were kept in diluted $10 \%$ povidone-iodine (Betadine; Purdue Pharma, Pickering, Ontario, Canada) for disinfection. For fish that underwent surgeries, surgery times were standardized at $\sim 240 \mathrm{~s}$; for groups $\mathrm{HC}$ and $\mathrm{E}$, where no incision was made, all "surgery" times were made to be exactly $240 \mathrm{~s}$.

A video camera mounted on a tripod was used to record the surgeries for all fish regardless of track, allowing for many more samples of behaviour during surgery. Surgery videos were used to score the number of voluntary thrashes (rapid lateral flexes) during the procedures, as well as the mean ventilation rates (calculated from the number of opercular movements during the surgery) over a $15 \mathrm{~s}$ period $\left(\mathrm{VR}_{1}\right)$. This $15 \mathrm{~s}$ period began as soon as possible after the incision (or mock incision) had been made, based on visibility in the videos. Following handling procedures, each fish was put through either a behavioural or physiological evaluation of post-handling stress. Fish in groups BB and BP were not handled on the surgery table, and instead went straight from the sensory deprivation chambers to the behaviour- and physiology-track protocols, respectively. Fish masses were recorded on an electronic balance (OHAUS, Parsippany, New Jersey, USA) after data collection was complete. The body lengths of fish in both baseline groups were also recorded at the end of their procedures to minimize handling impacts. 


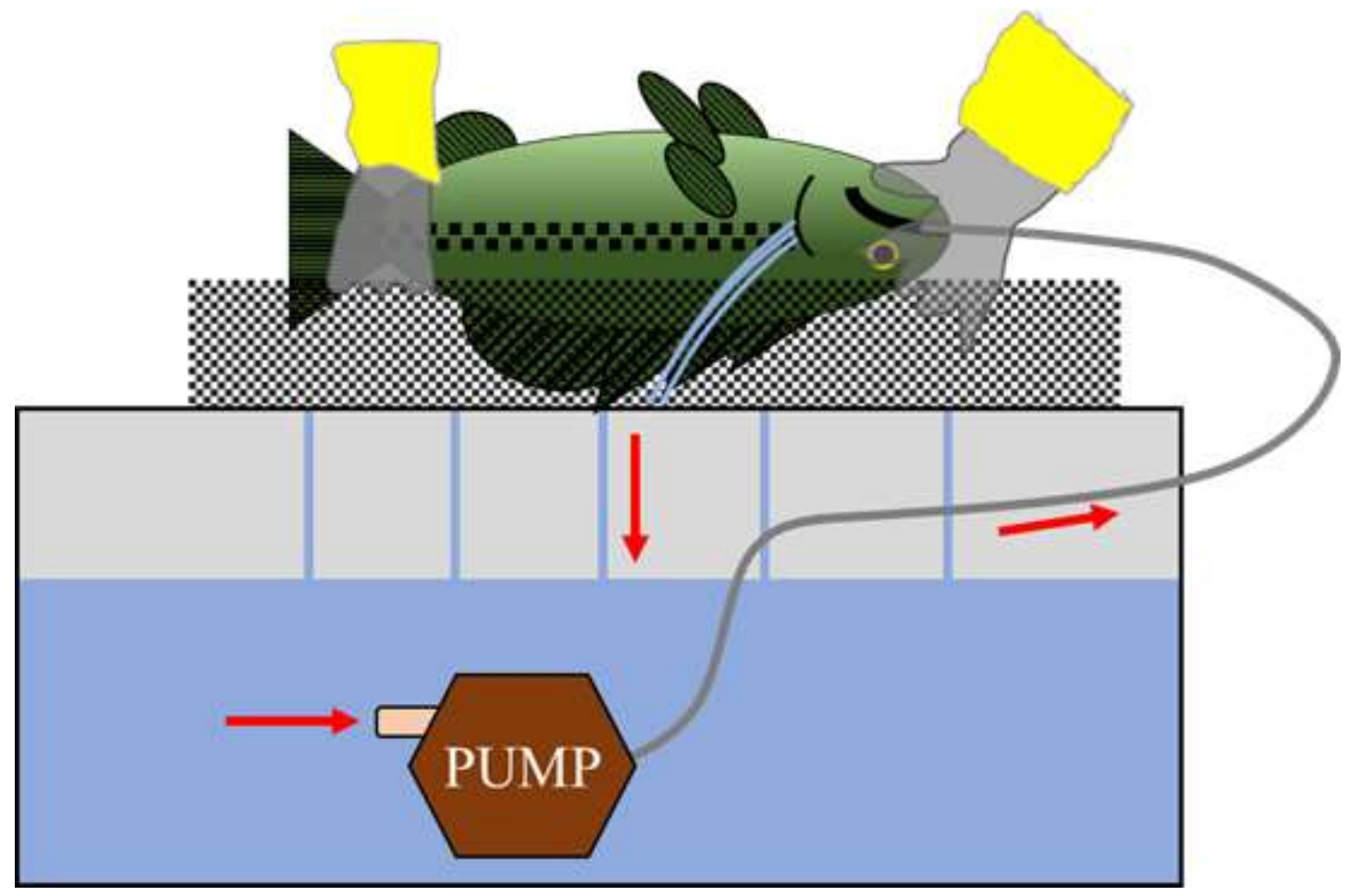

Figure 3. Schematic of the surgical setup used in this experiment. Red arrows indicated direction of water flow from the recirculation pump up a tube into the fish's mouth, out behind the opercula, onto the mesh trough, and through the perforated cooler lid into the source. The hands of the operator of the electric fish handling gloves (FHGs) are positioned as they would typically appear during surgery (surgeon not shown); one hand gently but firmly secures the caudal peduncle region, while the other hand holds the fish by the top and bottom of the head and maintains adequate water supply to the gills by controlling the tube. 


\subsubsection{Experimental procedure: Behaviour track}

Ninety-six Largemouth Bass (TL mean $\pm \mathrm{SD}=330 \pm 29.3 \mathrm{~mm}$ ) were subjected to the behaviour-track protocol. Following the treatment handling procedures, or immediately following removal from the sensory deprivation chambers in the case of BB fish, each individual was transferred to a $\sim 45 \mathrm{~L}$ cooler filled with lake water from the holding tank. As soon as the fish was settled ( $\sim 3-5 \mathrm{~s})$, the number of opercular movements over a $30 \mathrm{~s}$ period was recorded. This was followed by a RAMP test consisting of 5 quick binary scores: (1) does the fish initiate a flight response when the tail was grabbed; (2) do the fish's eyes follow the handler when held at the water's surface and rotated laterally; (3) does the fish attempt regular opercular movement during $5 \mathrm{~s}$ of air exposure; (4) when held sideways in the air and gripped in the middle of its body, does the fish attempt to free itself; and (5) does the fish regain equilibrium within $3 \mathrm{~s}$ when flipped upside down in the water. The fish was then allowed to rest in the cooler for $1 \mathrm{~min}$, after which another $30 \mathrm{~s}$ opercular movement count and subsequent RAMP test were performed. When the opercula were fully open during normal breathing, they were sometimes observed to rapidly twitch half-closed, open fully again, then shut normally in unison; the frequencies of these twitches were also recorded during both opercular movement counts and then pooled. Both opercular movement counts were converted to mean ventilation rates $\left(\mathrm{VR}_{2}\right.$ and $\left.\mathrm{VR}_{3}\right)$ by dividing the number of counts observed by $30 \mathrm{~s}$, giving VRs in ventilations per $\mathrm{s}$. The difference between the two cooler ventilation rates $(\Delta \mathrm{VR})$ was also calculated. After the second RAMP test, the fish was placed in a refuge in a behavioural arena for acclimatization and refuge emergence and line cross trials. The refuge $(30 \times 60 \times 30 \mathrm{~cm} ; 1 \times \mathrm{w} \times \mathrm{h})$ was constructed with black spray-painted plastic sheeting and had a hinged door and removable floor operated by pulley systems to allow for fish to be inserted with minimal escape risk, and to permit refuge opening and lifting. 
Behavioural trials were conducted in one of two large circular tanks with inner diameters of $3.5 \mathrm{~m}$ and filled with lake water to an approximate depth of $110 \mathrm{~cm}$, as with the holding tank. The arenas were intersected with lateral and longitudinal lines at every half meter with black spray-painted rebar (the crossing of which was used to provide an index of exploratory behaviour; e.g. Cooke et al. 2017). The refuge was placed along the edge of the tank facing towards the centre. A $9 \mathrm{~m}^{2}$ canvas gazebo was erected above each behaviour tank to attempt to standardize lighting and prevent environmental debris (leaves, twigs, caterpillars, etc.) from falling into the tanks and contaminating the water. At the apex of each gazebo, a camera was raised via a pulley system to record the behavioural trials and mitigate observer effects.

Once a fish was placed inside the refuge, the door was closed, and it was lowered into the arena. Using a long strand of fishing line tied to one end of the refuge floor, the floor of the refuge was slid out from beneath the refuge so that the refuge could be lifted later without hitting the fish. Following this, fish were given 10 min to acclimatize in the dark refuge. The door to the refuge was then opened via a pulley, and fish were given up to 10 min for voluntary refuge emergence. If a fish emerged during the $10 \mathrm{~min}$, the refuge remained in the tank; if not, then the refuge was slowly lifted straight upwards and out of the tank after the 10-min mark. After emergence or refuge removal, the number of gridlines crossed over a 10-min period was recorded. All behavioural metrics (binary refuge emergence score, time taken to emerge if applicable, whether the raised refuge was considered to be a threat, number of lines crosses, and, if applicable, the number of refuge re-entries and total time spent back in the refuge) were scored through video analysis. A positive refuge emergence score was assigned when the fish's full body had left the refuge. Whether the lifting of the refuge was considered to be a threat was scored positive if the fish initiated a flight (fast swimming) response away from the refuge as it 
was being lifted; if this was observed, line crosses were not counted until the flight response ended (i.e. the fish came to rest). During the line crosses trial, a cross was counted only when the fish's whole body had crossed over the line. Following behavioural trials, fish were netted out of the arena, weighed, and returned to their sensory deprivation chambers.

\subsubsection{Experimental procedure: Physiology track}

Seventy-six Largemouth Bass (TL mean $\pm \mathrm{SD}=334 \pm 27 \mathrm{~mm}$ ) were subjected to the physiology-track protocol. Following the relevant handling procedures, fish from all treatment groups except BP were placed back into their chambers in the holding tank. Blood samples $(\sim 200 \mu \mathrm{L})$ were taken from the caudal vasculature of each fish at 30 - and 120-min following return to the chambers. BP fish were removed from their sensory deprivation chambers, and a $\sim 200 \mu \mathrm{L}$ blood sample was taken in under 2-3 min to ensure accurate baseline values (Lawrence et al. 2018). All blood samples were taken using heparinized (10 000 USP units/mL sodium heparin; Sandoz, Boucherville, Quebec, Canada) 21-gauge needles and $1 \mathrm{~mL}$ syringes.

Blood glucose and lactate concentrations were measured using Accu-Chek Compact Plus (Hoffman-La Roche Limited, Mississauga, Ontario, Canada) and Lactate Plus (Nova Biomedical Corporation Canada Ltd., Mississauga, Ontario, Canada) handheld meters. These medical-grade devices have been validated for use on whole blood samples from teleost fish (Stoot et al. 2014). Both glucose and lactate meters display "LO" when the measured glucose/lactate concentrations fell below the $0.3 \mathrm{mM}$ detection limit (on both devices). Therefore, any "LO" readings were set at $0.3 \mathrm{mM}$ in the analyses so as to allow for a conservative comparison of these data across treatments. No "LO" glucose readings occurred. Several "LO" lactate readings occurred in the baseline group, two in the SEH group (one at $30 \mathrm{~min}$ and one at $120 \mathrm{~min}$ ), one in the E group (at 
$120 \mathrm{~min}$ ), and one in the SEL group (at $120 \mathrm{~min}$ ). To measure haematocrit, blood was collected in $40 \mathrm{~mm}$ heparinized (ammonium heparin) microhaematocrit capillary tubes (Iris Diagnostics, Chatsworth, California, USA) and centrifuged at $13700 \mathrm{~g}$ for $2 \mathrm{~min}$ (StatSpin CritSpin; Iris Sample Processing, Westwood, Massachusetts, USA). The remaining blood was held on ice for $<3 \mathrm{~h}$ and centrifuged at $2000 \mathrm{~g}$ for $5 \mathrm{~min}$ (Benchmark MyFuge ${ }^{\mathrm{TM}}$ Mini; Mandel Scientific, Guelph, Ontario, Canada). The plasma was decanted, flash frozen, and stored in a $-80^{\circ} \mathrm{C}$ freezer until plasma cortisol and osmolality assays could be carried out. Osmolality assays were conducted using a vapour pressure osmometer (VAPRO Vapour Pressure Osmometer 5600, ELITech Group, Puteaux, France). Commercial radioimmunoassay kits (ImmuChem Cortisol Coated Tube RIA Kit, MP Biomedicals, Solon, OH, U.S.A.) were used to determine plasma cortisol concentrations, with an intra-assay variability of $8.26 \%$. One BP fish had a plasma cortisol concentration of $158 \mathrm{ng} / \mathrm{mL}$, which far exceeds the maximum value of pre-established representative baseline values of both wild (Lawrence et al. 2018) and captive (Trushenski et al. 2012b) Largemouth Bass, as well as the other BP fish whose plasma cortisol levels ( $\mathrm{min} / \mathrm{max}=$ 8.3 to $76.9 \mathrm{ng} / \mathrm{L}$ ) were within or reasonably close to said baseline ranges. This fish may have been experiencing pre-existing physiological stress from an unquantifiable cause that resulted in

elevated plasma cortisol (e.g. parasitism; Sures 2008). This fish was therefore excluded from the statistical analyses, to the benefit of model assumptions (distribution of residuals) but with no impact on the overall meaning and interpretation of results.

\subsubsection{Statistical analyses}

The statistical analyses were broken down into five comparisons between treatment pairs, each to address one questions: (1) Does handling increase stress and influence behaviour 
(baselines vs. HC); (2) Does electroanesthesia increase stress and influence behaviour (HC vs. E); (3) Does surgery increase stress and influence behaviour (E vs. SE); (4) Does the infiltration process increase stress and influence behaviour (SE vs. SEH); and (5) Does lidocaine increase/decrease stress and influence behaviour (SEH vs. SEL). For the first question only, blood chemistry data at $30 \mathrm{~min}$ and $120 \mathrm{~min}$ had to be analyzed separately to be compared with baseline values (which were taken at one time point only and therefore could not be incorporated into a model that accounted for repeated sampling in the HC group).

Summary statistics (e.g. normality tests) were conducted in PAST v. 3.25 (Hammer et al. 2001). All other statistical analyses were performed in RStudio v. 1.1.463 (RStudio Team 2016) with R v. 3.6.0 (R Core Team 2019). Figures were generated using the "ggplot2" package (Wickham 2016). General linear models (LMs) were fitted for all ventilation rate data (VR $1-3$, $\Delta \mathrm{VR}$ ) with fish mass and water temperature initially included as linear covariates, and for continuous measures of behaviour in the arena (refuge emergence time, time in re-entered refuge) with fish length and water temperature initially included as linear covariates. Generalized linear models (GLMs) with poisson error distributions were fitted for the number of lateral thrashes during surgery with fish mass and water temperature initially included as linear covariates, and for behavioural responses measured as counts with water temperature and either mass (for RAMP scores calculated as the sum of the five binary reflex scores, opercular twitches) or length (for line crosses, refuge re-entries) initially included as linear covariates. GLMs with binomial error distributions were fitted for binary responses (refuge emergence, threat perception from refuge lifting) with fish length and water temperature initially included as linear covariates. For fish that did not emerge from the refuge, whether the refuge lift was perceived as a threat was initially included as a predictor in the line cross count model in case 
flight responses were associated with changes in swimming activity in the subsequent trial. In addition to plasma cortisol and osmolality, blood glucose and lactate, and haematocrit values at 30- and 120-min post-surgery, scopes were calculated by subtracting the values at $30 \mathrm{~min}$ from those at 120 min to assess the magnitude and direction of change in each metric over the sampling period. Blood chemistry data were analysed using linear mixed-effects models (LMMs), fitted with the "Imer" function from the "Ime4" package (Bates et al. 2015), including treatment, time (30 or $120 \mathrm{~min}$ ), and the two-way interaction of treatment and time as categorical predictors, fish mass as a linear covariate, and individual fish identity (ID) as a random effect. All models underwent AICc model selection to test if covariates (e.g. fish mass, water temperature) contributed significantly to model variance; if they didn't, they were removed from the model. Each global model and the nested models within were sorted by AICc using the "dredge" function from the "MuMIn" package (Barton 2019). The model with the lowest AICc value that still contained treatment as a predictor was selected for subsequent analysis. Model selection outputs are provided in Appendix I. LMs, GLMs, and LMMs were analysed using the "Anova" function in the "car" package (Fox and Weisberg 2019), with $F$-tests calculated for LMs and LMEs and likelihood-ratio $\chi^{2}$ tests for the GLMs. Random effects were analysed using the "ranova" function from the "ImerTest" package (Kuznetsova et al. 2017) and by computing intraclass correlation coefficients (ICCs) from variance outputs from the base R "summary" function. Post-hoc analyses of pairwise comparisons between categorical predictor levels were conducted using the "lsmeans" function from the "emmeans" package (Lenth 2019) to generate asymptotic $95 \%$ confidence intervals.

Wasserstein et al. (2019) summarize an increasingly popular shift in researchers' attitudes towards $P$ values and the limitations of arbitrary notions of "statistical significance". I follow 
several of the recommendations therein towards a more comprehensive means of interpreting results. To that end, I make use of complementing $P$ values with the inclusion of local effect sizes, as well as comparisons to findings from similar research where available. For categorical predictors (e.g. treatment), Cohen's $f^{2}$ is given; as an approximate guideline, Cohen (1988) recommends considering $f^{2} \geq 0.02, f^{2} \geq 0.15$, and $f^{2} \geq 0.35$ as small, medium, and large effect sizes, respectively. Predictors with low effect sizes explain little of the variation in the observed data, while those with medium and large effect sizes explain moderate and high amounts of variation in the observed data, respectively.

\subsection{Results}

Appendix I contains tables summarizing the outputs of all statistical analyses. Since the ultimate goal of this experiment was to determine whether or not the welfare of electroanesthetized fish was improved by the application of a local analgesic, and given the volume of results generated, I present here detailed in-text results only for the comparison of SEH vs. SEL fish. The first four questions presented (controlling for the effects of handling, electroanesthesia, surgery, and drug administration on physiology and behaviour) are not the main interest of this experiment, therefore I only summarize and report biologically relevant findings in these sections, with the remaining analysis outputs readily available in Appendix I.

\subsubsection{BP/BB vs. HC: Does handling increase stress and influence behaviour?}

Handling increased stress, based on detectable changes in primary and secondary physiological stress markers (Table S1). Behavioural observations between HC fish (handled extensively) and BB fish (handled minimally) showed fewer differences (Tables S3-S4); HC fish 
were less likely to perceive the lifting refuge as a threat and were more exploratory in the arena than BB fish, but otherwise the two treatment groups behaved similarly following surgery.

\subsubsection{HC vs. E: Does electroanesthesia increase stress and influence behaviour?}

Electroanesthesia effectively facilitated handling, reducing the number of voluntary escape attempts during surgery relative to $\mathrm{HC}$ fish (Table S2) without exacerbating the stress response measured through primary and secondary physiological stress markers (Table S1). Intra-individual variation (differences in response changes across individual fish) explained more of the total variability in haematological responses than fixed effects (i.e. treatment, time; Table S5). Similarly, no differences in post-surgery behaviour were detected between $\mathrm{E}$ and $\mathrm{HC}$ fish (Tables S3-S4) with the exception of line cross counts, which were lower in electroanesthetized fish $\left(P<0.0001 ; \mathrm{DF}=1 ; f^{2}=9.17\right)$.

\subsubsection{E vs. SE: Does surgery increase stress and influence behaviour?}

Under electroanesthesia, fish behaviour was not affected while undergoing surgery (Table S2). Primary and secondary stress markers did not differ between E and SE fish following surgery, with the exception of plasma osmolality, for which the treatments exhibited different trends over time (Table S1). Intra-individual variation outweighed the variation explained by fixed effects for blood glucose and blood lactate, but explained less than half of the total variance for plasma cortisol and plasma osmolality, and less than a quarter for haematocrit (Table S5). SE fish has lower mean line cross counts in the arena than $\mathrm{E}$ fish $\left(P=0.007 ; \mathrm{DF}=1 ; f^{2}=0.36\right)$, but otherwise behavioural responses were consistent between treatments. 


\subsubsection{SE vs. SEH: Does the infiltration process increase stress and influence behaviour?}

The drug administration process (saline infiltration in SEH fish) slightly increased the probability of voluntary escape attempts during surgery $\left(P=0.037 ; \mathrm{DF}=1 ; f^{2}=0.08\right)$, slightly decreased mean $\mathrm{VR}_{1}\left(P=0.043 ; \mathrm{DF}=1 ; f^{2}=0.10\right)$, and increased mean $\mathrm{VR}_{2}(P=0.012 ; \mathrm{DF}=$ $\left.1 ; f^{2}=0.27\right)$. Mean haematocrit was slightly higher in SEH fish than SE fish $(P=0.063 ; \mathrm{DF}=1$; $f^{2}=0.15$ ), but otherwise SE and SEH fish exhibited similar behavioural and physiological responses post-surgery (Tables S1, S3-S4). Intra-individual variation outweighed the variation explained by fixed effects for plasma cortisol, blood glucose, blood lactate, and haematocrit, but not for plasma osmolality (Table S5). 


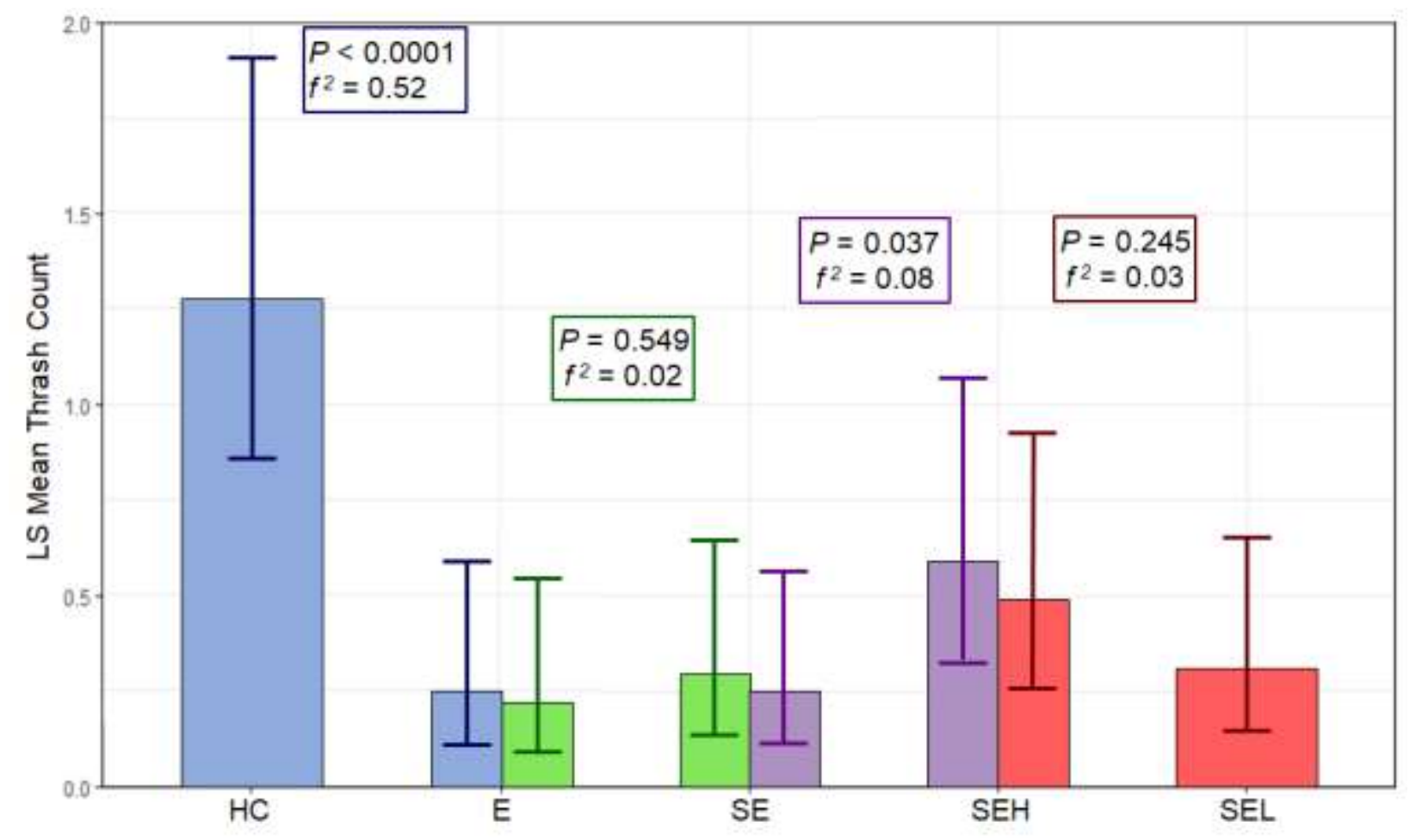

Figure 4. Least squares mean thrash counts observed during surgeries for each treatment, with asymptotic $95 \%$ confidence intervals. Treatments are given by letter codes (see Fig. 1; HC = handling control; $\mathrm{E}=$ electroanesthesia; $\mathrm{SE}=$ surgery and electroanesthesia; $\mathrm{SEH}=$ surgery, electroanesthesia, and saline infiltration; SEL = surgery, electroanesthesia, and lidocaine infiltration). Column colours denote each treatment comparison, with corresponding $P$ values and effect sizes in matching boxes; LS means are generated during each analysis and so two columns are present for all treatments but HC and SEL. Differences between treatment pairs are denoted by (*). Sample sizes per treatment were $n=27$ (HC), $n=27$ (E), $n=28$ (SE), $n=28$ (SEH), and $n=28$ (SEL). 


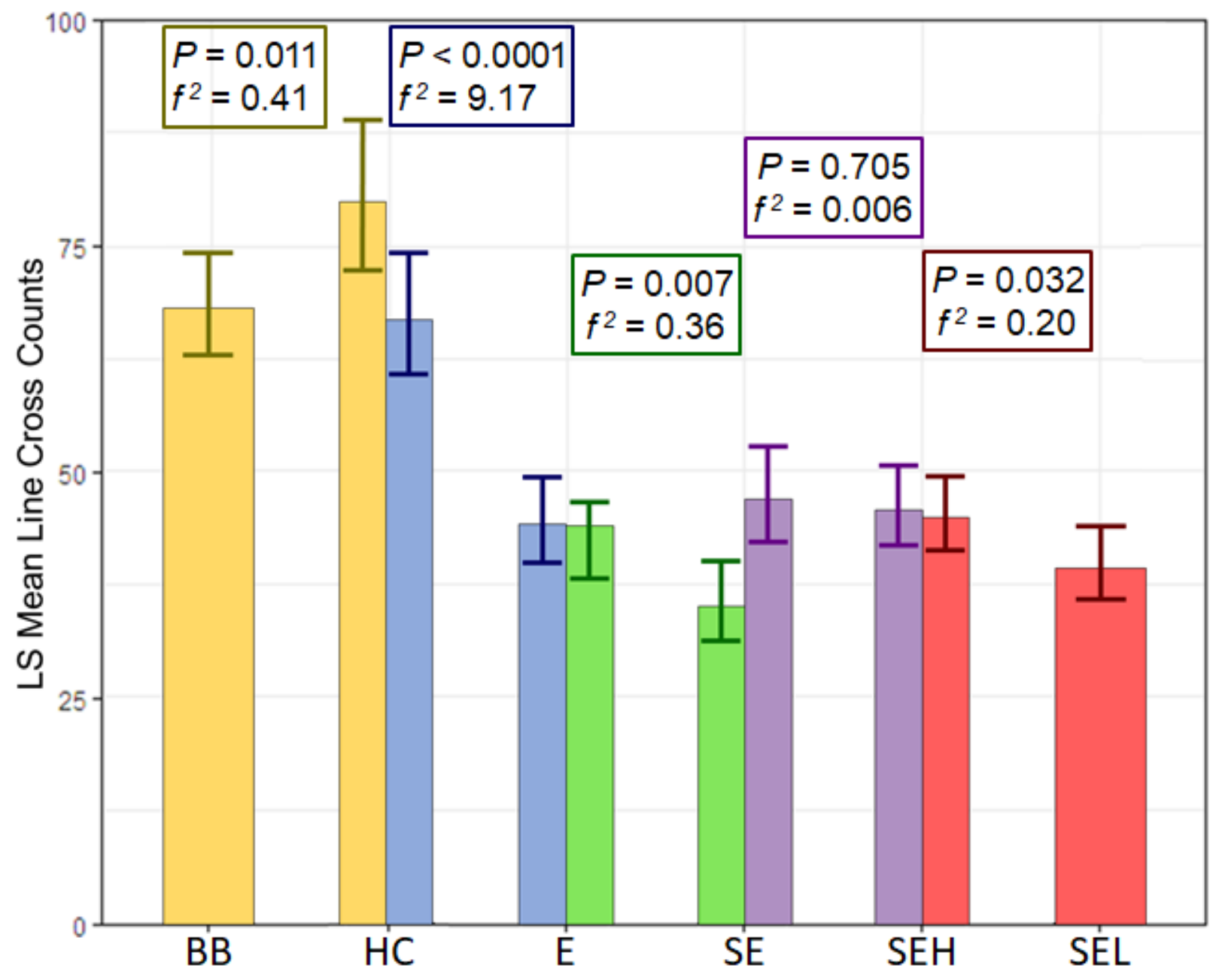

Figure 5. Least squares mean line cross counts for each treatment, with asymptotic $95 \%$ confidence intervals. Treatments are given by letter codes $(\mathrm{BB}=$ baseline behaviour; $\mathrm{HC}=$ handling control; $\mathrm{E}=$ electroanesthesia; $\mathrm{SE}=$ surgery and electroanesthesia; $\mathrm{SEH}=$ surgery, electroanesthesia, and saline infiltration; SEL = surgery, electroanesthesia, and lidocaine infiltration). Column colours denote each treatment comparison, with corresponding $P$ values and effect sizes in matching boxes; LS means are generated during each analysis and so two columns are present for all treatments but BB and SEL. Differences between treatment pairs are denoted by $(*)$. Sample sizes per treatment were $n=14$ (BB), $n=14(\mathrm{HC}), n=12(\mathrm{E}), n=14$ (SE), $n=13(\mathrm{SEH})$, and $n=16$ (SEL). 


\subsubsection{SEH vs. SEL: Does lidocaine increase/decrease stress and influence behaviour?}

The administration of lidocaine to the surgery site in SEL fish neither improved fish handling on the surgery table nor did it make it more difficult relative to SEH fish. Changes in physiological stress markers following surgery were consistent between the two treatments. Postsurgery behavioural responses were largely consistent as well except for arena activity, which was lower in SEL fish than SEH fish.

Mean thrash counts during surgery did not differ between SEH and SEL fish $(P=0.245$; $\mathrm{DF}=1 ; f^{2}=0.03 ;$ Figure 4$)$. Mean thrash counts increased by $\sim 46 \%$ for every $1^{\circ} \mathrm{C}$ increase in water temperature $(P=0.002)$. Mean ventilation rates during surgery $\left(\mathrm{VR}_{1}\right)$ were higher for SEL fish than SEH fish, but treatment explained little overall variation in $\mathrm{VR}_{1}\left(P=0.042 ; \mathrm{DF}=1 ; f^{2}\right.$ $=0.09$ ).

In SEH and SEL fish, treatment did not affect (or explain much variation in) mean differences in plasma cortisol, blood glucose, blood lactate, plasma osmolality, or haematocrit (Table S1; Figures 5-9). For both SEH and SEL fish, mean plasma cortisol increased slightly from 30 to 120 min post-surgery $\left(P=0.024 ; \mathrm{DF}=1 ; f^{2}=0.05\right.$; Figure 6$)$. Decreases in mean values from 30 to $120 \mathrm{~min}$ were observed for blood lactate $\left(P=0.003\right.$; $\mathrm{DF}=1 ; f^{2}=0.02$; Figure 8), plasma osmolality $\left(P=0.044 ; \mathrm{DF}=1 ; f^{2}=0.05\right.$; Figure 9$)$, and haematocrit $(P<0.0001$; DF $=1 ; f^{2}=0.23$; Figure 10 ). Intra-individual variation outweighed the variation explained by all fixed effects for plasma cortisol (ICC $=0.554)$, blood glucose $($ ICC $=0.824)$, blood lactate (ICC $=0.790)$, plasma osmolality $(\mathrm{ICC}=0.624)$, and haematocrit $(\mathrm{ICC}=0.628)$.

SEL and SEH fish did not differ in any responses measured in the cooler. Treatment had no effect on, and explained little variation in $\operatorname{VR}_{2}\left(P=1.0 ; \mathrm{DF}=1 ; f^{2}<0.001\right), \mathrm{VR}_{3}(P=0.837$; $\left.\mathrm{DF}=1 ; f^{2}=0.001\right), \Delta \mathrm{VR}\left(P=0.842 ; \mathrm{DF}=1 ; f^{2}=0.002\right)$, mean opercular twitch counts $(P=$ 
0.492; $\left.\mathrm{DF}=1 ; f^{2}=0.02\right)$, or either RAMP score $\left(\mathrm{RAMP} 1: P=0.684 ; \mathrm{DF}=1 ; f^{2}=0.005\right.$;

RAMP 2: $P=0.807 ; \mathrm{DF}=1 ; f^{2}=0.002$ ) between SEH and SEL fish. Mean $\mathrm{VR}_{2}$ increased by $\sim 0.07$ ventilations $/ \mathrm{s}$ per $1^{\circ} \mathrm{C}$ increase in water temperature $(P=0.006)$. A decrease of $\sim 0.1$ ventilations/s per $100 \mathrm{~g}$ increase in fish mass was observed for both $\mathrm{VR}_{2}(P=0.006)$ and $\mathrm{VR}_{3}(P$ $=0.002)$.

In the arena, no SEH fish emerged voluntarily from the refuge, therefore I could not quantify differences in refuge emergence, refuge emergence time, refuge re-entry counts, and time in the re-entered refuge. Treatment explained little variation in whether the refuge lifting was perceived as a threat, and did not elicit any observable differences between SEH and SEL fish $\left(P=0.848 ; \mathrm{DF}=1 ; f^{2}=0.001\right)$. Mean line cross counts were lower for SEL fish than SEH fish, with treatment explaining moderate variation in the observed counts $\left(P=0.032 ; \mathrm{DF}=1 ; f^{2}\right.$ $=0.20 ;$ Figure 5). Fish that perceived the lifting refuge as a threat had higher mean line cross counts than those that did not, with threat perception explaining a very high proportion of the observed variation in line cross counts $\left(P<0.001 ; \mathrm{DF}=1 ; f^{2}=8.22\right)$. Mean line cross counts tended to decrease by $\sim 1 \%$ per $1 \mathrm{~mm}$ increase in fish length $(P=0.010)$.

\subsection{Discussion}

\subsubsection{Does lidocaine improve the welfare of electroanesthetized fish?}

Electroanesthesia was able to successfully facilitate fish handling, as evidenced by the reduction in voluntary movements while on the surgery table relative to the handling control. Because the incidence of these movements did not differ between fish from any treatment that received electroanesthesia, and also that the evaluated physiological and behavioural metrics post-surgery were highly consistent between E and SE fish, it is possible that electroanesthesia 
may also provide some analgesic effect. However, I stress that future research is needed to test the extent to which this may be true while considering the variation in applicable current parameters. Reduced swimming activity following surgeries was observed in E fish, but I do not expect any of the treatments with (or without) electroanesthesia to have had lethal short-term consequences on tested fish had they been released immediately into the wild following surgeries based on the lack of differences in RAMP scores for each comparison. Overall, I found insufficient evidence to suggest that the welfare of electroanesthetized Largemouth Bass undergoing surgeries improved with the administration of $\sim 1 \mathrm{mg} / \mathrm{kg}$ lidocaine at the surgery site, given the general consistencies between physiological and behavioural responses in SEH and SEL fish. It is unclear, however, whether a $\sim 1 \mathrm{mg} / \mathrm{kg}$ dose of lidocaine was sufficient to induce an analgesic effect in this experiment. There is insufficient information on appropriate doses for locally administered lidocaine in fish, with recommendations such as the dose used in this experiment ( $\sim 1 \mathrm{mg} / \mathrm{kg}$ fish) based on work in other taxa (i.e. mammals; Chatigny et al. 2017). A higher lidocaine dose of $10 \mathrm{mg} / \mathrm{kg}$ was infiltrated in the dorsal musculature of Rainbow Trout Oncorhynchus mykiss and resulted in higher damage to muscular tissues over a 15-day period relative to a saline control group (Chatigny et al. 2018), but Chatigny et al. (2017) also reported the use of $20 \mathrm{mg} / \mathrm{kg}$ infiltrated lidocaine in Rainbow Trout without any apparent adverse impacts on survival. Researchers attempting to replicate this experiment or carry out similar work in another species would benefit greatly from an evidence-based understanding of appropriate doses for lidocaine (and other local analgesics), such as species-specific dose-response curves for various taxa. In addition, the legally mandated euthanasia of SEL fish did little to improve individual fish welfare, nor was it practical given the context of the surgical procedure I simulated (which aims to put tracking tags in live fish). 


\subsubsection{Surgery behaviour and ventilation rate $\left(V R_{1}\right)$}

The differences in how effectively fish were immobilized while undergoing surgery across treatments, quantified by rapid, voluntary lateral flexes ("thrashes"), indicated that electroanesthesia is an effective way of facilitating safe fish handling during the routine procedures used here. This is consistent with other research that has evaluated the efficacy of electroanesthesia relative to handling controls (e.g. Ward et al. 2017). The increase in mean thrash counts for SEH fish relative to SE fish appears to indicate that, while the drug administration process may be more disturbing or provide more irritation to the fish, the actual increase observed is still less than 1 expected thrash per surgery; a much more dramatic difference in thrash counts was observed between $\mathrm{HC}$ and $\mathrm{E}$ fish. While the lidocaine may have counteracted any irritation from the administration process itself, its application did not add to or improve on the ease of handling attributable to electroanesthesia alone at the tested dose. Increases in mean thrash counts with increasing water temperature could be an indication of the general increase in swimming activity with increasing temperature (e.g. Hasler et al. 2009). The positive relationship between mean thrash counts and fish mass might be explained by aggression/antipredator behaviour which, by some metrics, increases with size (e.g. Cooke et al. 2017). In the only other known experiment to also quantify rapid lateral thrashes using the same electroimmobilization equipment, Ward et al. (2017) did not find a relationship between the number of escape attempts and fish size, though substantial differences exist between that experiment and the one presented here (e.g. water temperature, selected current strengths, range of fish sizes, presence/absence of invasive treatments, and differences in handling times).

Ventilation rates during surgery were sometimes difficult to quantify. While the opercula of the fish undergoing surgery were almost always visible (barring cases where arms/hands 
briefly obscured the view), there were a number of instances where the ventilation rates could not be recorded immediately after the incision had been made because the fish was being prevented from exhibiting normal opercular movements. The specific way that fish were held varied with the handler wearing the FHGs, and though I attempted to standardize handling and ensure that opercular movements were visible during the surgery, differences in handling technique and position may have led to impeded opercular movements (e.g. slight pressure at the base of the opercula). Thus, some VRs were recorded just after the incision was made while others could only be recorded during suturing. Any time post-incision should capture a potential effect of the surgery on VR, but it is possible that the behavioural responses to the surgery were not consistent throughout the procedure. Or, VR simply may not be a suitable behavioural metric of stress in this experiment. VR may be better used as an indicator of metabolic rate (Grantner and Taborsky 1998) and attempts to measure stress directly with it are hampered by sensitivity to many stimuli and time delays from stressor to visible response (which can manifest over at least 30 min; Barreto and Volpato 2004). If there were any immediate effects recorded during the surgery, these could therefore be confounded by pre-surgery handling. I measured fish length before the surgeries were carried out, which could have led to an interaction of stress from presurgery handling and the surgery itself that was not accounted for.

\subsubsection{Behaviour track}

Assessments of ventilation rates $\mathrm{VR}_{2}$ and $\mathrm{VR}_{3}$, as well as $\Delta \mathrm{VR}$, yielded results that are consistent with the known relationships between oxygen consumption/metabolism and both fish size and water temperature (Brown et al. 2005). The only noteworthy difference in $\mathrm{VR}_{2}$, between SEH and SE fish, cannot be easily interpreted given the aforementioned difficulty of using VR as 
a behavioural metric of stress. It is more likely that any potential effects of tested treatments on VRs were measured on an inadequate temporal scale and/or influenced by initial handling procedures (as noted by Barreto and Volpato 2004).

Opercular twitches have only been documented in fish as a response to reaching critical thermal maxima (Bilyk et al. 2012), but the fish in this experiment were exposed to lake water at temperatures to which they are accustomed and were not incapacitated as would be expected in a severe heat stress event. Since these twitches were observed across all treatments (including BB), and with no discernable mechanism to explain the occurrence of opercular twitches in otherwise normally breathing fish, I can only recommend that this phenomenon be investigated in future work. In the event that it is a proxy for stress, opercular twitches would corroborate the increase in stress from more intense handling ( $\mathrm{HC}$ ) compared with minimal handling (BB), as well as the overall lack of differences in physiological stress responses induced from E vs. HC, SE vs. E, SEH vs. SE, or SEL vs. SEH in this experiment. The lack of differences in RAMP scores across treatments suggests that under the environmental conditions of this experiment, none of the procedures used are expected to increase short-term mortality in Largemouth Bass.

Recommendations of the investigated treatments are therefore based on other behavioural and physiological metrics.

Because only 10 fish in total could be tested per day across both behaviour and physiology tracks, and because I did not always have 10 fish to test each day, not all treatments for both tracks could be run through on a given day. Refuge emergence did not occur on every date that behavioural trials were run, and on a number of dates emergence rates of either $100 \%$ or $0 \%$ were observed. Another uncontrolled environmental factor such as barometric pressure, which can influence fish movements (Guy et al. 1992), may very well have elicited day-to-day 
differences in refuge emergence rates, which in turn might have contributed to the lack of emergences in the $\mathrm{E}$ and SEH groups. The refuge may not have been small enough to give smaller tested fish sufficient incentive to emerge, but this bias should have been consistent across treatments. It is conceivable that an electroanesthetized fish might be more reluctant to emerge from a safe place than baseline or handling control fish, but it makes little sense that this reluctance would not then be shared by electroanesthetized fish that had also received further stress from a ventral incision (a small number of emergences were observed in SE and SEL fish). Faster refuge emergence times were seen at higher water temperatures, where a general increase in swimming activity is elicited (Hasler et al. 2009).

Physiological stress can increase with longer handling times (e.g. Meka and McCormick 2005), and if it can be linked to behavioural responses (e.g. Fürtbauer et al. 2015), a difference in swimming activity between $\mathrm{BB}$ and $\mathrm{HC}$ fish might have been more pronounced had $\mathrm{BB}$ fish not also undergone the cooler portion of the behaviour track. The changes in mean line cross counts between $\mathrm{E}$ and $\mathrm{HC}$ fish appear to indicate that electroanesthesia can depress exploratory behaviour. This could be the result of energy diversion towards recovering from physiological stress (a phenomenon that has been documented in other taxa in response to oxidative stress; Nilsson et al. 1993), but $\mathrm{E}$ and $\mathrm{HC}$ fish had comparable changes in blood chemistry responses. A plausible explanation for this discrepancy is that increasing blood lactate following electroanesthesia may be a result of both elevated cortisol and stimulation of muscles by the current (Trushenski et al. 2012b), which was not experienced by HC fish, whose blood lactate levels would have been more greatly influenced by increased activity on the surgery table. Although the statistical analyses yielded further decreasing line cross counts from E to SE fish, and SEH to SEL fish, the biological relevance of these differences should be brought into 
question. As clearly visible in Figure 5, the least squares means used to estimate population means and generate confidence intervals for each treatment are calculated separately during each analysis and were therefore not always consistent (e.g. the LS means for SE fish differed starkly from one another). As a result, the differences in line cross counts between E/SE fish and SEH/SEL fish could very well be a result of the statistical methods that had to be employed for these data, and are small enough in terms of practical effect to not be considered biologically relevant.

For fish that did not emerge from the refuge, the frequency that the raising of the refuge was perceived as a threat did not differ across non-baseline treatment comparisons. Despite controlling for this in the analysis of line crosses and allowing for fish that did flee to finish their flight response before beginning line cross counts, differences in line cross counts were still observed for fish that fled compared with those that did not. Furthermore, these differences were not consistent between treatment comparisons. This suggests that across treatments, the brief flight response observed may have been coupled with other, relatively long-lasting physiological processes that are linked to relevant behavioural responses (e.g. heart rate or cardiac output; Johnsson et al. 2001; Cooke et al. 2003).

\subsubsection{Physiological stress responses}

Changes in mean plasma cortisol, blood glucose, and blood lactate concentrations appeared be consistent across the addition of electroanesthesia, surgery, and drug administration to general handling. Moreover, the magnitude and direction of changes in plasma cortisol (Figure 6), blood glucose (Figure 7), and blood lactate (Figure 8) between 30 and 120 minutes was highly similar for all treatments. As a result, any differences that may exist between these 
metrics for E, SE, SEH, and SEL fish were not biologically relevant, having been masked beneath the physiological stress response induced by handling itself. The increase in plasma cortisol from 30 to 120 min was surprising, as I expected plasma cortisol would peak roughly 30 min after exposure to a stressor (Barton 2002; e.g. Trushenski et al. 2012a; 2012b). It is likely that increased cortisol levels at 120 min post-surgery may be the result of the cumulative stress of repeated sampling. The possibility of stress due to conspecific water cortisol release (e.g. Ellis et al. 2004, Fanouraki et al. 2008) also cannot be ruled out.

Fluctuations in plasma osmolality have been observed as part of the typical stress response following various forms of electroimmobilization, and are sometimes (but not always) consistent with respect to treatment and time (e.g. Bowzer et al. 2012; Trushenski and Bowker 2012; Trushenski et al. 2012a; 2012b). It is difficult to elucidate the reason that plasma osmolality decreased over time in E fish while remaining relatively constant in SE fish. With reference to the baseline average, it seems that plasma osmolality at 30 min was elevated in $\mathrm{E}$ fish rather than depressed in SE fish, with recovery to near baseline values being observed by 120 min for all treatments (Figure 9). The one difference in haematocrit levels, between SE and SEH fish, is likewise puzzling in the absence of blood $\mathrm{pH}$ data or concentrations of hormones that could contribute to elevated counts and/or swelling of red blood cells. The construction of the holding setup, with air bubblers running continuously and new water flowing in, would have precluded hypoxia events that can correspond with elevated haematocrit (Gaulke et al. 2014).

In general, high intra-individual variation was a much more important factor than treatment in influencing the responses of all haematological stress metrics, as individual fish often accounted for more than half of the observed variation in each response. Intra-individual variation in physiological changes to various stimuli has been previously reported in other fish 
(e.g. Cook et al. 2012), with these changes possibly being grounded in genetic differences among individuals (Prunet et al. 2008) that were not assessed here. There is a paucity of research on the extent of intra-individual variation in physiological stress responses in circumstances comparable to this experiment, hampering my ability to interpret the relative contributions of intra-individual variation in a broader context. 


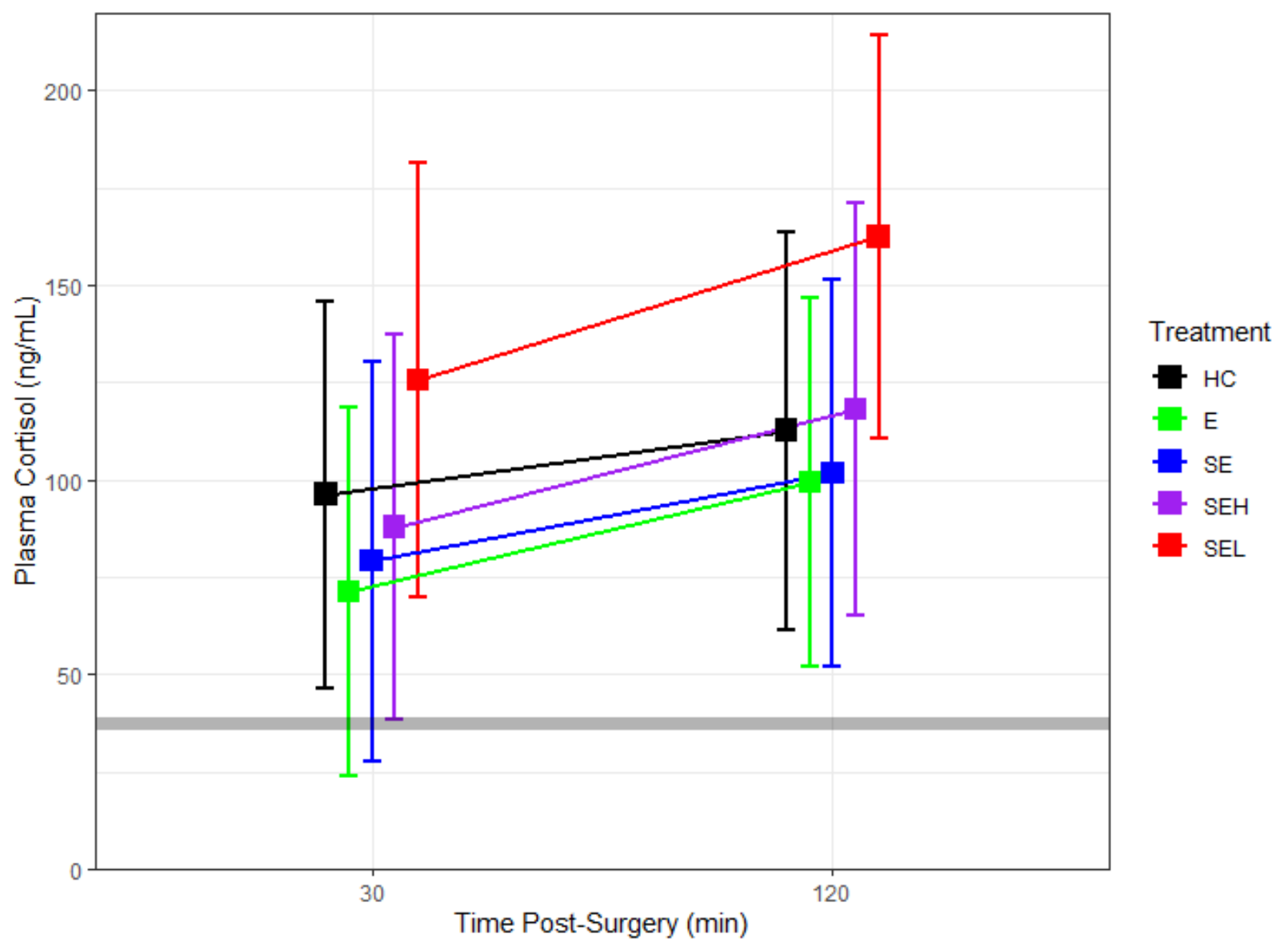

Figure 6. Least squares mean ( \pm asymptotic 95\% CIs) plasma cortisol concentrations for each treatment at 30- and 120-min post-surgery. Treatments have been jittered for clarity of viewing. The horizontal grey line represents the mean value from the baseline group. Treatments are given by letter codes $(\mathrm{HC}=$ handling control; $\mathrm{E}=$ electroanesthesia; $\mathrm{SE}=$ surgery and electroanesthesia; $\mathrm{SEH}=$ surgery, electroanesthesia, and saline infiltration; SEL = surgery, electroanesthesia, and lidocaine infiltration). Sample sizes per treatment were $n=12(\mathrm{HC}), n=$ $13(\mathrm{E}), n=11(\mathrm{SE}), n=12(\mathrm{SEH})$, and $n=10(\mathrm{SEL})$ at $30 \mathrm{~min}$, and $n=11(\mathrm{HC}), n=13(\mathrm{E}), n=$ $12(\mathrm{SE}), n=10(\mathrm{SEH})$, and $n=12(\mathrm{SEL})$ at $120 \mathrm{~min}$. 


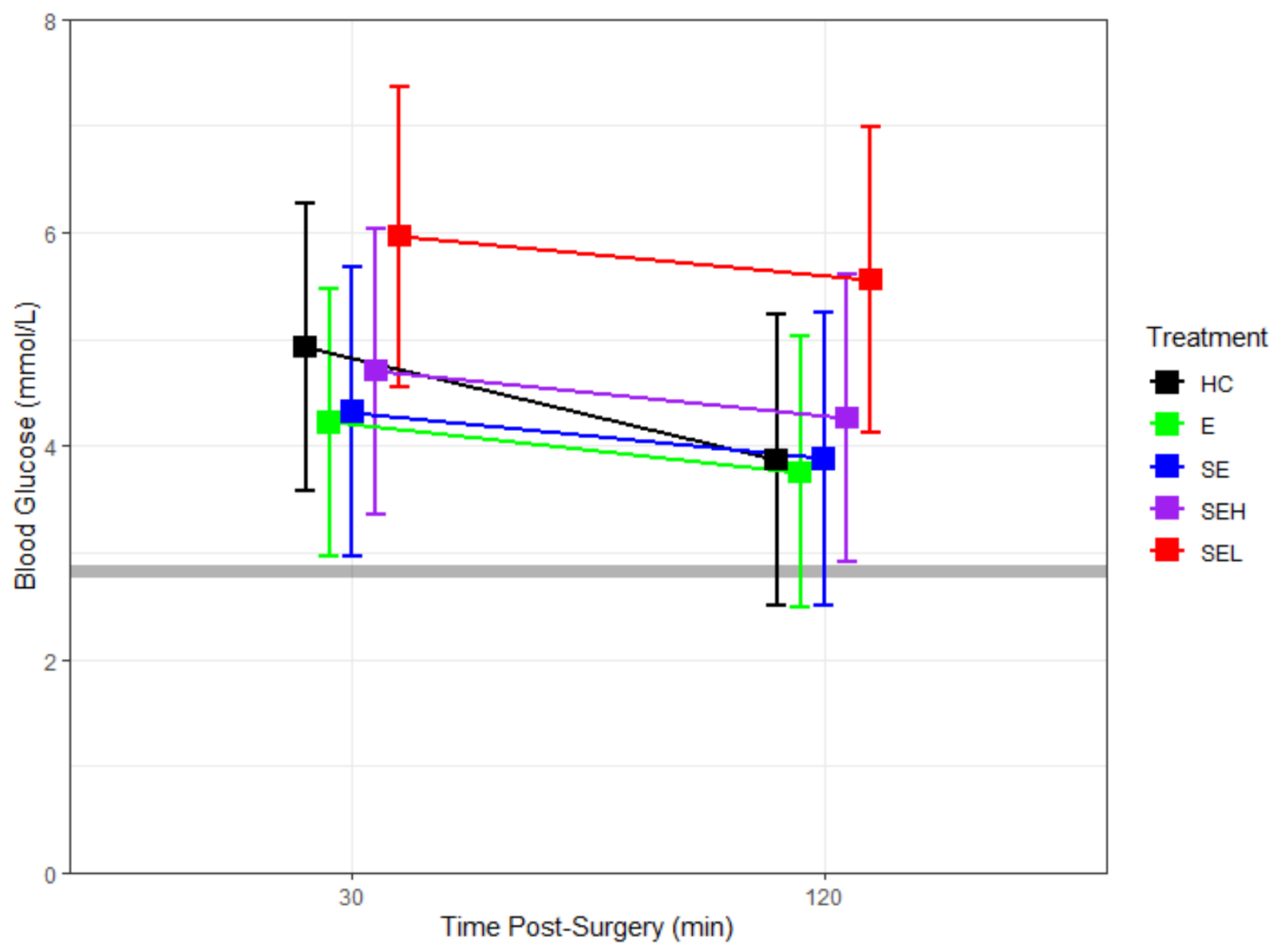

Figure 7. Least squares mean ( \pm asymptotic $95 \%$ CIs) blood glucose concentrations for each treatment at 30- and 120-min post-surgery. Treatments have been jittered for clarity of viewing. The horizontal grey line represents the mean value from the baseline group. Treatments are given by letter codes $(\mathrm{HC}=$ handling control; $\mathrm{E}=$ electroanesthesia; $\mathrm{SE}=$ surgery and electroanesthesia; $\mathrm{SEH}=$ surgery, electroanesthesia, and saline infiltration; $\mathrm{SEL}=$ surgery, electroanesthesia, and lidocaine infiltration). Sample sizes per treatment were $n=12$ (HC), $n=$ 14 (E), $n=12(\mathrm{SE}), n=12(\mathrm{SEH})$, and $n=12(\mathrm{SEL})$ at $30 \mathrm{~min}$, and $n=11(\mathrm{HC}), n=13(\mathrm{E}), n=$ $11(\mathrm{SE}), n=12(\mathrm{SEH})$, and $n=11(\mathrm{SEL})$ at $120 \mathrm{~min}$. 


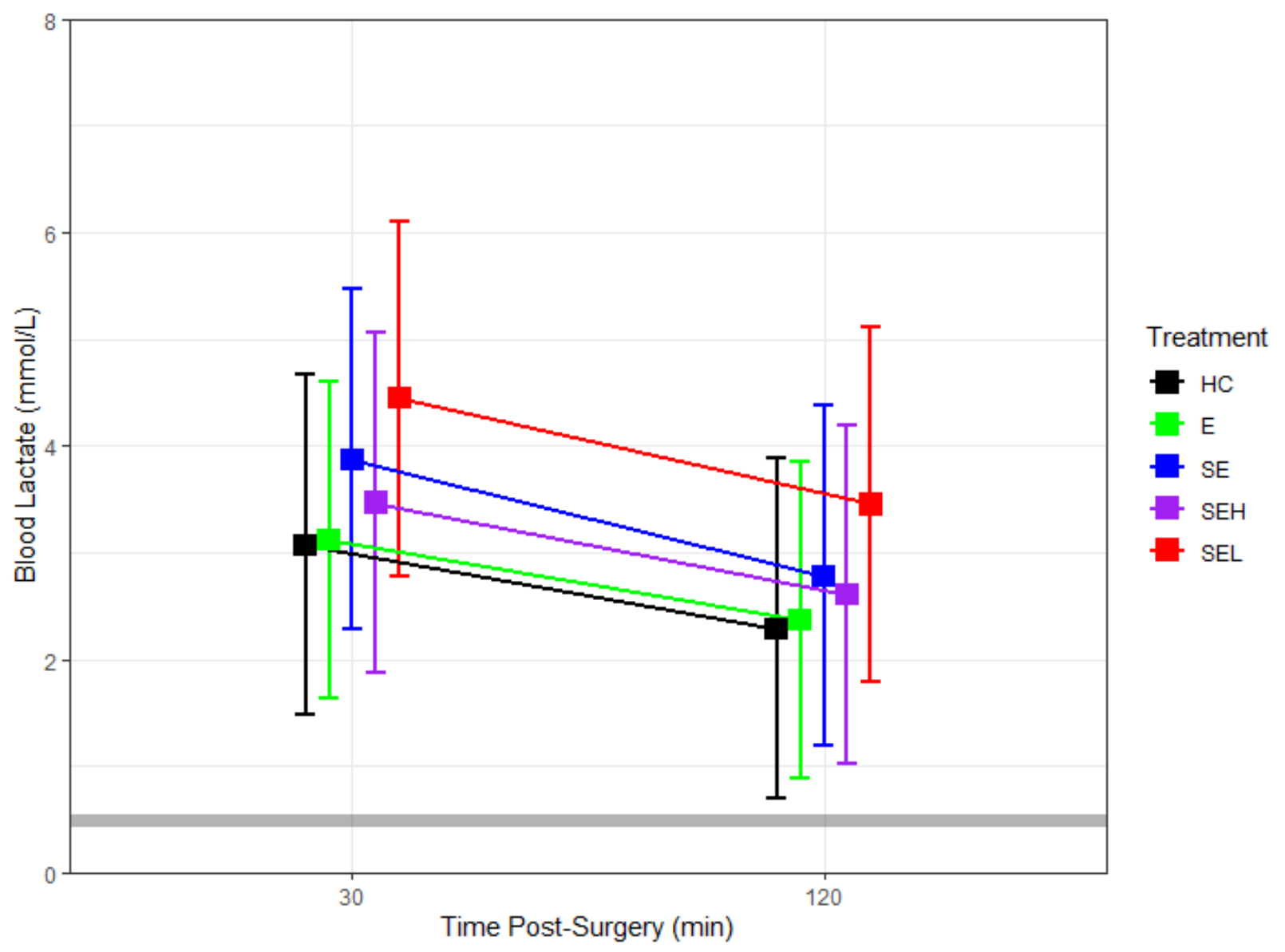

Figure 8. Least squares mean ( \pm asymptotic $95 \%$ CIs) blood lactate concentrations for each treatment at 30- and 120-min post-surgery. Treatments have been jittered for clarity of viewing. The horizontal grey line represents the mean value from the baseline group. Treatments are given by letter codes $(\mathrm{HC}=$ handling control; $\mathrm{E}=$ electroanesthesia; $\mathrm{SE}=$ surgery and electroanesthesia; $\mathrm{SEH}=$ surgery, electroanesthesia, and saline infiltration; $\mathrm{SEL}=$ surgery, electroanesthesia, and lidocaine infiltration). Sample sizes per treatment were $n=12$ (HC), $n=$ $14(\mathrm{E}), n=12(\mathrm{SE}), n=12(\mathrm{SEH})$, and $n=12(\mathrm{SEL})$ at $30 \mathrm{~min}$, and $n=12(\mathrm{HC}), n=14(\mathrm{E}), n=$ $12(\mathrm{SE}), n=12(\mathrm{SEH})$, and $n=12(\mathrm{SEL})$ at $120 \mathrm{~min}$. 


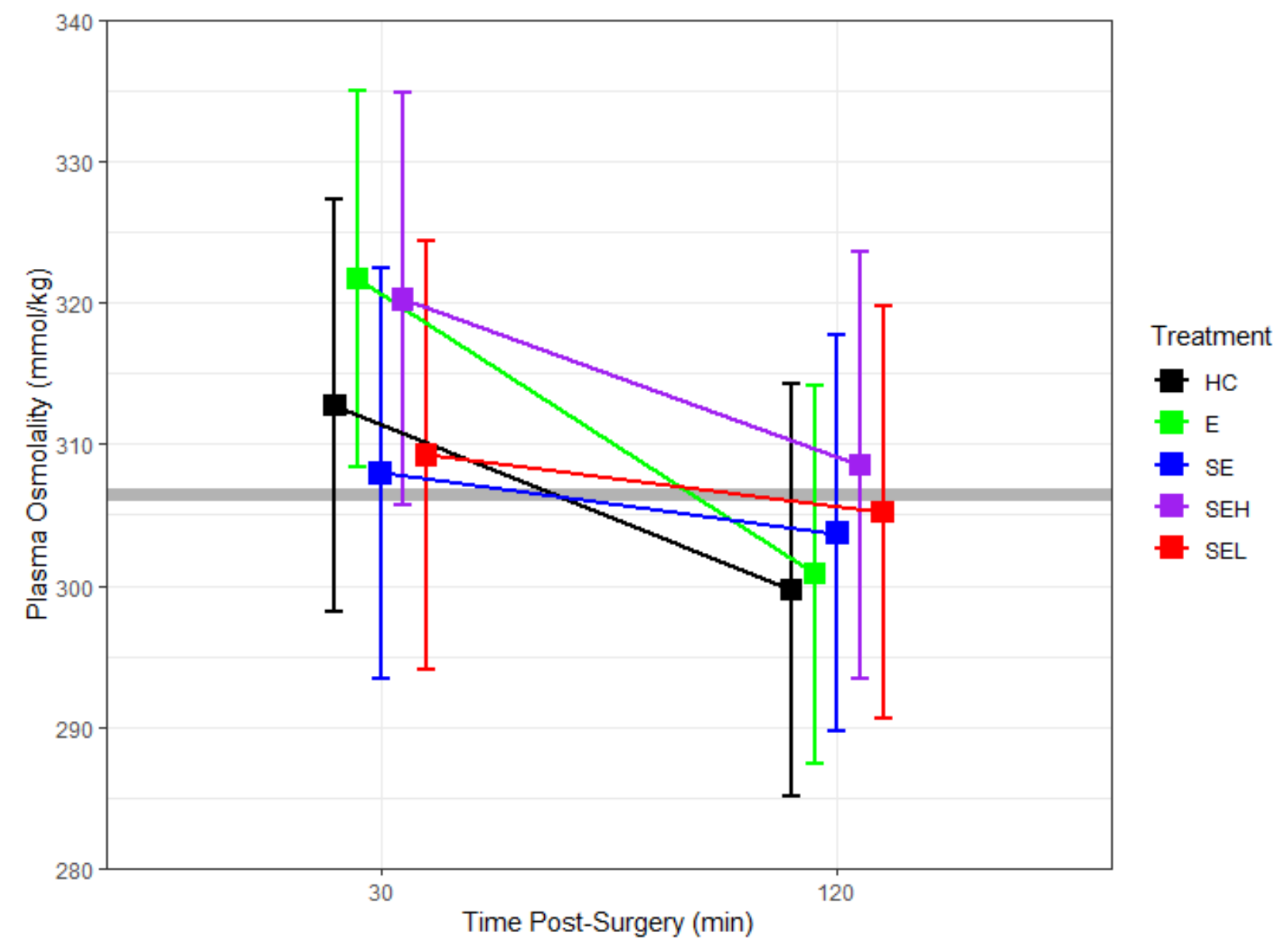

Figure 9. Least squares mean ( \pm asymptotic $95 \%$ CIs) plasma osmolality concentrations for each treatment at 30- and 120-min post-surgery. Treatments have been jittered for clarity of viewing. The horizontal grey line represents the mean value from the baseline group. Treatments are given by letter codes $(\mathrm{HC}=$ handling control; $\mathrm{E}=$ electroanesthesia; $\mathrm{SE}=$ surgery and electroanesthesia; $\mathrm{SEH}=$ surgery, electroanesthesia, and saline infiltration; $\mathrm{SEL}=$ surgery, electroanesthesia, and lidocaine infiltration). Sample sizes per treatment were $n=11$ (HC), $n=$ $13(\mathrm{E}), n=11(\mathrm{SE}), n=11(\mathrm{SEH})$, and $n=11(\mathrm{SEL})$ at $30 \mathrm{~min}$, and $n=11(\mathrm{HC}), n=13(\mathrm{E}), n=$ $12(\mathrm{SE}), n=10(\mathrm{SEH})$, and $n=12(\mathrm{SEL})$ at $120 \mathrm{~min}$. 


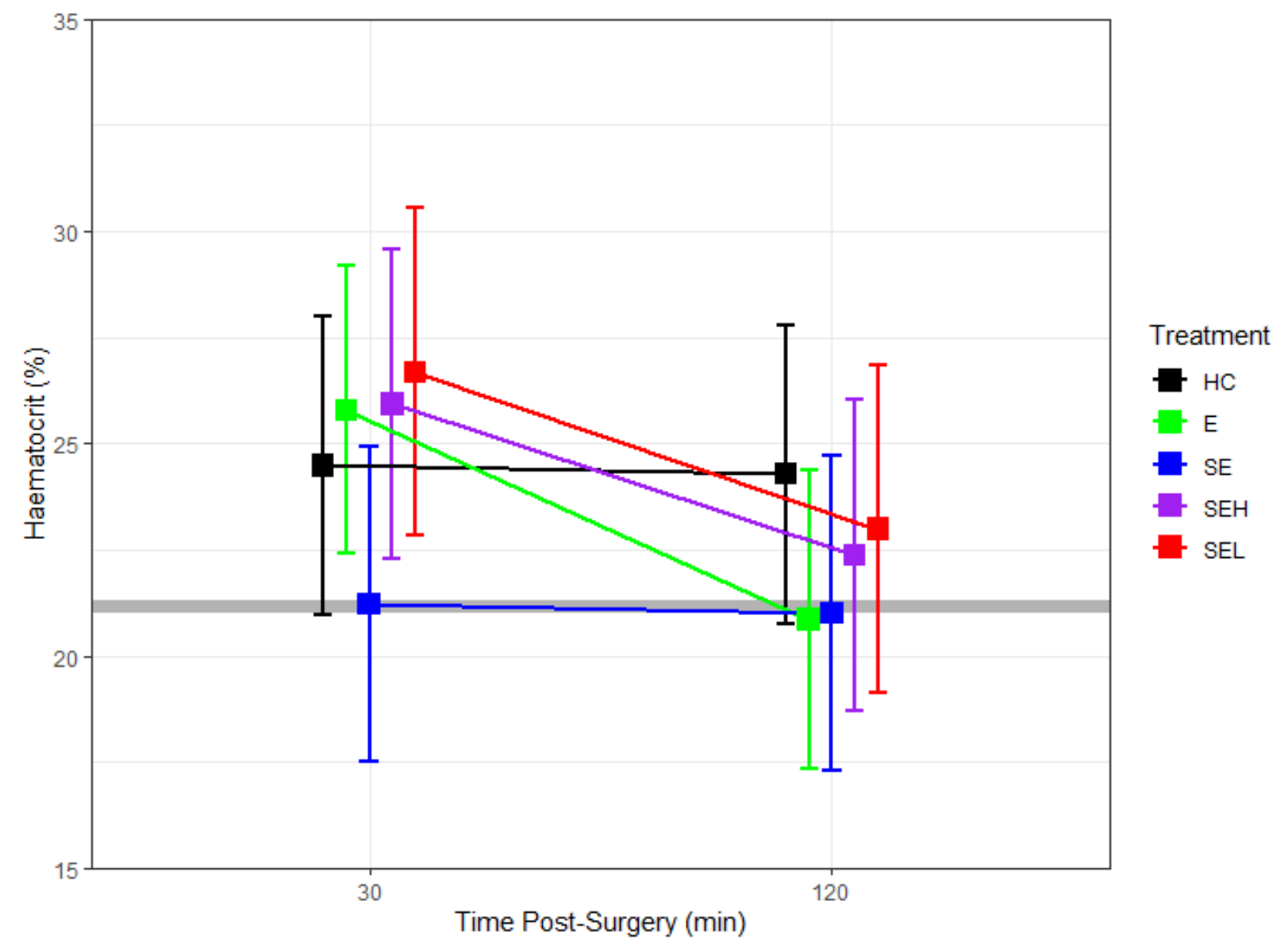

Figure 10. Least squares mean ( \pm asymptotic $95 \%$ CIs) haematocrit levels for each treatment at 30- and 120-min post-surgery. Treatments have been jittered for clarity of viewing. The horizontal grey line represents the mean value from the baseline group. Treatments are given by letter codes $(\mathrm{HC}=$ handling control; $\mathrm{E}=$ electroanesthesia; $\mathrm{SE}=$ surgery and electroanesthesia; $\mathrm{SEH}=$ surgery, electroanesthesia, and saline infiltration; SEL = surgery, electroanesthesia, and lidocaine infiltration). Sample sizes per treatment were $n=12(\mathrm{HC}), n=13(\mathrm{E}), n=11(\mathrm{SE}), n=$ $11(\mathrm{SEH})$, and $n=11(\mathrm{SEL})$ at $30 \mathrm{~min}$, and $n=12(\mathrm{HC}), n=12(\mathrm{E}), n=11(\mathrm{SE}), n=11(\mathrm{SEH})$, and $n=11(\mathrm{SEL})$ at $120 \mathrm{~min}$. 


\subsubsection{Improving the electroanesthesia apparatus}

The electroanesthesia apparatus used in this experiment is effective but could be improved in several ways. First, it has limited flexibility in that there are only 5 discrete current output settings $(4,6.3,10,16$, and $25 \mathrm{~mA})$ which do not provide as much sensitivity in eliciting electroanesthesia as a continuous dial would, and therefore may not always be able to provide the ideal current to achieve electroanesthesia. The voltage output ( $\sim 32 \mathrm{~V})$ also cannot be controlled, and may be higher than necessary (a TENS unit, although emitting different current types, is also effective on many species while operating with a $9 \mathrm{~V}$ batter). Lastly the fabric/metal mesh gloves that serve as electrodes in contact with the fish are heavily subject to wear and tear, causing diminished efficacy as the metal wires snap and lose connectivity from stretching over various hands, getting caught on fish teeth, etc. Overcoming these obstacles could improve the efficacy of electroanesthesia as administered in this experiment, and might have allowed for greater precision in the symptom-based administration of electroanesthesia. Suggested improvements include the integration of a continuous spectrum of current outputs (rather than discrete values), and more structurally sound gloves that can conform to diverse hand sizes (possibly via electrode plates on the palms and/or fingertips rather than thin mesh). Researchers building their own electroanesthesia setups may wish to refer to the methods of others like Hudson et al. (2011) or Vandergoot et al. (2011). The development of an alternative system to the FHGs as they currently exist could improve researchers' ability to administer electroanesthesia in a more consistent and controlled fashion. 


\section{Conclusions}

Based on the available evidence to date, electroimmobilization appears to be an effective tool for use in fisheries research and practice. Once the equipment is obtained and settings are optimized it can be used without causing significant stress or injury and high rates of survival can be expected. Notably, recovery of reflexes appears to be particularly rapid and there is no chemical "hangover" or withdrawal concerns as occurs when using chemical anesthetics (see 2.5.3. Additional Applications; Table 1). Therefore, electroimmobilization serves to maintain the welfare state of fish while also addressing broader ecological and human health concerns. I identified a number of research gaps that once addressed will further refine use and operating guidelines for the tools used in electroimmobilization.

I have also found no evidence that $\sim 1 \mathrm{mg} / \mathrm{kg}$ of infiltrated lidocaine improved the welfare of electroanesthetized adult Largemouth Bass undergoing a brief surgical procedure. While this experiment does not show that local analgesics are definitively ineffective when used alongside electroanesthesia, there are currently no experiments that provide evidence to support this practice. For hatchery fish, or wild fish released during active angling seasons, it is also important to consider the food safety issues imparted by lidocaine (and other pharmaceuticals) should fish be consumed.

The electroimmobilization literature is still riddled with knowledge gaps, and electroimmobilization has yet to be truly incorporated into animal care guidelines. Research such as the experiment described herein would be of substantial benefit towards the formulation of evidence-based guidelines for the use of this technology. It has been my observation that electroimmobilization has rapidly grown to be a common tool. Although some perceive it to be 
inconsistent with fish welfare (e.g. potentially causing nociception) the research to date suggests fish rapidly resume natural behaviours (e.g. migration, spawning, parental care), which supports the continued use of electroimmobilization. There are examples of electroimmobilization variably embraced and rejected by IACUCs in Canada and the United States with the most common concern for rejection being lack of certainty regarding whether the immobilization itself induces stress and "pain" or mutes discomfort that may be experienced from procedures (e.g. blood withdrawal, laparotomy) conducted while fish are immobilized. The potential for fish to consciously experience "pain" (whether by electroimmobilization or other stimuli) is outside the scope of this thesis but is nonetheless a significant knowledge barrier in the fish welfare literature. There will undoubtedly be more research on electroimmobilization in the coming years that will clarify and optimize the ways in which it is used to support fisheries research that maintains or enhances fish welfare. 


\section{$\underline{\text { References }}$}

Abrams, A. E. I., A. M. Rous, J. L. Brooks, and M. J. Lawrence. 2018. Comparing immobilization, recovery, and stress indicators associated with electric fish handling gloves and a portable electrosedation system. Transactions of the American Fisheries Society 147: 390-399.

Ackerman, P. A., J. D. Morgan, and G. K. Iwama. 2005. Anesthetics. In: CCAC guidelines on the care and use of fish in research, teaching and testing. $22 \mathrm{pp}$. Available at: https://www.ccac.ca/Documents/Standards/Guidelines/Add_PDFs/Fish_Anesthetics.pdf (February 2019).

American Veterinary Medical Association. 2008. Literature review on the welfare implications of electroimmobilization. Animal Welfare Division, 3 pp. Available at: https://admin.avma.org/KB/Resources/LiteratureReviews/Documents/electroimmobilizati on_bgnd.pdf (January 2019).

Balazik, M. T. 2015. Capture and brief invasive procedures using electronarcosis does not appear to affect postrelease habits in male Atlantic sturgeon during the spawning season. North American Journal of Fisheries Management 35(2): 398-402.

Balazik, M. T., B. C. Langford, G. C. Garman, M. L. Fine, J. K. Stewart, R. J. Latour, and S. P. McIninch. 2013. Comparison of MS-222 and Electronarcosis as Anesthetics on Cortisol Levels in Juvenile Atlantic Sturgeon. Transactions of the American Fisheries Society 142(6): 1640-1643.

Barreto, R. E., and G. L. Volpato. 2004. Caution for using ventilation frequency as an indicator of stress in fish. Behavioural Processes 66(1): 43-51.

Barton, B. A., and G. K. Iwama. 1991. Physiological changes in fish from stress in aquaculture with emphasis on the response and effects of corticosteroids. Annual Review of Fish Diseases 1: 3-26.

Barton, B. A. 2002. Stress in fishes: A diversity of responses with particular reference to changes in circulating corticosteroids. Integrative and Comparative Biology 42(3): 517-525.

Barton, K. 2019. MuMIn: Multi-Model Inference. R package version 1.43.6.

Bates, D., M. Mächler, B. Bolker, and S. Walker. 2015. Fitting linear mixed-effects models using lme4. Journal of Statistical Software 67(1): 1-48.

Baxter, G. D., and S. M. McDonough. Principles of electrotherapy in veterinary physiotherapy. In: C. M. McGowan, L. Goff, and N. Stubbs (Editors). 2007. Animal physiotherapy: assessment, treatment and rehabilitation of animals. Blackwell Publishing Ltd., Hoboken, New Jersey. 
Bilyk, K. T., C. W. Evans, and A. L. DeVries. 2012. Heat hardening in Antarctic notothenioid fishes. Polar Biology 35(9): 1447-1451.

Bowzer, J. C., J. T. Trushenski, B. R. Gause, and J. D. Bowker. 2012. Efficacy and physiological responses of grass carp to different sedation techniques: II. Effect of pulsed DC electricity voltage and exposure time on sedation and blood chemistry. North American Journal of Aquaculture 74(4): 567-574.

Browman, H. I., and A. B. Skiftesvik. 2011. Welfare of aquatic organisms: Is there some faithbased HARKing going on here? Diseases of Aquatic Organisms 94(3): 255-257.

Browman, H. I., S. J. Cooke, I. G. Cowx, S. W. G. Derbyshire, A. Kasumyan, B. Key, J. D. Rose, A. Schwab, A. Berit Skiftesvik, E. D. Stevens, C. A. Watson, and R. Arlinghaus. 2019. Welfare of aquatic animals: Where things are, where they are going, and what it means for research, aquaculture, recreational angling, and commercial fishing. ICES Journal of Marine Science 76(1): 82-92.

Brown, C., and V. A. Braithwaite. 2004. Size matters: A test of boldness in eight populations of the poeciliid Brachyraphis episcopi. Animal Behaviour 68(6): 1325-1329.

Brown, C., C. Gardner, and V. A. Braithwaite. 2005. Differential stress responses in fish from areas of high- and low-predation pressure. Journal of Comparative Physiology B 175(5): 305-312.

Brownstein, M. J. 1993. A brief history of opiates, opioid peptides, and opioid receptors. Proceedings of the National Academy of Sciences of the United States of America 90(12): 5391-5393.

CCAC (Canadian Council on Animal Care). 2005. Guidelines on: the care and use of fish in research, teaching and testing. $94 \mathrm{pp}$. Available at: https://www.ccac.ca/Documents/Standards/Guidelines/Fish.pdf (February 2019).

Chatigny, F., D. B. Groman, S. A. Martinson, and E. D. Stevens. 2018. Evaluation of tissue changes following intramuscular infiltration of lidocaine in rainbow trout Oncorhynchus mykiss. Journal of Fish Biology 92(4): 888-900.

Chatigny, F., C. Kamunde, C. M. Creighton, and E. D. Stevens. 2017. Uses and doses of local anesthetics in fish, amphibians, and reptiles. Journal of the American Association for Laboratory Animal Science 56(3): 244-253.

Chiba, H., T. Hattori, H. Yamada, and M. Iwata. 2006. Comparison of the effects of chemical anesthesia and electroanesthesia on plasma cortisol levels in the Japanese Eel Anguilla japonica. Fisheries Science 72: 693-695.

Chidiac, E. J., R. N. Kaddoum, and S. F. Fuleihan. 2012. Mandragora: Anesthetic of the ancients. Anesthesia \& Analgesia 115(6): 1437-1441. 
Cohen, J. 1988. Statistical Power Analysis for the Behavioral Sciences ( $2^{\text {nd }}$ Ed.). Lawrence Erlbaum Associates, Hillsdale, NJ, U.S.A.

Connor, J. T. H. 2004. The Victorian revolution in surgery. Science 304(5667): 54-55.

Cook, K. V., C. M. O’Connor, S. H. McConnachie, K. M. Gilmour, and S. J. Cooke. 2012. Condition dependent intra-individual repeatability of stress-induced cortisol in a freshwater fish. Comparative Biochemistry and Physiology Part A: Molecular \& Integrative Physiology 161(3): 337-343.

Cooke, E. L. L., A. D. Wilson, C. K. Elvidge, and S. J. Cooke. 2017. Does capture method or the presence of aquatic protected areas influence the selective harvest of behavioural types in largemouth bass? Canadian Journal of Fisheries and Aquatic Sciences 74(8): 1151-1157.

Cooke, S. J., J. Steinmetz, J. F. Degner, E. C. Grant, D. P. Philipp. 2003. Metabolic fright responses of different-sized largemouth bass (Micropterus salmoides) to two avian predators show variations in nonlethal energetic costs. Canadian Journal of Zoology 81(4): 699-709.

Cowx, I. G., and P. Lamarque (Editors). 1990. Fishing with electricity: applications in freshwater fisheries management. Alden Press, Oxford, U.K.

DeSantana, J. M., D. M. Walsh, C. Vance, B. A. Rakel, and K. A. Sluka. 2008. Effectiveness of transcutaneous electrical nerve stimulation for treatment of hyperalgesia and pain. Current Rheumatology Reports 10(6): 492-499.

Dolan, C. R., and L. E. Miranda. 2004. Injury and mortality of warmwater fishes immobilized by electrofishing. North American Journal of Fisheries Management 24: 118-127.

Duryea, J. K. 2014. Evaluating methods to anesthetize Gopher Rockfish Sebastes carnatus for immediate release in the field: induction, recovery, and cortisol stress response to surgical anesthesia. Master's Thesis. San José State University, San Jose, California.

Ellis, T., J. D. James, C. Stewart, and A. P. Scott. 2004. A non-invasive stress assay based upon measurement of free cortisol released into the water by rainbow trout. Journal of Fish Biology 65(5): 1233-1252.

Fanouraki, E., N. Papandroulakis, T. Ellis, C. C. Mylonas, A. P. Scott, and M. Pavlidis. 2008. Water cortisol is a reliable indicator of stress in European sea bass, Dicentrarchus labrax. Behaviour 145(10): 1267-1281.

Faust, M. D., C. S. Vandergoot, E. T. Hostnik, T. R. Binder, J. L. M. Hinderer, J. T. Ives, and C. C. Krueger. 2017. Use of electricity to sedate lake trout for intracoelomic implantation of electronic transmitters. North American Journal of Fisheries Management 37(4): 768777. 
Fox, J., and S. Weisberg. 2019. An R companion to applied regression, $3^{\text {rd }}$ Ed. Sage, Thousand Oaks, CA, U.S.A.

Francis, J., and J. Dingley. 2015. Electroanaesthesia—from torpedo fish to TENS. Anaesthesia 70: $93-103$.

Fürtbauer, I., A. Pond, M. Heistermann, and A. J. King. 2015. Personality, plasticity, and predation: Linking endocrine and behavioural reaction norms in stickleback fish. Functional Ecology 29(7): 931-940.

Gao, Y., D. Li, X. Peng, and R. Tang. 2014. Effects of low-voltage constant direct current on plasma biochemical profiles and gene expression levels in Crucian Carp Carassius carassius. Fisheries science 80(5): 993-1000.

Gaulke, G. L., C. E. Dennis, D. H. Wahl, and C. D. Suski. 2014. Acclimation to a low oxygen environment alters the hematology of largemouth bass (Micropterus salmoides). Fish Physiology and Biochemistry 40(1): 129-140.

Grandin, T. 2013. Making slaughterhouses more humane for cattle, pigs, and sheep. Annual Review of Animal Biosciences 1: 491-512.

Grantner, A., and M. Taborsky. 1998. The metabolic rates associated with resting, and with the performance of agonistic, submissive and digging behaviours in the cichlid fish Neolamprologus pulcher (Pisces: Cichlidae). Journal of Comparative Physiology B 168(6): 427-433.

Griffin, G., M. Dansereau, and C. Gauthier. 2007. Categories of invasiveness-a precautionary approach. AATEX 14: 715-720.

Grimm, K. A., L. A. Lamont, W. J. Tranquilli, S. A. Greene, and S. A. Robertson (Editors). 2015. Veterinary Anesthesia and Analgesia: The Fifth Edition of Lumb and Jones. John Wiley \& Sons, Hoboken, NJ, U.S.A.

Guy, C. S., R. M. Neumann, and D. W. Willis. 1992. Movement patterns of adult black crappie, Pomoxis nigromaculatus, in Brant Lake, South Dakota. Journal of Freshwater Ecology 7(2): 137-147.

Hammer, Ø., D. A. T. Harper, and P. D. Ryan. 2001. PASTL Paleontological Statistics software package for education and data analysis. Palaeontologia Electronica 4(1): 9pp.

Hasler, C. T., C. D. Suski, K. C. Hanson, S. J. Cooke, D. P. Philipp, and B. L. Tufts. 2009. Effect of water temperature on laboratory swimming performance and natural activity levels of adult largemouth bass. Canadian Journal of Zoology 87(7): 589-596. 
Hasler, C. T., S. R. Midway, J. D. Jeffrey, J. A. Tix, C. Sullivan, and C. D. Suski. 2016. Exposure to elevated $\mathrm{pCO}_{2}$ alters post-treatment diel movement patters of largemouth bass over short time scales. Freshwater Biology 61(9): 1590-1600.

Hayden, T. A., C. M. Holbrook, D. Fielder, C. S. Vandergoot, R. A. Bergstedt, J. M. Dettmers, C. C. Krueger, and S. J. Cooke. 2014. Acoustic telemetry reveals large-scale migration patterns for walleye in Lake Huron. PLoS One 9(12): e114833.

Health Canada. 2010. List of veterinary drugs that are authorized for sale by Health Canada for use in food-producing aquatic animals. Health Canada, Ottawa. Available at: https://www.canada.ca/en/health-canada/services/drugs-health-products/veterinarydrugs/legislation-guidelines/policies/list-veterinary-drugs-that-authorized-sale-healthcanada-use-food-producing-aquatic-animals.html (February 2019).

Henyey, E., B. Kynard, and P. Zhuang. 2002. Use of electronarcosis to immobilize juvenile lake and shortnose sturgeons for handling and the effects on their behavior. Journal of Applied Ichthyology 18(4-6): 502-504.

Houston, A. H., W. C. Roberts, and J. A. Kennington. 1996. Hematological response in fish: Pronephric and splenic involvements in the goldfish, Carassius auratus L. Fish Physiology and Biochemistry 15(6): 481-489.

Hudson, J. M., J. R. Johnson, and B. Kynard. 2011. A portable electronarcosis system for anesthetizing salmonids and other fish. North American Journal of Fisheries Management 31: 335-339.

Jennings, C. A., and G. L. Looney. 1998. Evaluation of two types of anesthesia for performing surgery on striped bass. North American Journal of Fisheries Management 18(1): 187190.

Johnson, J. L., J. T. Trushenski, and J. D. Bowker. 2016. Induction, recovery, and hematological responses of pallid sturgeon to chemical and electrical sedation. North American Journal of Fisheries Management 36: 568-575.

Johnsson, J. I., J. Höjesjö, and I. A. Fleming. 2001. Behavioural and heart rate responses to predation risk in wild and domesticated Atlantic salmon. Canadian Journal of Fisheries and Aquatic Sciences 58(4): 788-794.

Keep, S. G., M. B. Allen, and J. S. Zendt. 2015. Comparison of electronarcosis and carbon dioxide sedation effects on travel time in adult Chinook and Coho salmon. North American Journal of Fisheries Management 35(5): 906-912.

Kim, J., B. Doyle, and N. Mandrak. 2017. Electrosedation of freshwater fishes for the surgical implantation of transmitters. Canadian Journal of Zoology 95: 575-580. 
Kuznetsova, A., P. B. Brockhoff, and H. B. Christensen. 2017. lmerTest package: Tests in linear mixed effects models. Journal of Statistical Software 82(13): 1-26.

Kynard, B., and E. Lonsdale. 1975. Experimental study of galvanonarcosis for Rainbow Trout Salmo gairdneri immobilization. Journal of the Fisheries Research Board of Canada 32: 300-302.

Lamarque, P. 1989. Electrofishing: fish reactions with neurophysiological explanations. National Research Council, Canada Institute for Scientific and Technical Information 5442. Available at: http://www.dfo-mpo.gc.ca/Library/111566.pdf (February 2019).

Lang, S. J. 1992. John Bradmore and his book Philomena. Social History of Medicine 5(1): 121 130.

Lawrence, M., S. Jain-Schlaepfer, A. Zolderdo, D. Algera, K. Gilmour, A. Gallagher, and S. J. Cooke. 2018. Are 3 minutes good enough for obtaining baseline physiological samples from teleost fish. Canadian Journal of Zoology 96: 774-786.

Lenth, R. 2019. emmeans: Estimated marginal means, aka least-squares means. R package version 1.3.4. Available at: https://CRAN.R-project.org/package=emmeans.

Maksimov, Yu., S. Malkyavichyus, and V. Yudin [Максимов, Ю., С. Малькявичюс, В. Юдин]. 1987. Selective action of the electric field on fish with electric trawl [Селективное действие электрического поля на рыб при электротраловом лове; article in Russian]. Acta Hydrobiologica Lituanica 6: 69-74.

Matsche, M. A. 2013. A portable electro-immobilization and laparoscopy system for sex determination and gonadal biopsy in largemouth bass Micropterus salmoides. Journal of Fish Biology 83(5): 1391-1400.

McCormick, S. D. 2001. Endocrine control of osmoregulation in teleost fish. American Zoologist 41(4): 781-794.

McFarlane, W. J., K. F. Cubitt, H. Williams, D. Rowsell, R. Moccia, R. Gosine, and R. S. McKinley. 2004. Can feeding status and stress level be assessed by analyzing patterns of muscle activity in free swimming rainbow trout (Oncorhynchus mykiss Walbaum)? Aquaculture 239(1-4): 467-484.

Meka, J. M., and S. D. McCormick. 2005. Physiological response of wild rainbow trout to angling: Impact of angling duration, fish size, body condition, and temperature. Fisheries Research 72(2-3): 311-322.

Miranda, L. E., and C. R. Dolan. 2004. Electrofishing power requirements in relation to duty cycle. North American Journal of Fisheries Management 24: 55-62. 
Monsef Rad, S. F., S. Y. Paighambari, A. Haji Moradlou, F. Mashayekhi, and R. Qorbani. 2016. Evaluation of electronarcosis and clove oil for short-term anesthesia in Common Carp Cyprinus carpio L. 1758. Caspian Journal of Environmental Sciences 14(4): 229-310.

Müller, A. 1970. Basic principles of electroanesthesia [Grundlegendes zur elektroanästhesie; article in German]. Schweizer Archiv für Tierheilkunde 112(5): 215-232.

Nascimento, C. R., M. M. Souza, and C. B. Martinez. 2012. Copper and the herbicide atrazine impair the stress response of the freshwater fish Prochilodus lineatus. Comparative Biology and Physiology Part C: Toxicology \& Pharmacology 155(3): 456-461.

Nilsson, G. E., P. R. Rose, and D. Johansson. 1993. Anoxic depression of spontaneous locomotor activity in crucian carp quantified by a computerized imaging technique. Journal of Experimental Biology 180(1): 153-162.

Oberdörster, E. 2004. Manufactured nanomaterials (fullerenes, C60) induce oxidative stress in the brain of juvenile largemouth bass. Environmental Health Perspectives 112(10): 10581062.

Oswald, R. L. 1978. Injection anaesthesia for experimental studies in fish. Comparative Biochemistry and Physiology Part C: Comparative Pharmacology 61(1): 1-26.

Prunet, P., M. T. Cairns, S. Winberg, and T. G. Pottinger. 2008. Functional genomics of stress responses in fish. Reviews in Fisheries Science 16(Supp. 1): 157-166.

Prystay, T. 2018. Exploring the relationship between physiological performance and reproductive investment in wild fish using heart rate biologgers. Master's thesis, Carleton University, Ottawa, Canada. Available: https://curve.carleton.ca/dda3a907-8c9f-44d3ad5f-a88b2c8d1f81.

Prystay, T. S., C. K. Elvidge, W. M. Twardek, J. M. Logan, C. H. Reid, S. H. Clarke, J. G. Foster, E. L. L. Cooke, and S. J. Cooke. 2017. Comparison of the behavioral consequences and recovery patterns of largemouth bass exposed to MS-222 or electrosedation. Transactions of the American Fisheries Society 146: 556-566.

Quarnstrom, F. 1992. Electronic dental anesthesia. Anesthesia Progress 39(4-5): 162-177.

Quinn, S., and C. Paukert. 2009. Centrarchid Fisheries. In: Cooke, S. J., and D. P. Philipp (Editors). Centrarchid Fishes: Diversity, Biology and Conservation. Blackwell Publishing, West Sussex, UK.

R Core Team. 2019. R: A language and environment for statistical computing. R Foundation for Statistical Computing, Vienna, Austria.

Raby, G. D., M. R. Donaldson, S. G. Hinch, D. A. Patterson, A. G. Lotto, D. Robichaud, K. K. English, W. G. Willmore, A. P. Farrell, M. W. Davis, and S. J. Cooke. 2012. Validation 
of reflex indicators for measuring vitality and predicting the delayed mortality of wild coho salmon bycatch released from fishing gears. Journal of Applied Ecology 49(1): 9098.

Raposo de Magalhães, C., D. Schrama, A. P. Farinha, D. Revets, A. Kuehn, S. Planchon, P. M. Rodrigues, and M. Cerqueira. 2020. Protein changes as robust signatures of fish chronic stress: A proteomics approach to fish welfare research. BMC Genomics 21: 1-16.

Reid, C. H., C. S. Vandergoot, J. D. Midwood, E. D. Stevens, J. Bowker, and S. J. Cooke. 2019. On the electroimmobilization of fishes for research and practice: Opportunities, challenges, and research needs. Fisheries 44(12): 576-585.

Robb, H. F., and B. Roth. 2003. Brain activity of Atlantic Salmon Salmo salar following electrical stunning using various field strengths and pulse durations. Aquaculture 216: $363-369$.

Rose, J. D., R. Arlinghaus, S. J. Cooke, B. K. Diggles, W. Sawynok, E. D. Stevens, and C. D. L. Wynne. 2014. Can fish really feel pain? Fish and Fisheries 15(1): 97-133.

Ross, L. G., and B. Ross. 2008. Anaesthetic and Sedative Techniques for Aquatic Animals ( $3^{\text {rd }}$ Ed.). Blackwell Publishing, Oxford, U.K.

Rous, A. M., A. Forrest, E. H. McKittrick, G. Letterio, J. Roszell, T. Wright, and S. J. Cooke. 2015. Orientation and position of fish affects recovery time from electrosedation. Transactions of the American Fisheries Society 144: 820-828.

RStudio Team. 2016. RStudio: Integrated development for R. RStudio, Inc., Boston, MA.

Savino, J. F., and R. A. Stein. 1982. Predator-prey interaction between largemouth bass and bluegills as influenced by simulated, submersed vegetation. Transactions of the American Fisheries Society 111(3): 255-266.

Schneider, J. C., P. W. Laarman, and H. Gowing. 2000. Length-weight relationships. Chapter 17. In J. C. Schneider, ed. Manual of Fisheries Survey Methods II: With Periodic Updates, pp. 1-18. Michigan Department of Natural Resources, Fisheries Special Report 25, Ann Arbor.

Schnick, R. R. 2006. Zero withdrawal anesthetic for all finfish and shellfish: need and candidates. Fisheries 31(3): 122-126.

Sibernagel, C., and P. Yochem. 2016. Effectiveness of the anesthetic AQUI-S®20E in marine finfish and elasmobranchs. Journal of Wildlife Diseases 52(2s): S96-S103.

Smith-Root. 2016. User's guide: electric fish handling gloves (manual). Smith-Root, Vancouver, Washington. 
Soetaert, M., A. Decostere, H. Polet, B. Verschueren, and K. Chiers. 2015. Electrotrawling: a promising alternative fishing technique warranting further exploration. Fish and Fisheries 16(1): 104-124.

Steffey, E. 2014. A History of Veterinary Anesthesia. In: Eger II E., L. Saidman, and R. Westhorpe (Editors). The Wondrous Story of Anesthesia. Springer, New York, NY, U.S.A.

Stoot, L. J., N. A. Cairns, F. Cull, J. J. Taylor, J. D. Jeffrey, F. Morin, J. W. Mandelman, T. D. Clark, and S. J. Cooke. 2014. Use of portable blood physiology point-of-care devices for basic and applied research on vertebrates: a review. Conservation Physiology 2(1): cou011.

Summerfelt R. C., and L. S. Smith. 1990. Anesthesia, surgery, and related techniques. In: C. B. Shreck and P. B. Moyle (Editors). Methods for Fish Biology. American Fisheries Society, Bethesda, Maryland.

Sures, B. 2008. Environmental parasitology. Interactions between parasites and pollutants in the aquatic environment. Parasite 15(3): 434-438.

Teulier, L., L. Guillard, C. Leon, C. Romestaing, and Y. Voituron. 2018. Consequences of electroshock-induced narcosis in fish muscle: from mitochondria to swim performance. Journal of Fish Biology 92(6): 1805-1818.

Trushenski, J. T., and J. D. Bowker. 2012. Effect of voltage and exposure time on fish response to electrosedation. Journal of Fish and Wildlife Management 3: 276-287.

Trushenski, J. T., J. D. Bowker, S. J. Cooke, D. Erdahl, T. Bell, J. R. MacMillan, R. P. Yanong, J. E. Hill, M. C. Fabrizio, J. E. Garvey, and S. Sharon. 2013. Issues regarding the use of sedatives in fisheries and the need for immediate-release options. Transactions of the American Fisheries Society 142: 156-170.

Trushenski, J. T., J. D. Bowker, B. R. Gause, and B. L. Mulligan. 2012a. Chemical and electrical approaches to sedation of Hybrid Striped Bass: induction, recovery, and physiological responses to sedation. Transactions of the American Fisheries Society 141: 455-467.

Trushenski, J. T., J. D. Bowker, B. L. Mulligan, and B. R. Gause. 2012b. Induction, recovery, and hematological responses of Largemouth Bass to chemo- and electrosedation. North American Journal of Aquaculture 74(2): 214-23.

Twardek, W. M., A. D. Schultz, J. E. Claussen, S. J. Cooke, J. A. Stein, J. B. Koppelman, F. J. S. Phelan, and D. P. Philipp. 2017. Potential consequences of angling on nest-site fidelity in largemouth bass. Environmental Biology of Fishes 100(5): 611-616.

Vance, C. G., D. L. Dailey, B. A. Rakel, and K. A. Sluka. 2014. Using TENS for pain control: the state of the evidence. Pain Management 4(3): 197-209. 
Vandergoot, C. S., K. J. Murchie, S. J. Cooke, J. M. Dettmers, R. A. Bergstedt, and D. G. Fielder. 2011. Evaluation of two forms of electroanesthesia and carbon dioxide for shortterm anesthesia in Walleye. North American Journal of Fisheries Management 31: 914 922.

Vibert, R. 1963. Neurophysiology of electric fishing. Transactions of the American Fisheries Society 92(3): 265-275.

Ward, T. D., J. W. Brownscombe, L. F. G. Gutowsky, R. Ballagh, N. Sakich, D. McLean, G. Quesnel, S. Gambhir, C. M. O’Connor, and S. J. Cooke. 2017. Electric fish handling gloves provide effective immobilization and do not impede reflex recovery of adult largemouth bass. North American Journal of Fisheries Management 37(3): 652-659.

Wasserstein, R. L., A. L. Schirm, and N. A. Lazar. 2019. Moving to a world beyond "p < 0.05 ". The American Statistician 73(S1): 1-19.

Wawersik, J. 1997. History of chloroform anesthesia. Anaesthesiologie und Reanimation 22(6): 144-152.

Wickham, H. 2016. ggplot2: Elegant Graphics for Data Analysis. Springer-Verlag, New York, NY.

Wilson, A. D. M., T. A. Hayden, C. S. Vandergoot, R. T. Kraus, J. M. Dettmers, S. J. Cooke, and C. C. Krueger. 2017. Do intracoelomic telemetry transmitters alter the post-release behaviour of migratory fish? Ecology of Freshwater Fish 26(2): 292-300.

Zydlewski, G. B., W. Gale, J. Holmes, J. Johnson, T. Brigham, and W. Thorson. 2008. Use of electroshock for euthanizing and immobilizing adult spring Chinook Salmon in a hatchery. North American Journal of Aquaculture 70(4): 415-424. 


\section{$\underline{\text { Appendix I }}$}

\section{Data Analysis Outputs for Chapter 3.}

Table S1. Least squares means and asymptotic 95\% confidence intervals of all physiological responses for (a) BP vs. HC, (b) HC vs. E, (c) E vs. SE, (d) SE vs. SEH, and (e) SEH vs. SEL. Noteworthy covariate effects are described below each table. When treatment/time interactions are present, time and treatment are interpreted together. An "NA" denotes the exclusion of time or the treatment/time interaction following model selection. Treatment comparisons had 1 degree of freedom.

\begin{tabular}{|c|c|c|c|c|c|c|}
\hline \multirow[t]{2}{*}{ (a) } & \multicolumn{3}{|c|}{$30 \mathrm{~min}$} & \multicolumn{3}{|c|}{$120 \mathrm{~min}$} \\
\hline & $\begin{array}{l}\text { BP mean } \\
(95 \% \mathrm{CI})\end{array}$ & $\begin{array}{l}\text { HC mean } \\
(95 \% \mathrm{CI})\end{array}$ & $\begin{array}{c}\text { HC vs. } \\
\text { BP } \\
P\left(f^{2}\right)\end{array}$ & $\begin{array}{l}\text { BP mean } \\
(95 \% \mathrm{CI})\end{array}$ & $\begin{array}{l}\text { HC mean } \\
(95 \% \mathrm{C})\end{array}$ & $\begin{array}{c}\mathrm{HC} \text { vs. BP } \\
P\left(f^{2}\right)\end{array}$ \\
\hline $\begin{array}{l}\text { Plasma cortisol } \\
\text { (ng/mL) }\end{array}$ & $\begin{array}{c}37.6 \\
(1.81,73.5)\end{array}$ & $\begin{array}{c}95.0 \\
(57.73 \\
132.3) \\
\end{array}$ & $\begin{array}{l}0.014 \\
(0.31)\end{array}$ & $\begin{array}{c}37.6 \\
(2.82,72.5)\end{array}$ & $\begin{array}{r}115.3 \\
(77.45, \\
153.1) \\
\end{array}$ & $\begin{array}{l}0.002 \\
(0.60)\end{array}$ \\
\hline $\begin{array}{l}\text { Blood glucose } \\
\quad(\mathrm{mM})\end{array}$ & $\begin{array}{c}2.83 \\
(1.82,3.84)\end{array}$ & $\begin{array}{c}4.85 \\
(3.88,5.82)\end{array}$ & $\begin{array}{l}0.002 \\
(0.58)\end{array}$ & $\begin{array}{c}2.83 \\
(2.14,3.52)\end{array}$ & $\begin{array}{c}3.82 \\
(3.13,4.51)\end{array}$ & $\begin{array}{l}0.024 \\
(0.30)\end{array}$ \\
\hline $\begin{array}{l}\text { Blood lactate } \\
\qquad(\mathrm{mM})\end{array}$ & $\begin{array}{c}0.539 \\
(-0.121,1.20)\end{array}$ & $\begin{array}{c}3.06 \\
(2.37,3.75)\end{array}$ & $\begin{array}{c}<0.0001 \\
\quad(1.81)\end{array}$ & $\begin{array}{c}0.579 \\
(-0.055,1.21)\end{array}$ & $\begin{array}{c}2.231 \\
(1.57 .2 .89)\end{array}$ & $\begin{array}{c}0.0003 \\
(0.84)\end{array}$ \\
\hline $\begin{array}{c}\text { Plasma } \\
\text { osmolality } \\
(\mathrm{mmol} / \mathrm{kg})\end{array}$ & $\begin{array}{c}305 \\
(295,316)\end{array}$ & $\begin{array}{c}313 \\
(302,324)\end{array}$ & $\begin{array}{l}0.227 \\
(0.07)\end{array}$ & $\begin{array}{c}305 \\
(295,316)\end{array}$ & $\begin{array}{c}300 \\
(289,312)\end{array}$ & $\begin{array}{l}0.430 \\
(0.03)\end{array}$ \\
\hline $\begin{array}{c}\text { Haematocrit } \\
(\%)\end{array}$ & $\begin{array}{c}20.7 \\
(17.7,23.7)\end{array}$ & $\begin{array}{c}24.4 \\
(21.5,27.3)\end{array}$ & $\begin{array}{l}0.045 \\
(0.22)\end{array}$ & $\begin{array}{c}20.7 \\
(18.0,23.3)\end{array}$ & $\begin{array}{c}24.2 \\
(21.7,26.7)\end{array}$ & $\begin{array}{l}0.031 \\
(0.25)\end{array}$ \\
\hline
\end{tabular}

Covariates: Mean blood lactate increased with fish mass by $0.23 \mathrm{mM}$ per $100 \mathrm{~g}$ at $30 \mathrm{~min}(P=0.087)$ and $0.40 \mathrm{mM}$ per $100 \mathrm{~g}$ at 120 $\min (P=0.004)$ post-surgery. 


\begin{tabular}{|c|c|c|c|c|c|c|c|}
\hline (b) & $\begin{array}{l}\text { HC mean } \\
(95 \% \mathrm{CI})\end{array}$ & $\begin{array}{l}\text { E mean } \\
(95 \% \mathrm{CI})\end{array}$ & $\begin{array}{l}\mathrm{HC} \text { vs. } \mathrm{E} \\
P\left(f^{2}\right)\end{array}$ & $\begin{array}{c}30 \text { min mean } \\
(95 \% \mathrm{CI})\end{array}$ & $\begin{array}{l}120 \text { min mean } \\
(95 \% \mathrm{C})\end{array}$ & $\begin{array}{l}\text { Time } \\
P\left(f^{2}\right)\end{array}$ & $\begin{array}{c}\text { Treatment:Time } \\
P\end{array}$ \\
\hline $\begin{array}{l}\text { Plasma cortisol } \\
\text { (ng/mL) }\end{array}$ & $\begin{array}{c}103.4 \\
(67.8,139)\end{array}$ & $\begin{array}{c}86.8 \\
(53.7,120)\end{array}$ & $\begin{array}{l}0.417 \\
(0.02)\end{array}$ & $\begin{array}{c}83.8 \\
(56.6,111)\end{array}$ & $\begin{array}{c}106.4 \\
(78.7,134)\end{array}$ & $\begin{array}{l}0.067 \\
(0.04)\end{array}$ & 0.630 \\
\hline $\begin{array}{l}\text { Blood glucose } \\
\quad(\mathrm{mM})\end{array}$ & $\begin{array}{c}4.34 \\
(3.38,5.30)\end{array}$ & $\begin{array}{c}4.08 \\
(3.19,4.97)\end{array}$ & $\begin{array}{c}0.641 \\
(0.006)\end{array}$ & $\begin{array}{c}4.58 \\
(3.88,5.27)\end{array}$ & $\begin{array}{c}3.84 \\
(3.13,4.55)\end{array}$ & $\begin{array}{l}0.005 \\
(0.06)\end{array}$ & NA \\
\hline $\begin{array}{l}\text { Blood lactate } \\
\quad(\mathrm{mM})\end{array}$ & $\begin{array}{c}2.73 \\
(1.67,3.78)\end{array}$ & $\begin{array}{c}2.68 \\
(1.70,3.66)\end{array}$ & $\begin{array}{c}0.944 \\
(<0.001)\end{array}$ & $\begin{array}{c}3.09 \\
(2.33,3.84)\end{array}$ & $\begin{array}{c}2.32 \\
(1.57,3.07)\end{array}$ & $\begin{array}{l}0.001 \\
(0.06)\end{array}$ & NA \\
\hline $\begin{array}{c}\text { Plasma } \\
\text { osmolality } \\
(\mathrm{mmol} / \mathrm{kg})\end{array}$ & $\begin{array}{c}307 \\
(297,316)\end{array}$ & $\begin{array}{c}310 \\
(302,319)\end{array}$ & $\begin{array}{l}0.487 \\
(0.03)\end{array}$ & $\begin{array}{c}317 \\
(310,324)\end{array}$ & $\begin{array}{c}300 \\
(293,307)\end{array}$ & $\begin{array}{c}<0.0001 \\
(0.36)\end{array}$ & 0.182 \\
\hline $\begin{array}{c}\text { Haematocrit } \\
(\%)\end{array}$ & $\begin{array}{c}30 \text { min: } 24.4 \\
(21.2,27.5) \\
120 \text { min: } 24.2 \\
(21.0,27.3)\end{array}$ & $\begin{array}{c}30 \text { min: } 25.9 \\
(22.9,29.0) \\
120 \text { min: } 21.2 \\
(18.0,24.4)\end{array}$ & $\begin{array}{l}0.586 \\
(0.08)\end{array}$ & --- & --- & $\begin{array}{l}0.043 \\
(0.17)\end{array}$ & 0.068 \\
\hline
\end{tabular}

Covariates: N/A. 


\begin{tabular}{|c|c|c|c|c|c|c|c|}
\hline (c) & $\begin{array}{c}\text { E mean } \\
(95 \% \mathrm{CI})\end{array}$ & $\begin{array}{l}\text { SE mean } \\
(95 \% \mathrm{CI})\end{array}$ & $\begin{array}{c}\text { E vs. SE } \\
P\left(f^{2}\right)\end{array}$ & $\begin{array}{c}30 \text { min } \\
\text { mean } \\
(95 \% \mathrm{CI}) \\
\end{array}$ & $\begin{array}{c}120 \text { min mean } \\
(95 \% \mathrm{C})\end{array}$ & $\begin{array}{l}\text { Time } \\
P\left(f^{2}\right)\end{array}$ & $\begin{array}{c}\text { Treatment:Time } \\
P\end{array}$ \\
\hline $\begin{array}{l}\text { Plasma cortisol } \\
\quad(\mathrm{ng} / \mathrm{mL})\end{array}$ & $\begin{array}{c}86.9 \\
(63.6,110)\end{array}$ & $\begin{array}{c}89.0 \\
(64.0,114)\end{array}$ & $\begin{array}{c}0.889 \\
(<0.001)\end{array}$ & $\begin{array}{c}75.1 \\
(55.1,95.1)\end{array}$ & $\begin{array}{c}100.8 \\
(81.2,120.3)\end{array}$ & $\begin{array}{l}0.010 \\
(0.10)\end{array}$ & 0.770 \\
\hline $\begin{array}{l}\text { Blood glucose } \\
\quad(\mathrm{mM})\end{array}$ & $\begin{array}{c}4.09 \\
(3.40,4.77)\end{array}$ & $\begin{array}{c}4.01 \\
(3.27,4.75)\end{array}$ & $\begin{array}{c}0.847 \\
(<0.001)\end{array}$ & $\begin{array}{c}4.28 \\
(3.75,4.81)\end{array}$ & $\begin{array}{c}3.81 \\
(3.27,4.36)\end{array}$ & $\begin{array}{l}0.015 \\
(0.04)\end{array}$ & NA \\
\hline $\begin{array}{l}\text { Blood lactate } \\
\quad(\mathrm{mM})\end{array}$ & $\begin{array}{c}2.68 \\
(1.65,3.71)\end{array}$ & $\begin{array}{c}3.38 \\
(2.27,4.49)\end{array}$ & $\begin{array}{l}0.284 \\
(0.04)\end{array}$ & $\begin{array}{c}3.48 \\
(2.66,4.30)\end{array}$ & $\begin{array}{c}2.58 \\
(1.76,3.40)\end{array}$ & $\begin{array}{l}0.005 \\
(0.07)\end{array}$ & NA \\
\hline $\begin{array}{c}\text { Plasma } \\
\text { osmolality } \\
(\mathrm{mmol} / \mathrm{kg})\end{array}$ & $\begin{array}{c}30 \text { min: } 321 \\
(310,332) \\
120 \text { min: } 300 \\
(289,310)\end{array}$ & $\begin{array}{c}30 \text { min: } 309 \\
(297,321) \\
120 \text { min: } 305 \\
(294,316)\end{array}$ & $\begin{array}{l}0.060 \\
(0.09)\end{array}$ & --- & --- & $\begin{array}{c}0.0003 \\
(0.28)\end{array}$ & 0.034 \\
\hline $\begin{array}{c}\text { Haematocrit } \\
(\%)\end{array}$ & $\begin{array}{c}23.6 \\
(21.1,26.2)\end{array}$ & $\begin{array}{c}20.9 \\
(18.2,23.6)\end{array}$ & $\begin{array}{l}0.092 \\
(0.08)\end{array}$ & NA & NA & NA & NA \\
\hline
\end{tabular}

Covariates: N/A. 


\begin{tabular}{|c|c|c|c|c|c|c|c|}
\hline (d) & $\begin{array}{l}\text { SE mean } \\
(95 \% \mathrm{CI})\end{array}$ & $\begin{array}{l}\text { SEH mean } \\
(95 \% \mathrm{CI})\end{array}$ & $\begin{array}{c}\text { SE vs. SEH } \\
P\left(f^{2}\right)\end{array}$ & $\begin{array}{c}30 \text { min mean } \\
(95 \% \mathrm{CI})\end{array}$ & $\begin{array}{c}120 \text { min mean } \\
(95 \% \mathrm{C})\end{array}$ & $\begin{array}{l}\text { Time } \\
P\left(f^{2}\right)\end{array}$ & $\begin{array}{c}\text { Treatment:Time } \\
P\end{array}$ \\
\hline $\begin{array}{l}\text { Plasma cortisol } \\
(\mathrm{ng} / \mathrm{mL})\end{array}$ & $\begin{array}{c}89.0 \\
(51.9,126)\end{array}$ & $\begin{array}{c}104 \\
(66.2,141)\end{array}$ & $\begin{array}{l}0.521 \\
(0.01)\end{array}$ & $\begin{array}{c}82.6 \\
(54.2,111)\end{array}$ & $\begin{array}{c}109.9 \\
(81.1,139)\end{array}$ & $\begin{array}{l}0.019 \\
(0.06)\end{array}$ & 0.681 \\
\hline $\begin{array}{l}\text { Blood glucose } \\
\qquad(\mathrm{mM})\end{array}$ & $\begin{array}{c}4.00 \\
(3.23,4.78)\end{array}$ & $\begin{array}{c}4.47 \\
(3.70,5.24)\end{array}$ & $\begin{array}{l}0.316 \\
(0.04)\end{array}$ & $\begin{array}{c}4.46 \\
(3.88,5.04)\end{array}$ & $\begin{array}{c}4.01 \\
(3.43,4.6)\end{array}$ & $\begin{array}{l}0.031 \\
(0.04)\end{array}$ & NA \\
\hline $\begin{array}{l}\text { Blood lactate } \\
\qquad(\mathrm{mM})\end{array}$ & $\begin{array}{c}3.38 \\
(2.18,4.57)\end{array}$ & $\begin{array}{c}3.04 \\
(1.85,4.24)\end{array}$ & $\begin{array}{c}0.636 \\
(0.006)\end{array}$ & $\begin{array}{c}3.70 \\
(2.78,4.62)\end{array}$ & $\begin{array}{c}2.72 \\
(1.80,3.64)\end{array}$ & $\begin{array}{l}0.009 \\
(0.07)\end{array}$ & NA \\
\hline $\begin{array}{c}\text { Plasma } \\
\text { osmolality } \\
\text { (mmol/kg) }\end{array}$ & $\begin{array}{c}307 \\
(299,315)\end{array}$ & $\begin{array}{c}314 \\
(306,322)\end{array}$ & $\begin{array}{l}0.124 \\
(0.09)\end{array}$ & $\begin{array}{c}315 \\
(308,322)\end{array}$ & $\begin{array}{c}307 \\
(300,314)\end{array}$ & $\begin{array}{l}0.054 \\
(0.09)\end{array}$ & 0.356 \\
\hline $\begin{array}{l}\text { Haematocrit } \\
\qquad(\%)\end{array}$ & $\begin{array}{c}20.9 \\
(18.1,23.7)\end{array}$ & $\begin{array}{c}24.1 \\
(21.3,26.9)\end{array}$ & $\begin{array}{l}0.063 \\
(0.15)\end{array}$ & NA & NA & NA & NA \\
\hline
\end{tabular}

Covariates: N/A. 


\begin{tabular}{|c|c|c|c|c|c|c|c|}
\hline (e) & $\begin{array}{l}\text { SEH mean } \\
(95 \% \mathrm{CI})\end{array}$ & $\begin{array}{l}\text { SEL mean } \\
(95 \% \mathrm{CI})\end{array}$ & $\begin{array}{c}\text { SEH vs. SEL } \\
P\left(f^{2}\right)\end{array}$ & $\begin{array}{c}30 \text { min mean } \\
(95 \% \mathrm{CI})\end{array}$ & $\begin{array}{l}120 \text { min mean } \\
(95 \% \mathrm{C})\end{array}$ & $\begin{array}{l}\text { Time } \\
P\left(f^{2}\right)\end{array}$ & $\begin{array}{c}\text { Treatment:Time } \\
P\end{array}$ \\
\hline $\begin{array}{l}\text { Plasma cortisol } \\
\text { (ng/mL) }\end{array}$ & $\begin{array}{c}103 \\
(62.6,144)\end{array}$ & $\begin{array}{c}144 \\
(103.2,184)\end{array}$ & $\begin{array}{l}0.103 \\
(0.11)\end{array}$ & $\begin{array}{c}107 \\
(74.8,139)\end{array}$ & $\begin{array}{c}140 \\
(107.9,172)\end{array}$ & $\begin{array}{l}0.024 \\
(0.05)\end{array}$ & 0.872 \\
\hline $\begin{array}{l}\text { Blood glucose } \\
\qquad(\mathrm{mM})\end{array}$ & $\begin{array}{c}4.47 \\
(3.11,5.84)\end{array}$ & $\begin{array}{c}5.68 \\
(4.31,7.05)\end{array}$ & $\begin{array}{l}0.149 \\
(0.09)\end{array}$ & NA & NA & NA & NA \\
\hline $\begin{array}{l}\text { Blood lactate } \\
\qquad(\mathrm{mM})\end{array}$ & $\begin{array}{c}3.04 \\
(1.62,4.46)\end{array}$ & $\begin{array}{c}3.74 \\
(2.32,5.16)\end{array}$ & $\begin{array}{l}0.415 \\
(0.02)\end{array}$ & $\begin{array}{c}3.88 \\
(2.83,4.92)\end{array}$ & $\begin{array}{c}2.90 \\
(1.86,3.95)\end{array}$ & $\begin{array}{l}0.003 \\
(0.05)\end{array}$ & NA \\
\hline $\begin{array}{c}\text { Plasma } \\
\text { osmolality } \\
(\mathrm{mmol} / \mathrm{kg})\end{array}$ & $\begin{array}{c}314 \\
(302,327)\end{array}$ & $\begin{array}{c}308 \\
(296,320)\end{array}$ & $\begin{array}{l}0.405 \\
(0.04)\end{array}$ & $\begin{array}{c}315 \\
(306,325)\end{array}$ & $\begin{array}{c}307 \\
(298,317)\end{array}$ & $\begin{array}{l}0.044 \\
(0.05)\end{array}$ & 0.301 \\
\hline $\begin{array}{c}\text { Haematocrit } \\
(\%)\end{array}$ & $\begin{array}{c}24.1 \\
(21.5,26.7)\end{array}$ & $\begin{array}{c}25.0 \\
(22.4,27.6)\end{array}$ & $\begin{array}{c}0.550 \\
(0.007)\end{array}$ & $\begin{array}{c}26.4 \\
(24.5,28.4)\end{array}$ & $\begin{array}{c}22.7 \\
(20.7,24.7)\end{array}$ & $\begin{array}{c}<0.0001 \\
\quad(0.23)\end{array}$ & NA \\
\hline
\end{tabular}

Covariates: N/A. 
Table S2. Least squares means and asymptotic 95\% confidence intervals for mean thrash counts and ventilation rates during surgery, for (a) HC vs. E, (b) E vs. SE, (c) SE vs. SEH, and (d) SEH vs. SEL. Noteworthy covariate effects are described below each table. Treatment comparisons had 1 degree of freedom.

\begin{tabular}{|c|c|c|c|}
\cline { 2 - 4 } \multicolumn{1}{c|}{} & $\begin{array}{c}\text { HC mean } \\
(95 \% \mathrm{CI})\end{array}$ & $\begin{array}{c}\text { E mean } \\
(95 \% \mathrm{CI})\end{array}$ & $\begin{array}{c}\mathrm{HC} \text { vs. E } \\
P\left(f^{2}\right)\end{array}$ \\
\hline Thrash Count & 1.28 & 0.25 & $<0.0001$ \\
& $(0.86,1.91)$ & $(0.11,0.59)$ & $(0.52)$ \\
\hline $\mathrm{VR}_{1}$ & 1.11 & 1.07 & 0.692 \\
(ventilations/s) & $(0.93,1.29)$ & $(0.86,1.29)$ & $(0.004)$ \\
\hline
\end{tabular}

Covariates: Mean thrash count increased by 0.1 and 0.3 thrashes per $100 \mathrm{~g}$ mass increase $(P=0.041)$ and $1{ }^{\circ} \mathrm{C}$ temperature increase $(P=0.013)$, respectively. Mean $\mathrm{VR}_{1}$ increased by 0.1 ventilations/s per $1^{\circ} \mathrm{C}$ temperature increase $(P$ $=0.021)$.

\begin{tabular}{|c|c|c|c|}
\cline { 2 - 4 } \multicolumn{1}{c|}{} & E mean & SE mean & E vs. SE \\
$(95 \% \mathrm{CI})$ & $(95 \% \mathrm{CI})$ & $P\left(f^{2}\right)$ \\
\hline \multirow{2}{*}{ Thrash Count } & 0.22 & 0.29 & 0.549 \\
& $(0.09,0.54)$ & $(0.13,0.64)$ & $(0.007)$ \\
\hline VR $_{1}$ & 1.047 & 0.95 & 0.354 \\
(ventilations/s) & $(0.87,1.22)$ & $(0.79,1.11)$ & $(0.02)$ \\
\hline
\end{tabular}

Covariates: Mean thrash count increased by 0.4 thrashes per $100 \mathrm{~g}$ mass increase $(P=0.001)$. Mean $\mathrm{VR}_{1}$ increased by 0.1 ventilations/s per $1{ }^{\circ} \mathrm{C}$ temperature increase $(P$ $=0.0002)$, and decreased by 0.08 ventilations $/ \mathrm{s}$ per $100 \mathrm{~g}$ mass increase $(P=0.009)$.

\begin{tabular}{|c|c|c|c|}
\cline { 2 - 4 } \multicolumn{1}{c|}{} & $\begin{array}{c}\text { SE mean } \\
(95 \% \mathrm{CI})\end{array}$ & $\begin{array}{c}\text { SEH mean } \\
(95 \% \mathrm{CI})\end{array}$ & $\begin{array}{c}\text { SE vs. SEH } \\
P\left(f^{2}\right)\end{array}$ \\
\hline \multirow{2}{*}{ Thrash Count } & 0.25 & 0.59 & 0.037 \\
& $(0.11,0.56)$ & $(0.32,1.07)$ & $(0.08)$ \\
\hline $\mathrm{VR}_{1}$ & 0.96 & 0.77 & 0.043 \\
(ventilations/s) & $(0.81,1.12)$ & $(0.62,0.91)$ & $(0.10)$ \\
\hline
\end{tabular}

Covariates: Mean thrash count increased by 0.3 and 0.4 thrashes per $100 \mathrm{~g}$ mass increase $(P=0.038)$ and $1{ }^{\circ} \mathrm{C}$ temperature increase $(P=0.001)$, respectively. Mean $\mathrm{VR}_{1}$ increased by 0.07 ventilations/s per $1^{\circ} \mathrm{C}$ temperature increase $(P=0.010)$, and decreased by 0.09 ventilations/s per $100 \mathrm{~g}$ mass increase $(P=0.003)$.

\begin{tabular}{|c|c|c|c|}
\cline { 2 - 4 } \multicolumn{1}{c|}{} & $\begin{array}{c}\text { SEH mean } \\
(95 \% \mathrm{CI})\end{array}$ & $\begin{array}{c}\text { SEL mean } \\
(95 \% \mathrm{CI})\end{array}$ & $\begin{array}{c}\text { SEH vs. SEL } \\
P\left(f^{2}\right)\end{array}$ \\
\hline \multirow{2}{*}{ Thrash Count } & 0.48 & 0.30 & 0.245 \\
& $(0.26,0.92)$ & $(0.15,0.65)$ & $(0.03)$ \\
\hline $\mathrm{VR}_{1}$ & 0.78 & 0.97 & 0.042 \\
(ventilations/s) & $(0.64,0.93)$ & $(0.82,1.12)$ & $(0.09)$ \\
\hline
\end{tabular}

Covariates: Mean thrash count increased by 0.4 thrashes per $1{ }^{\circ} \mathrm{C}$ temperature increase $(P=0.002)$. 
Table S3. Least squares means and asymptotic 95\% confidence intervals for measurements taken in the cooler, for (a) BB vs. HC, (b) HC vs. E, (c) E vs. SE, (d) SE vs. SEH, and (e) SEH vs. SEL. Noteworthy covariate effects are described below each table. Treatment comparisons had 1 degree of freedom.

\begin{tabular}{|c|c|c|c|}
\cline { 2 - 4 } \multicolumn{1}{c|}{} & $\begin{array}{c}\text { BB mean } \\
(95 \% \mathrm{CI})\end{array}$ & $\begin{array}{c}\text { HC mean } \\
(95 \% \mathrm{CI})\end{array}$ & $\begin{array}{c}\text { BB vs. HC } \\
P\left(f^{2}\right)\end{array}$ \\
\hline \multirow{2}{*}{$\mathrm{VR}_{2}$ (ventilations/s) } & 0.96 & 0.99 & 0.623 \\
& $(0.85,1.06)$ & $(0.88,1.10)$ & $(0.009)$ \\
\hline \multirow{2}{*}{$\mathrm{VR}_{3}$ (ventilations/s) } & 1.08 & 1.18 & 0.244 \\
& $(0.93,1.22)$ & $(1.03,1.34)$ & $(0.05)$ \\
\hline \multirow{2}{*}{$\Delta \mathrm{VR}$ (ventilations/s) } & 0.13 & 0.19 & 0.396 \\
& $(-0.001,0.251)$ & $(0.06,0.32)$ & $(0.03)$ \\
\hline \multirow{2}{*}{ Opercular Twitches } & 0.69 & 1.41 & 0.074 \\
& $(0.33,1.46)$ & $(0.82,2.44)$ & $(0.14)$ \\
\hline \multirow{2}{*}{ RAMP 1 } & 4.57 & 4.62 & 0.961 \\
& $(3.53,5.93)$ & $(3.53,6.05)$ & $(<0.001)$ \\
\hline \multirow{2}{*}{ RAMP 2 } & 4.57 & 4.71 & 0.826 \\
& $(3.53,5.93)$ & $(3.63,6.17)$ & $(0.002)$ \\
\hline
\end{tabular}

Covariates: N/A. 


\begin{tabular}{|c|c|c|c|}
\cline { 2 - 4 } \multicolumn{1}{c|}{} & $\begin{array}{c}\text { HC mean } \\
(95 \% \mathrm{CI})\end{array}$ & $\begin{array}{c}\text { E mean } \\
(95 \% \mathrm{CI})\end{array}$ & $\begin{array}{c}\text { HC vs. E } \\
P\left(f^{2}\right)\end{array}$ \\
\hline \multirow{2}{*}{$\mathrm{VR}_{2}$ (ventilations/s) } & 0.96 & 0.91 & 0.418 \\
& $(0.87,1.05)$ & $(0.82,1.01)$ & $(0.03)$ \\
\hline \multirow{2}{*}{$\mathrm{VR}_{3}$ (ventilations/s) } & 1.13 & 1.23 & 0.330 \\
& $(0.96,1.29)$ & $(1.05,1.41)$ & $(0.04)$ \\
\hline \multirow{2}{*}{$\Delta$ VR (ventilations/s) } & 0.17 & 0.27 & 0.222 \\
& $(0.04,0.31)$ & $(0.14,0.41)$ & $(0.06)$ \\
\hline \multirow{2}{*}{ Opercular Twitches } & 1.42 & 1.85 & 0.401 \\
& $(0.82,2.44)$ & $(1.17,2.92)$ & $(0.03)$ \\
\hline \multirow{2}{*}{ RAMP 1 } & 4.60 & 4.88 & 0.725 \\
& $(3.51,6.02)$ & $(3.78,6.28)$ & $(0.004)$ \\
\hline \multirow{2}{*}{ RAMP 2 } & 4.73 & 4.94 & 0.796 \\
& $(3.63,6.17)$ & $(3.83,6.35)$ & $(0.002)$ \\
\hline
\end{tabular}

Covariates: Mean $\mathrm{VR}_{2}$ increased by 0.05 ventilations/s with every $1^{\circ} \mathrm{C}$ increase $(P=0.014)$, and decreased by 0.03 ventilations/s per $100 \mathrm{~g}$ mass increase $(P=0.0625)$. Mean $\mathrm{VR}_{3}$ and mean $\Delta \mathrm{VR}$ decreased by $0.08(P=0.004)$ and $0.05(P=0.022)$ ventilations/s, respectively. 


\begin{tabular}{|c|c|c|c|}
\cline { 2 - 4 } \multicolumn{1}{c|}{} & $\begin{array}{c}\text { E mean } \\
(95 \% \mathrm{CI})\end{array}$ & $\begin{array}{c}\text { SE mean } \\
(95 \% \mathrm{CI})\end{array}$ & $\begin{array}{c}\text { E vs. SE } \\
P\left(f^{2}\right)\end{array}$ \\
\hline \multirow{2}{*}{$\mathrm{VR}_{2}$ (ventilations/s) } & 0.90 & 0.84 & 0.370 \\
& $(0.79,1.01)$ & $(0.74,0.94)$ & $(0.03)$ \\
\hline \multirow{2}{*}{$\mathrm{VR}_{3}$ (ventilations/s) } & 1.14 & 1.14 & 0.981 \\
$(0.97,1.31)$ & $(0.97,1.32)$ & $(<0.001)$ \\
\hline \multirow{2}{*}{$\Delta$ VR (ventilations/s) } & 0.26 & 0.29 & 0.683 \\
& $(0.11,0.41)$ & $(0.15,0.44)$ & $(0.006)$ \\
\hline \multirow{2}{*}{ Opercular Twitches } & 1.92 & 1.67 & 0.631 \\
& $(1.18,2.67)$ & $(1.05,3.13)$ & $(0.009)$ \\
\hline \multirow{2}{*}{ RAMP 1 } & 4.88 & 5.00 & 0.874 \\
& $(3.78,6.28)$ & $(3.89,6.42)$ & $(0.001)$ \\
\hline \multirow{2}{*}{ RAMP 2 } & 4.82 & 4.94 & 0.882 \\
& $(3.77,6.17)$ & $(3.84,6.35)$ & $(0.001)$ \\
\hline
\end{tabular}

Covariates: Mean $\mathrm{VR}_{2}$ increased by 0.05 ventilations/s per $1^{\circ} \mathrm{C}$ temperature increase $(P=0.007)$. Mean $\mathrm{VR}_{3}$ and mean $\Delta \mathrm{VR}$ decreased by 0.05 ventilations/s $(P=0.030)$ and 0.04 ventilations/s $(P=0.057)$ per $100 \mathrm{~g}$ mass increase. Mean opercular twitch counts increased by 0.2 twitches per $1^{\circ} \mathrm{C}$ temperature increase $(P=0.012)$. 


\begin{tabular}{|c|c|c|c|}
\cline { 2 - 4 } \multicolumn{1}{c|}{} & $\begin{array}{c}\text { SE mean } \\
(95 \% \mathrm{CI})\end{array}$ & $\begin{array}{c}\text { SEH mean } \\
(95 \% \mathrm{CI})\end{array}$ & $\begin{array}{c}\text { SE vs. SEH } \\
P\left(f^{2}\right)\end{array}$ \\
\hline \multirow{2}{*}{$\mathrm{VR}_{2}$ (ventilations/s) } & 0.83 & 1.03 & 0.012 \\
& $(0.71,0.95)$ & $(0.90,1.16)$ & $(0.27)$ \\
\hline \multirow{2}{*}{$\mathrm{VR}_{3}$ (ventilations/s) } & 1.14 & 1.24 & 0.243 \\
& $(1.00,1.28)$ & $(1.10,1.38)$ & $(0.05)$ \\
\hline \multirow{2}{*}{$\Delta$ VR (ventilations/s) } & 0.29 & 0.22 & 0.428 \\
& $(0.15,0.44)$ & $(0.07,0.37)$ & $(0.02)$ \\
\hline \multirow{2}{*}{ Opercular Twitches } & 1.69 & 1.89 & 0.704 \\
& $(1.06,2.70)$ & $(1.18,3.05)$ & $(0.006)$ \\
\hline \multirow{2}{*}{ RAMP 1 } & 5.00 & 4.88 & 0.874 \\
& $(3.89,6.42)$ & $(3.78,6.28)$ & $(0.001)$ \\
\hline \multirow{2}{*}{ RAMP 2 } & 4.82 & 4.63 & 0.793 \\
& $(3.77,6.17)$ & $(3.57,6.00)$ & $(0.002)$ \\
\hline
\end{tabular}

Covariates: Mean $\mathrm{VR}_{2}$ increased by 0.05 ventilations/s per $1{ }^{\circ} \mathrm{C}$ temperature increase $(P=0.026)$. Mean opercular twitch counts increased by 0.2 twitches per $1{ }^{\circ} \mathrm{C}$ temperature increase $(P=0.074)$.

\begin{tabular}{|c|c|c|c|}
\cline { 2 - 4 } \multicolumn{1}{c|}{} & $\begin{array}{c}\text { SEH mean } \\
(95 \% \mathrm{CI})\end{array}$ & $\begin{array}{c}\text { SEL mean } \\
(95 \% \mathrm{CI})\end{array}$ & $\begin{array}{c}\text { SEH vs. SEL } \\
P\left(f^{2}\right)\end{array}$ \\
\hline \multirow{2}{*}{$\mathrm{VR}_{2}$ (ventilations/s) } & 1.01 & 1.01 & 1.00 \\
& $(0.88,1.14)$ & $(0.89,1.13)$ & $(<0.001)$ \\
\hline \multirow{2}{*}{$\mathrm{VR}_{3}$ (ventilations/s) } & 1.22 & 1.24 & 0.837 \\
& $(1.10,1.35)$ & $(1.12,1.36)$ & $(0.001)$ \\
\hline \multirow{2}{*}{$\Delta$ VR (ventilations/s) } & 0.18 & 0.19 & 0.842 \\
& $(0.04,0.32)$ & $(0.06,0.33)$ & $(0.002)$ \\
\hline \multirow{2}{*}{ Opercular Twitches } & 1.71 & 2.07 & 0.492 \\
& $(1.09,2.71)$ & $(1.37,3.14)$ & $(0.02)$ \\
\hline \multirow{2}{*}{ RAMP 1 } & 4.88 & 4.56 & 0.684 \\
& $(3.78,6.28)$ & $(3.51,5.93)$ & $(0.005)$ \\
\hline \multirow{2}{*}{ RAMP 2 } & 4.63 & 4.81 & 0.807 \\
& $(3.57,6.00)$ & $(3.73,6.21)$ & $(0.002)$ \\
\hline
\end{tabular}

Covariates: Mean $\mathrm{VR}_{2}$ increased by 0.07 ventilations/s with every $1^{\circ} \mathrm{C}$ increase $(P=0.006)$, and decreased by 0.1 ventilations/s per $100 \mathrm{~g}$ mass increase $(P=0.006)$. Mean $\mathrm{VR}_{3}$ decreased by 0.1 ventilations/s per $100 \mathrm{~g}$ mass increase $(P=0.002)$. 
Table S4. Least squares means and asymptotic 95\% confidence intervals for behavioural trials in the arena, for (a) BB vs. HC, (b) HC vs. E, (c) E vs. SE, (d) SE vs. SEH, and (e) SEH vs. SEL. Noteworthy covariate effects are described below each table. "NA" denotes responses that could not be analyzed since no E or SEH fish emerged from the refuge voluntarily, and all refuges were removed from the arena during those trials. Treatment comparisons had 1 degree of freedom.

\begin{tabular}{|c|c|c|c|}
\cline { 2 - 4 } \multicolumn{1}{c|}{} & $\begin{array}{c}\text { BB mean } \\
(95 \% \mathrm{CI})\end{array}$ & $\begin{array}{c}\text { HC mean } \\
(95 \% \mathrm{CI})\end{array}$ & $\begin{array}{c}\text { BB vs. HC } \\
P\left(f^{2}\right)\end{array}$ \\
\hline $\begin{array}{c}\text { Refuge Emergence } \\
\text { (proportion) }\end{array}$ & 0.29 & 0.36 & 0.686 \\
$(0.10,0.60)$ & $(0.14,0.66)$ & $(0.006)$ \\
\hline Emergence Time (s) & 277 & 212 & 0.091 \\
$(207,346)$ & $(151,273)$ & $(0.88)$ \\
\hline Threat Perception & 0.59 & 0.04 & 0.058 \\
(proportion) & $(0.14,0.93)$ & $(0.0002,0.88)$ & $(0.22)$ \\
\hline Line Cross Count & 68.1 & 80.2 & 0.011 \\
& $(62.4,74.4)$ & $(72.3,89.0)$ & $(0.41)$ \\
\hline Refuge Re-entry & 0.75 & 1.2 & 0.497 \\
Count & $(0.21,2.73)$ & $(0.48,2.99)$ & $(0.05)$ \\
\hline \multirow{2}{*}{ Time in Refuge (s) } & 86.2 & 79.0 & 0.933 \\
& $(-88.3,261)$ & $(-77.2,235)$ & $(0.001)$ \\
\hline
\end{tabular}

Covariates: Mean refuge emergence times decreased by $\sim 4 \mathrm{~s}$ for every $1 \mathrm{~mm}$ increase in fish length $(P=0.001)$, and by $\sim 101$ $\mathrm{s}$ for every $1^{\circ} \mathrm{C}$ increase in water temperature $(P=0.0007)$. The log odds of perceiving the lifting refuge as a threat increased by 10 per $100 \mathrm{~mm}$ length increase $(P=0.005)$, and decreased by 1 per $1{ }^{\circ} \mathrm{C}$ temperature increase $(P=0.060)$. Mean line cross counts increased by $18 \%$ when the lifted refuge was perceived as a threat $(P=0.030)$. 


\begin{tabular}{|c|c|c|c|}
\cline { 2 - 4 } \multicolumn{1}{c|}{} & $\begin{array}{c}\text { HC mean } \\
(95 \% \mathrm{CI})\end{array}$ & $\begin{array}{c}\text { E mean } \\
(95 \% \mathrm{CI})\end{array}$ & $\begin{array}{c}\mathrm{HC} \text { vs. E } \\
P\left(f^{2}\right)\end{array}$ \\
\hline Refuge Emergence & NA & NA & NA \\
\hline Emergence Time & NA & NA & NA \\
\hline $\begin{array}{c}\text { Threat Perception } \\
\text { (proportion) }\end{array}$ & $\begin{array}{c}0.21 \\
(0.03,0.69)\end{array}$ & $\begin{array}{c}0.33 \\
(0.08,0.74)\end{array}$ & $\begin{array}{c}0.610 \\
(0.01)\end{array}$ \\
\hline $\begin{array}{c}67.1 \\
\text { Line Cross Count }\end{array}$ & $\begin{array}{c}44.4 \\
(60.8,74.2)\end{array}$ & $\begin{array}{c}<0.0001 \\
(9.17)\end{array}$ \\
\hline $\begin{array}{c}\text { Refuge Re-entry } \\
\text { Count }\end{array}$ & NA & NA & NA \\
\hline Time in Refuge & NA & NA & NA \\
\hline
\end{tabular}

Covariates: The log odds of perceiving the lifting refuge as a threat increased by 4 per $100 \mathrm{~mm}$ length increase $(P=0.006)$. Mean line cross counts decreased by $34 \%$ when the lifted refuge was perceived as a threat $(P<0.0001)$, and also increased by $60 \%$ $(P<0.0001)$ and $9 \%(P<0.0001)$ per $100 \mathrm{~mm}$ length increase and $1{ }^{\circ} \mathrm{C}$ temperature increase, respectively.

\begin{tabular}{|c|c|c|c|}
\cline { 2 - 4 } \multicolumn{1}{c|}{} & $\begin{array}{c}\text { E mean } \\
(95 \% \mathrm{CI})\end{array}$ & $\begin{array}{c}\text { SE mean } \\
(95 \% \mathrm{CI})\end{array}$ & $\begin{array}{c}\text { E vs. SE } \\
P\left(f^{2}\right)\end{array}$ \\
\hline Refuge Emergence & NA & NA & NA \\
\hline Emergence Time & NA & NA & NA \\
\hline $\begin{array}{c}\text { Threat Perception } \\
\text { (proportion) }\end{array}$ & $\begin{array}{c}0.21 \\
(0.03,0.69)\end{array}$ & $\begin{array}{c}0.33 \\
(0.08,0.74)\end{array}$ & $\begin{array}{c}0.173 \\
(0.08)\end{array}$ \\
\hline Line Cross Count & $\begin{array}{c}44.2 \\
(38.1,46.6)\end{array}$ & $\begin{array}{c}35.3 \\
(31.2,40.0)\end{array}$ & $\begin{array}{c}0.007 \\
(0.36)\end{array}$ \\
\hline Refuge Re-entry & NA & NA & NA \\
\hline Count & NA & NA & NA \\
\hline
\end{tabular}

Covariates: Mean line cross counts decreased by $36 \%$ when the lifted refuge was perceived as a threat $(P<0.0001)$, and also increased by $51 \%(P<0.0001)$ per $100 \mathrm{~mm}$ length increase. 


\begin{tabular}{|c|c|c|c|}
\cline { 2 - 4 } \multicolumn{1}{c|}{} & $\begin{array}{c}\text { SE mean } \\
(95 \% \mathrm{CI})\end{array}$ & $\begin{array}{c}\text { SEH mean } \\
(95 \% \mathrm{CI})\end{array}$ & $\begin{array}{c}\text { SE vs. SEH } \\
P\left(f^{2}\right)\end{array}$ \\
\hline Refuge Emergence & NA & NA & NA \\
\hline Emergence Time & NA & NA & NA \\
\hline $\begin{array}{c}\text { Threat Perception } \\
\text { (proportion) }\end{array}$ & $\begin{array}{c}0.11 \\
(0.01,0.58)\end{array}$ & $\begin{array}{c}0.39 \\
(0.13,0.72)\end{array}$ & $\begin{array}{c}0.112 \\
(0.11)\end{array}$ \\
\hline Line Cross Count & $\begin{array}{c}47.2 \\
(42.2,52.8)\end{array}$ & $\begin{array}{c}46.0 \\
(41.8,50.6)\end{array}$ & $\begin{array}{c}0.705 \\
(0.006)\end{array}$ \\
\hline $\begin{array}{c}\text { Refuge Re-entry } \\
\text { Count }\end{array}$ & NA & NA & NA \\
\hline Time in Refuge & NA & NA & NA \\
\hline
\end{tabular}

Covariates: The log odds of perceiving the lifting refuge as a threat decreased by 4 per $100 \mathrm{~mm}$ length increase $(P=0.050)$. Mean line cross counts increased by $63 \%$ when the lifted refuge was perceived as a threat $(P<0.0001)$, increased by $76 \%(P<$ $0.0001)$ per $100 \mathrm{~mm}$ length increase, and decreased by $8 \%$ per $1{ }^{\circ} \mathrm{C}$ temperature increase $(P<0.0001)$.

\begin{tabular}{|c|c|c|c|}
\cline { 2 - 4 } \multicolumn{1}{c|}{} & $\begin{array}{c}\text { SEH mean } \\
(95 \% \mathrm{CI})\end{array}$ & $\begin{array}{c}\text { SEL mean } \\
(95 \% \mathrm{CI})\end{array}$ & $\begin{array}{c}\text { SEH vs. } \\
\text { SEL } \\
P\left(f^{2}\right)\end{array}$ \\
\hline Refuge Emergence & NA & NA & NA \\
\hline Emergence Time & NA & NA & NA \\
\hline $\begin{array}{c}\text { Threat Perception } \\
\text { (proportion) }\end{array}$ & $\begin{array}{c}0.46 \\
(0.20,0.75)\end{array}$ & $\begin{array}{c}0.50 \\
(0.22,0.78)\end{array}$ & $\begin{array}{c}0.848 \\
(0.001)\end{array}$ \\
\hline $\begin{array}{c}45.2 \\
(41.2,49.5)\end{array}$ & $\begin{array}{c}39.6 \\
(35.8,43.9)\end{array}$ & $\begin{array}{c}0.032 \\
(0.20)\end{array}$ \\
\hline Refuge Re-entry & NA & NA & NA \\
\hline Time in Refuge & NA & NA & NA \\
\hline
\end{tabular}

Covariates: Mean line cross counts increased by $61 \%$ when the lifted refuge was perceived as a threat $(P<0.0001)$, and decreased by $43 \%(P=0.010)$ per $100 \mathrm{~mm}$ length increase. 
Table S5. Intraclass correlation coefficients (ICCs) denoting the proportion of variance for each physiological response explained by intra-individual variability, as opposed to fixed effects (e.g. treatment, time) for (a) HC vs E, (b) E vs. SE, (c) SE vs. SEH, and (d) SEH vs SEL. In (a), individual fish ID had to be removed during model selection in order to address singular fit.

\begin{tabular}{|c|c|c|c|c|c|}
\cline { 2 - 5 } \multicolumn{1}{c|}{$(\mathrm{a})$} & Plasma Cortisol & Blood Glucose & Blood Lactate & Plasma Osmolality & Haematocrit \\
\hline ICC (Fish I.D.) & 0.515 & 0.699 & 0.779 & 0.571 & NA \\
\hline
\end{tabular}

\begin{tabular}{|c|c|c|c|c|c|}
\cline { 2 - 5 } \multicolumn{1}{c|}{$(\mathrm{b})$} & Plasma Cortisol & Blood Glucose & Blood Lactate & Plasma Osmolality & Haematocrit \\
\hline ICC (Fish I.D.) & 0.435 & 0.719 & 0.645 & 0.263 & 0.229 \\
\hline
\end{tabular}

\begin{tabular}{c|c|c|c|c|c|}
\cline { 2 - 6 } \multicolumn{1}{c|}{$(\mathrm{c})$} & Plasma Cortisol & Blood Glucose & Blood Lactate & Plasma Osmolality & Haematocrit \\
\hline ICC (Fish I.D.) & 0.648 & 0.696 & 0.617 & 0.200 & 0.654 \\
\hline \multirow{3}{*}{ (d) } & Plasma Cortisol & Blood Glucose & Blood Lactate & Plasma Osmolality & Haematocrit \\
\cline { 2 - 6 } & 0.554 & 0.82 & 0.790 & 0.624 & 0.628 \\
\hline ICC (Fish I.D.) & &
\end{tabular}


Tables S6-S24: Model selection outputs. Outputs are presented as generated in RStudio. The global model structure is provided at above each output table. Models are automatically sorted from lowest to highest AICc. The leftmost row identifies individual models by number, with the highest number corresponding to the global model and the lower numbers corresponding with progressively simpler models. Intercept coefficients are provided under "(Intrc)". For linear covariates (e.g. mass, length), the partial regression coefficient $(\beta)$ is given when the variable is present in a given model; inclusion of categorical predictors (e.g. treatment) are denoted by "+". Any variables that are not included in a model are blank. Degrees of freedom ("df"), model log likelihood ("logLik"), AICc values, $\triangle \mathrm{AICc}$ values with respect to the uppermost model ("delta"), and AICc weight ("weight") are also provided.

Table S6. Model selection outputs for haematological responses of HC vs. BP fish, showing models for (a) plasma cortisol at 30 min, (b) plasma cortisol at $120 \mathrm{~min}$, (c) blood glucose at $30 \mathrm{~min}$, (d) blood glucose at $120 \mathrm{~min}$, (e) blood lactate at $30 \mathrm{~min}$, (f) blood lactate at $120 \mathrm{~min},(\mathrm{~g})$ plasma osmolality at $30 \mathrm{~min}$, (h) plasma osmolality at $120 \mathrm{~min}$, (i) haematocrit at $30 \mathrm{~min}$, and (j) haematocrit at 120 min post-surgery.

(a)

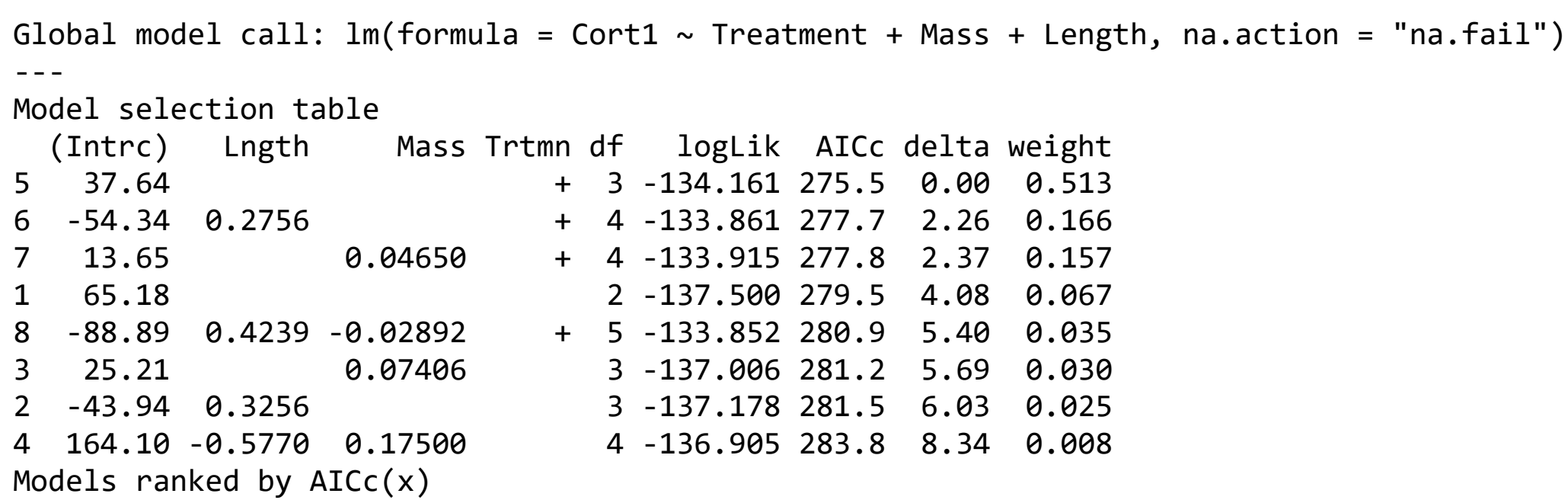


(b)

Global model call: $\operatorname{lm}($ formula = Cort2 Treatment + Mass + Length, na.action = "na.fail") -.-

Model selection table

\begin{tabular}{|c|c|c|c|c|c|c|c|c|}
\hline C) & Lngth & Mass & in & $d f$ & $k$ & Cc & delta & eigh \\
\hline 37.64 & & & + & 3 & -127.985 & 263.2 & 0.00 & 0.589 \\
\hline 64.89 & & $-0 . \epsilon$ & + & 4 & -127.668 & 265.4 & 2.27 & 18 \\
\hline 97.70 & -0.1800 & & + & 4 & -127 & 265 & 2.65 & \\
\hline 167 & 0.9598 & -0.2 & + & 5 & -127 & 2 & 30 & \\
\hline & & & & 2 & -133 & 27 & 60 & \\
\hline 137.30 & -0.1922 & & & 3 & -133 & 274.2 & 1.05 & \\
\hline & & -0 & & 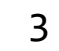 & -13 & .3 & .13 & \\
\hline 216.80 & -0.5379 & 0.06753 & & 4 & -133.476 & 277.1 & 13.89 & 0.00 \\
\hline
\end{tabular}

Models ranked by $\operatorname{AICC}(x)$

(c)

Global model call: $\operatorname{lm}($ formula = Glu1 Treatment + Mass + Length, na.action = "na.fail") - - -

Model selection table

(Intrc) Lngth Mass Trtmn df logLik AICc delta weight

$5 \quad 2.827$

$7 \quad 3.226$

$+3-39.16385 .6 \quad 0.00 \quad 0.620$

$6 \quad 3.037-0.0006205$

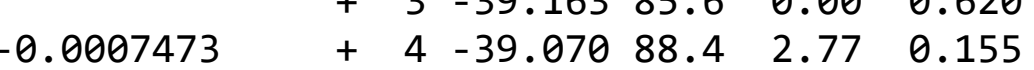

$\begin{array}{lll}-6.693 & 0.0404500 & -0.0078160\end{array}$

$+\quad 4-39.16188 .52 .95 \quad 0.142$

3.883

$4.435-0.0016370$

$3.938-0.0001008$

$+\quad 5-38.30690 .14 .550 .064$

$\begin{array}{lllll}2 & -44.414 & 93.4 & 7.84 & 0.012\end{array}$

$\begin{array}{lllll}3 & -44.405 & 96.1 & 10.48 & 0.003\end{array}$

$\begin{array}{llllll}3 & -44.413 & 96.1 & 10.50 & 0.003\end{array}$

$\begin{array}{llll}4 & 6.698 & -0.0113800 & 0.0018610\end{array}$

$\begin{array}{lllll}4 & -44.369 & 99.0 & 13.37 & 0.001\end{array}$

Models ranked by $\operatorname{AICc}(x)$ 
(d)

Global model call: $\operatorname{lm}($ formula = Glu2 Treatment + Mass + Length, na.action = "na.fail") - -

Model selection table

\begin{tabular}{|c|c|c|c|c|c|c|c|c|}
\hline Intrc) & Lngth & Mass & Trtmn & $d f$ & logLik & $\mathrm{AICC}$ & delta & weight \\
\hline 2.827 & & & + & 3 & -29.008 & 65.3 & 0.00 & 0.456 \\
\hline 5.123 & -0.006786 & & + & 4 & -28.497 & 67.3 & 2.00 & 0.168 \\
\hline 3.385 & & -0.0010470 & + & 4 & -28.641 & 7.6 & 2.28 & 0.146 \\
\hline 3.323 & & & & 2 & -31.895 & 68.4 & 3.07 & 0.098 \\
\hline 6.112 & -0.008307 & & & 3 & -31.298 & 69.9 & 4.58 & 0.046 \\
\hline 6.942 & -0.014450 & 0.0014570 & + & 5 & -28.432 & 70.6 & 5.26 & 0.033 \\
\hline 3.809 & & -0.0008995 & & 3 & -31.687 & 70.7 & 5.36 & 0.031 \\
\hline 12.170 & -0.034430 & 0.0050250 & & 4 & -30.559 & 71.5 & 6.12 & 0.021 \\
\hline
\end{tabular}

Models ranked by $\operatorname{AICC}(x)$

(e)

Global model call: $\operatorname{lm}($ formula = Lac1 Treatment + Mass + Length, na.action = "na.fail") - - -

Model selection table

(Intrc) Lngth Mass Trtmn df logLik AICc delta weight

$7-0.6896$

0.002276

$+4-33.523$

$\begin{array}{lll}77.0 & 0.00 & 0.382\end{array}$

50.4846

$+\quad 3-35.22877 .60 .550 .289$

$\begin{array}{lll}6 & -2.9380 & 0.01026\end{array}$

$+4-34.05178 .11 .060 .225$

$\begin{array}{lllll}8 & 3.2000 & -0.01608 & 0.005137\end{array}$

$\begin{array}{llll}4 & 13.8600 & -0.05825 & 0.013730\end{array}$

$+\quad 5-33.24179 .62 .60 \quad 0.104$

$\begin{array}{lll}3 & -0.1607 & 0.003536\end{array}$

$\begin{array}{lllll}4 & -44.879 & 99.8 & 22.71 & 0.000\end{array}$

11.7480

$\begin{array}{lllll}3 & -46.418 & 100.0 & 22.93 & 0.000\end{array}$

$\begin{array}{lll}2 & -2.4590 & 0.01255\end{array}$

$\begin{array}{lllll}2 & -47.934 & 100.4 & 23.37 & 0.000\end{array}$

Models ranked by $\operatorname{AICc}(x)$

$\begin{array}{lllll}3 & -47.308 & 101.8 & 24.71 & 0.000\end{array}$ 
(f)

Global model call: $\operatorname{lm}($ formula = Lac2 Treatment + Mass + Length, na.action = "na.fail") - - -

Model selection table

(Intrc) Lngth Mass Trtmn df logLik AICc delta weight

$7-1.5580$ 0.003959

$\begin{array}{lllll} & 4-32.51175 .0 & 0.00 & 0.494\end{array}$

$6-6.4550$

0.020800

$+4-32.76275 .5 \quad 0.500 .384$

$8-2.9320$

$0.005682 \quad 0.002948$

$+\quad 5-32.47378 .13 .080 .106$

50.4846

$3-1.2110$

0.004786

$+\quad 3-37.40882 .06 .940 .015$

$\begin{array}{llll}4 & 4.4760 & -0.023630 & 0.008921\end{array}$

$\begin{array}{lllll}3 & -40.148 & 87.4 & 12.42 & 0.001\end{array}$

$2-6.1260 \quad 0.022370$

11.3720

$\begin{array}{llllll}4 & -39.748 & 89.5 & 14.47 & 0.000\end{array}$

$\begin{array}{llllll}3 & -41.348 & 89.8 & 14.82 & 0.000\end{array}$

$\begin{array}{lllll}2 & -44.265 & 93.1 & 18.05 & 0.000\end{array}$

Models ranked by $\operatorname{AICC}(x)$

(g)

Global model call: $1 \mathrm{~m}($ formula $=0 \mathrm{sm1} \sim$ Treatment + Mass + Length, na.action = "na.fail")

- - -

Model selection table

(Intrc) Lngth Mass Trtmn df logLik AICc delta weight

1308.9

$4 \quad 473.5-0.68510 \quad 0.1205000$

305.4

$\begin{array}{lll}331.7 & -0.06817\end{array}$

308.5

$327.7-0.06696$

$455.1-0.61340 \quad 0.1066000$

306.3

$-0.0017540$

$\begin{array}{lllll}2 & -99.198 & 203.0 & 0.00 & 0.301 \\ 4 & -96.877 & 203.9 & 0.89 & 0.193 \\ 3 & -98.382 & 204.0 & 1.00 & 0.183 \\ 3 & -98.999 & 205.2 & 2.23 & 0.099 \\ 3 & -99.197 & 205.6 & 2.63 & 0.081 \\ 4 & -98.176 & 206.5 & 3.49 & 0.053 \\ 5 & -96.642 & 206.6 & 3.65 & 0.049 \\ 4 & -98.378 & 206.9 & 3.89 & 0.043\end{array}$

Models ranked by $\operatorname{AICC}(x)$ 
(h)

Global model call: $1 \mathrm{~m}($ formula $=0 \mathrm{sm} 2$ Treatment + Mass + Length, na.action = "na.fail")

Model selection table

\begin{tabular}{|c|c|c|c|c|c|c|c|c|}
\hline C) & Lngth & Mass & Trtmn & $d f$ & logLik & $\mathrm{AICC}$ & delta & weight \\
\hline 303.0 & & & & 2 & -99.717 & 204.0 & 0.00 & 0.370 \\
\hline 338.5 & -0.1065 & & & 3 & -99.247 & 205.7 & 1.69 & 0.159 \\
\hline 305.4 & & & + & 3 & -99.369 & 205.9 & 1.93 & \\
\hline 308.6 & & -0.010540 & & 3 & -99 & 206.4 & 2.36 & \\
\hline 428.1 & -0.4963 & 0.076140 & & 4 & -98 & 207.0 & 3.02 & \\
\hline 341.2 & -0.1073 & & + & 7 & -98. & 207.9 & 3.85 & \\
\hline 468.5 & -0.6535 & - & + & 5 & -97.437 & 208.2 & 4.20 & \\
\hline 310.0 & & -0.008894 & + & 4 & -99.272 & 208.7 & 4.65 & 0. \\
\hline
\end{tabular}

Models ranked by $\operatorname{AICc}(x)$

(i)

Global model call: $\operatorname{lm}($ formula $=$ Hae1 Treatment + Mass + Length, na.action = "na.fail") - - -

Model selection table

(Intrc) Lngth Mass Trtmn df logLik AICc delta weight

50.2068

$\begin{array}{lllll}+ & 341.513 & -75.8 & 0.00 & 0.333\end{array}$

$\begin{array}{lllll}2 & 39.263 & -73.9 & 1.84 & 0.133\end{array}$

$\begin{array}{lllll}4 & 42.009 & -73.8 & 1.97 & 0.124\end{array}$

$\begin{array}{lllll}4 & 0.6047 & -0.0017430 & 3.804 \mathrm{e}-04\end{array}$

$\begin{array}{lll}0.1805 & 5.332 \mathrm{e}-05\end{array}$

$0.1842 \quad 7.895 \mathrm{e}-05$

$+\quad 441.981-73.7 \quad 2.020 .121$

$\begin{array}{lll}0.1637 & 0.0001308\end{array}$

$\begin{array}{lllll}3 & 40.174 & -73.1 & 2.68 & 0.087\end{array}$

$0.5098-0.00136202 .945 e-04$

$2 \quad 0.1541 \quad 0.0002160$

$+441.610-73.02 .770 .083$

$+543.154-72.82 .990 .075$

Models ranked by $\operatorname{AICc}(x)$

$\begin{array}{lllll}3 & 39.485 & -71.7 & 4.06 & 0.044\end{array}$ 
(j)

Global model call: $\operatorname{lm}($ formula $=$ Hae2 Treatment + Mass + Length, na.action = "na.fail") -- Model selection table

(Intrc) Lngth

50.20680

$60.119402 .653 e-04$

70.18680

10.22500

30.19040

$20.11070 \quad 3.433 e-04$

$80.043975 .906 e-04-6.419 e-05$ $4 \quad 0.17360 \quad 6.948 e-05 \quad 5.317 e-05$ Models ranked by $\operatorname{AICC}(x)$
Mass Trtmn df logLik AICc delta weight

$+\quad 344.717-82.20 .00 \quad 0.412$

$+\quad 445.254-80.31 .890 .160$

$+\quad 445.071-79.92 .250 .134$

$\begin{array}{lllll}2 & 42.109 & -79.6 & 2.55 & 0.115\end{array}$

$\begin{array}{lllll}3 & 42.901 & -78.5 & 3.63 & 0.067\end{array}$

$\begin{array}{lllll}3 & 42.845 & -78.4 & 3.74 & 0.063\end{array}$

$+\quad 545.348-77.25 .00 \quad 0.034$

$\begin{array}{lllll}4 & 42.904 & -75.6 & 6.58 & 0.015\end{array}$ 
Table S7. Model selection outputs for haematological responses of E vs. HC fish, showing models for (a) plasma cortisol, (b) blood glucose, (c) blood lactate, (d) plasma osmolality, and (e) haematocrit.

(a)

\begin{tabular}{|c|c|c|c|c|c|c|c|c|c|c|c|}
\hline \multicolumn{12}{|c|}{ lodel selection table } \\
\hline & (Int) & Lng & Mss & Tim & Trt & Tim:Trt & $d f$ & logLik & AICC & delta & weight \\
\hline 29 & 72.60 & & & + & + & + & 6 & -248.818 & 511.6 & 0.00 & 0.696 \\
\hline 30 & 38.31 & 0.10440 & & + & + & + & 7 & -248.767 & 514.3 & 2.63 & 0.187 \\
\hline 13 & 75.37 & & & + & + & & 5 & -253.020 & 517.4 & 5.80 & 0.038 \\
\hline 31 & 68.82 & & 0.0075270 & + & + & + & 7 & -250.498 & 517.7 & 6.09 & 0.033 \\
\hline 32 & -78.32 & 0.60760 & -0.0972100 & + & + & + & 8 & -249.228 & 518.1 & 6.42 & 0.028 \\
\hline 14 & 40.35 & 0.10660 & & + & + & & 6 & -252.971 & 519.9 & 8.31 & 0.011 \\
\hline 15 & 71.69 & & 0.0073710 & + & + & & 6 & -254.703 & 523.4 & 11.77 & 0.002 \\
\hline 5 & 83.26 & & & + & & & 4 & -257.290 & 523.5 & 11.85 & 0.002 \\
\hline 16 & -82.16 & 0.63480 & -0.1020000 & + & + & & 7 & -253.426 & 523.6 & 11.95 & 0.002 \\
\hline 9 & 86.84 & & & & + & & 4 & -258.256 & 525.4 & 13.79 & 0.001 \\
\hline 6 & 31.90 & 0.15450 & & + & & & 5 & -257.218 & 525.8 & 14.20 & 0.001 \\
\hline 10 & 61.31 & 0.07779 & & & + & & 5 & -258.214 & 527.8 & 16.19 & 0.000 \\
\hline 7 & 72.39 & & 0.0204500 & + & & & 5 & -258.970 & 529.3 & 17.70 & 0.000 \\
\hline 8 & -31.24 & 0.42800 & -0.0522600 & + & & & 6 & -257.785 & 529.6 & 17.93 & 0.000 \\
\hline 12 & -86.87 & 0.71580 & -0.1231000 & & + & & 6 & -258.618 & 531.2 & 19.60 & 0.000 \\
\hline 11 & 86.74 & & 0.0001815 & & + & & 5 & -259.936 & 531.3 & 19.63 & 0.000 \\
\hline 1 & 94.35 & & & & & & 3 & -262.503 & 531.5 & 19.90 & 0.000 \\
\hline 2 & 52.93 & 0.12480 & & & & & 4 & -262.450 & 533.8 & 22.17 & 0.000 \\
\hline 3 & 87.40 & & 0.0131400 & & & & 4 & -264.200 & 537.3 & 25.67 & 0.000 \\
\hline 4 & -35.88 & 0.50880 & -0.0732400 & & & & 5 & -262.982 & 537.4 & 25.72 & 0.000 \\
\hline
\end{tabular}


(b)

Global model call: lmer(formula = Glu Treatment * Time + Mass + Length + (1 I Fish), na.action = "na.fail")

Model selection table

(Int) Lng

ng

Mss Tim Trt Tim:Trt df logLik AICc delta weight

54.565

134.446

294.321

14.220

94.098

$67.538-8.942 \mathrm{e}-03$

$147.692-9.867 e-03$

$307.669-1.018 \mathrm{e}-02$

$7 \quad 5.466$

$15 \quad 5.449$

$26.969-8.276 \mathrm{e}-03$

$-0.001700$

$-0.002009$

315.341

$107.117-9.181 \mathrm{e}-03$

$3 \quad 5.038$

$-0.002045$

115.020

$-0.001550$

$+$

$+\quad+$

$++$

$8 \quad 5.481-6.784 \mathrm{e}-05-0.001687$

$164.245 \quad 4.951 \mathrm{e}-03-0.002860$

$324.415 \quad 3.808 \mathrm{e}-03-0.002699$

$4 \quad 5.322-1.175 e-03-0.001349$

$\begin{array}{llll}12 & 4.100 & 3.779 e-03 & -0.002499\end{array}$

Models ranked by $\operatorname{AICc}(x)$ $\begin{array}{lllll}4 & -82.752 & 174.4 & 0.00 & 0.530\end{array}$

$\begin{array}{lllll}5 & -82.329 & 176.0 & 1.63 & 0.234\end{array}$

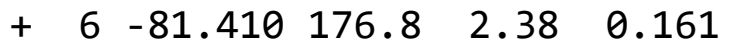

$\begin{array}{lllll}3 & -86.468 & 179.5 & 5.07 & 0.042\end{array}$

$\begin{array}{lllll}4 & -86.035 & 181.0 & 6.57 & 0.020\end{array}$

$\begin{array}{lllll}5 & -86.026 & 183.4 & 9.02 & 0.006\end{array}$

$\begin{array}{lllll}6 & -85.522 & 185.0 & 10.60 & 0.003\end{array}$

$+\quad 7-84.575185 .811 .420 .002$

$\begin{array}{llllll}5 & -87.700 & 186.8 & 12.37 & 0.001\end{array}$

$\begin{array}{lllll}6 & -87.120 & 188.2 & 13.80 & 0.001\end{array}$

$\begin{array}{llllll}4 & -89.791 & 188.5 & 14.08 & 0.000\end{array}$

$+\quad 7-86.182189 .014 .640 .000$

$\begin{array}{lllll}5 & -89.281 & 189.9 & 15.53 & 0.000\end{array}$

$\begin{array}{lllll}4 & -91.482 & 191.9 & 17.46 & 0.000\end{array}$

$\begin{array}{lllll}5 & -90.904 & 193.2 & 18.78 & 0.000\end{array}$

$\begin{array}{lllll}6 & -90.228 & 194.4 & 20.02 & 0.000\end{array}$

$\begin{array}{lllll}7 & -89.602 & 195.9 & 21.48 & 0.000\end{array}$

$+\quad 8-88.667196 .822 .450 .000$

$\begin{array}{lllll}5 & -94.000 & 199.4 & 24.97 & 0.000\end{array}$

$\begin{array}{lllll}6 & -93.380 & 200.7 & 26.32 & 0.000\end{array}$ 
(c)

Global model call: Imer(formula = Lac $~$ Treatment * Time + Mass + Length + (1 | Fish), na.action = "na.fail")

Model selection table

$$
\text { (Int) Lng }
$$

53.08500

$13 \quad 3.06500$

293.05700

12.70200

92.68200

60.30230

140.28990

$7 \quad 2.02500$

$30 \quad 0.28220$

152.02800

$2-0.08040$

312.02000

$10-0.09281$

86.75900

31.64200

111.64500

$\begin{array}{llll}16 & 7.26200 & -0.02154 & 0.005786\end{array}$

$\begin{array}{lllll}32 & 7.25400 & -0.02154 & 0.005786\end{array}$

$\begin{array}{lllll}4 & 6.37700 & -0.01949 & 0.005298\end{array}$

$12 \quad 6.87900-0.02154 \quad 0.005786$

Models ranked by $\operatorname{AICc}(x)$

Mss Tim Trt Tim:Trt df logLik AICc delta weight

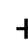

$+$

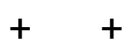

$++$

0.00837

0.00844

0.00844

0.00837

0.00844

0.002080

0.005298

0.002002

0.002080

$+\quad+$

$+\quad+$

$+$ $\begin{array}{lllll}4 & -86.376 & 181.6 & 0.00 & 0.612\end{array}$

$\begin{array}{lllll}5 & -85.969 & 183.2 & 1.64 & 0.270\end{array}$

$+\quad 6-85.892185 .7 \quad 4.050 .081$

$\begin{array}{lllll}3 & -91.186 & 188.9 & 7.27 & 0.016\end{array}$

$\begin{array}{lllll}4 & -90.779 & 190.4 & 8.80 & 0.008\end{array}$

$\begin{array}{lllll}5 & -89.656 & 190.6 & 9.01 & 0.007\end{array}$

$\begin{array}{lllll}6 & -89.229 & 192.3 & 10.72 & 0.003\end{array}$

$\begin{array}{lllll}5 & -91.170 & 193.6 & 12.04 & 0.001\end{array}$

$+\quad 7-89.152194 .813 .240 .001$

$\begin{array}{lllll}6 & -90.724 & 195.3 & 13.71 & 0.001\end{array}$

$\begin{array}{lllll}4 & -94.466 & 197.8 & 16.18 & 0.000\end{array}$

$+\quad 7-90.647197 .816 .230 .000$

$\begin{array}{lllll}5 & -94.038 & 199.4 & 17.78 & 0.000\end{array}$

$\begin{array}{lllll}6 & -93.453 & 200.8 & 19.17 & 0.000\end{array}$

$\begin{array}{lllll}4 & -95.980 & 200.8 & 19.21 & 0.000\end{array}$

$\begin{array}{lllll}5 & -95.533 & 202.4 & 20.77 & 0.000\end{array}$

$\begin{array}{llllll}7 & -92.945 & 202.4 & 20.83 & 0.000\end{array}$

$+\quad 8-92.867205 .123 .480 .000$

$\begin{array}{lllll}5 & -98.262 & 207.8 & 26.22 & 0.000\end{array}$

$\begin{array}{lllll}6 & -97.754 & 209.4 & 27.77 & 0.000\end{array}$ 
(d)

Global model call: Imer(formula = Osm Treatment * Time + Mass + Length + (1 | Fish), na.action = "na.fail")

Model selection table

(Int) Lng Mss Tim Trt Tim:Trt df logLik AICc delta weight

29321.0

$13 \quad 319.1$

$30324.0-0.009112$

$5 \quad 317.4$

31318.6

$14321.5-0.007302$

$32391.3-0.299200 \quad 0.055870$

$6 \quad 322.4-0.015260$

15316.3

0.005583

$16 \quad 393.3-0.316200 \quad 0.059470$

$7 \quad 315.9$

0.002836

$+6-182.782379 .6 \quad 0.00 \quad 0.821$

$\begin{array}{lllll}5 & -186.404 & 384.2 & 4.62 & 0.081\end{array}$

$8 \quad 377.5 \quad-0.253500 \quad 0.045440$

$+\quad 7-184.058384 .95 .30 \quad 0.058$ $\begin{array}{lllll}4 & -189.263 & 387.5 & 7.84 & 0.016\end{array}$

9310.2

1308.6

$10 \quad 312.2-0.005916$

$2 \quad 313.4-0.014430$

11306.5

$\begin{array}{llllll}7 & -185.741 & 388.3 & 8.67 & 0.011\end{array}$

$\begin{array}{llllll}6 & -187.680 & 389.4 & 9.80 & 0.006\end{array}$

$+\quad 8-185.519390 .711 .120 .003$

$\begin{array}{llllll}5 & -190.549 & 392.5 & 12.91 & 0.001\end{array}$

$\begin{array}{lllll}6 & -189.353 & 392.8 & 13.14 & 0.001\end{array}$

$\begin{array}{llllll}7 & -189.084 & 395.0 & 15.36 & 0.000\end{array}$

$\begin{array}{llllll}5 & -192.269 & 396.0 & 16.35 & 0.000\end{array}$

$\begin{array}{llllll}6 & -192.174 & 398.4 & 18.79 & 0.000\end{array}$

$\begin{array}{lllll}4 & -199.458 & 407.8 & 28.23 & 0.000\end{array}$

$\begin{array}{lllll}3 & -202.295 & 411.1 & 31.52 & 0.000\end{array}$

$\begin{array}{lllll}5 & -200.715 & 412.9 & 33.25 & 0.000\end{array}$

$\begin{array}{lllll}4 & -203.566 & 416.1 & 36.45 & 0.000\end{array}$

$\begin{array}{llllll}5 & -202.359 & 416.1 & 36.53 & 0.000\end{array}$

$12404.9-0.404700 \quad 0.076570$

$\begin{array}{llllll}6 & -201.812 & 417.7 & 38.06 & 0.000\end{array}$

$\begin{array}{lllll}4 & -205.267 & 419.5 & 39.85 & 0.000\end{array}$

$\begin{array}{llll}3 & 306.1 & & 0.004769 \\ 4 & 389.7 & -0.344200 & 0.062680\end{array}$

$\begin{array}{lllll}5 & -204.914 & 421.3 & 41.64 & 0.000\end{array}$

Models ranked by $\operatorname{AICc}(x)$ 
(e)

Global model call: $\operatorname{lm}($ formula $=$ Hae $\sim$ Treatment $*$ Time + Mass + Length, na.action $=$ "na.fail")

Model selection table

\section{(Int) Lng}

50.2519

290.2593

10.2396

$7 \quad 0.2373$

$13 \quad 0.2487$

60.2300

310.2486

$30 \quad 0.2464$

$8 \quad 0.3969-6.505 \mathrm{e}-04$

30.2241

90.2366

20.2141

150.2369

140.2322

320.3996

$4 \quad 0.3815$

110.2238

160.3880

100.2160

$120.3747-6.146 \mathrm{e}-04 \quad 1.290 \mathrm{e}-04$

Models ranked by $\operatorname{AICC}(x)$
Mss Tim Trt Tim:Trt df logLik AICc delta weight

$\begin{array}{lllll}3 & 85.614 & -164.7 & 0.00 & 0.218\end{array}$

$+\quad 587.600-163.80 .890 .140$

$\begin{array}{lllll}2 & 83.554 & -162.8 & 1.85 & 0.087\end{array}$

$\begin{array}{lllll}4 & 85.815 & -162.7 & 1.97 & 0.081\end{array}$

$\begin{array}{lllll}4 & 85.766 & -162.6 & 2.07 & 0.077\end{array}$

$\begin{array}{lllll}4 & 85.650 & -162.4 & 2.30 & 0.069\end{array}$

$+\quad 687.725-161.43 .250 .043$

$+\quad 687.614-161.23 .470 .038$

$\begin{array}{lllll}5 & 86.254 & -161.1 & 3.58 & 0.036\end{array}$

$\begin{array}{lllll}3 & 83.765 & -161.0 & 3.70 & 0.034\end{array}$

$\begin{array}{lllll}3 & 83.673 & -160.8 & 3.88 & 0.031\end{array}$

$\begin{array}{lllll}3 & 83.599 & -160.7 & 4.03 & 0.029\end{array}$

$\begin{array}{lllll}5 & 85.905 & -160.4 & 4.28 & 0.026\end{array}$

$\begin{array}{lllll}5 & 85.786 & -160.2 & 4.52 & 0.023\end{array}$

$+\quad 788.125-159.5 \quad 5.180 .016$

$\begin{array}{lllll}4 & 84.158 & -159.4 & 5.29 & 0.015\end{array}$

$\begin{array}{lllll}4 & 83.829 & -158.7 & 5.95 & 0.011\end{array}$

$\begin{array}{lllll}6 & 86.277 & -158.6 & 6.14 & 0.010\end{array}$

$\begin{array}{lllll}4 & 83.703 & -158.5 & 6.20 & 0.010\end{array}$

$\begin{array}{lllll}5 & 84.170 & -156.9 & 7.75 & 0.005\end{array}$ 
Table S8. Model selection outputs for haematological responses of SE vs. E fish, showing models for (a) plasma cortisol, (b) blood glucose, (c) blood lactate, (d) plasma osmolality, and (e) haematocrit.

(a)

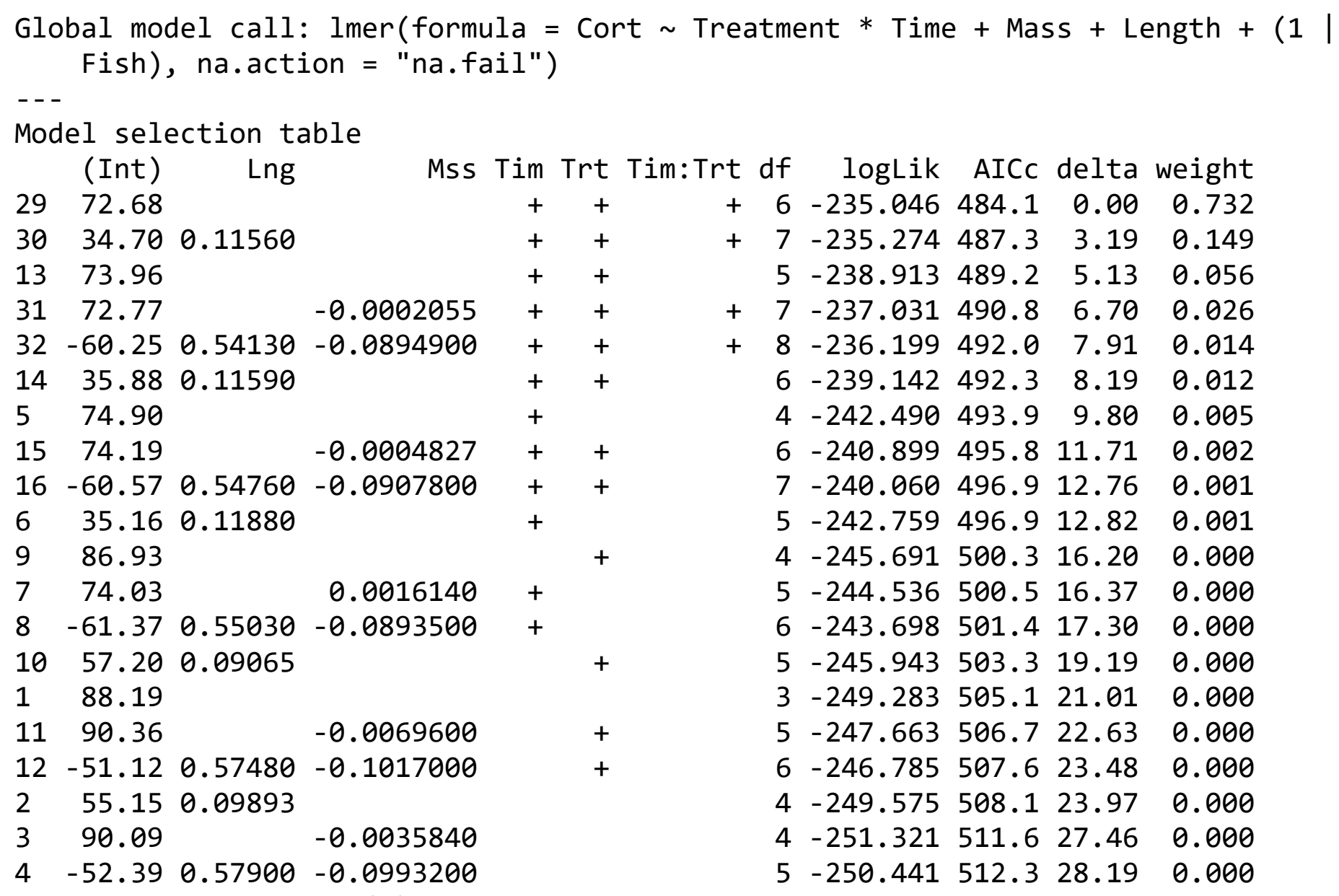


(b)

Global model call: lmer(formula = Glu Treatment * Time + Mass + Length + (1 | Fish), na.action = "na.fail")

Model selection table

(Int) Lng

54.281

134.319

14.063

94.100

294.321

$6 \quad 8.880-0.013770$

$28.812-0.014210$

$148.979-0.014180$

$7 \quad 5.752$

$108.923-0.014670$

35.561

$15 \quad 5.761$

$308.989-0.014200$

115.573

315.771

$8 \quad 6.253-0.002031$

$4 \quad 6.307-0.003020-0.002321$

$\begin{array}{lllll}16 & 6.250 & -0.001982 & -0.002575\end{array}$

$\begin{array}{lllll}12 & 6.306 & -0.002972 & -0.002471\end{array}$

$\begin{array}{llll}32 & 6.253 & -0.001955 & -0.002585\end{array}$

Models ranked by $\operatorname{AICc}(x)$
Mss Tim Trt Tim:Trt df logLik AICc delta weight

$\begin{array}{lllll}4 & -69.253 & 147.4 & 0.00 & 0.544\end{array}$

$\begin{array}{lllll}5 & -69.186 & 149.7 & 2.34 & 0.169\end{array}$

$\begin{array}{lllll}3 & -71.652 & 149.8 & 2.43 & 0.161\end{array}$

$\begin{array}{lllll}4 & -71.576 & 152.0 & 4.65 & 0.053\end{array}$

$+\quad 6-69.301152 .65 .160 .041$

$\begin{array}{lllll}5 & -71.698 & 154.8 & 7.37 & 0.014\end{array}$

$\begin{array}{lllll}4 & -74.022 & 156.9 & 9.54 & 0.005\end{array}$

$\begin{array}{lllll}6 & -71.637 & 157.2 & 9.83 & 0.004\end{array}$

$\begin{array}{lllll}5 & -73.104 & 157.6 & 10.18 & 0.003\end{array}$

$\begin{array}{llllll}5 & -73.947 & 159.3 & 11.86 & 0.001\end{array}$

$\begin{array}{lllll}4 & -75.466 & 159.8 & 12.43 & 0.001\end{array}$

$\begin{array}{llllll}6 & -73.016 & 160.0 & 12.59 & 0.001\end{array}$

$+\quad 7-71.750160 .212 .770 .001$

$\begin{array}{llllll}5 & -75.362 & 162.1 & 14.69 & 0.000\end{array}$

$+\quad 7-73.127162 .915 .530 .000$

$\begin{array}{lllll}6 & -76.230 & 166.4 & 19.02 & 0.000\end{array}$

$\begin{array}{lllll}5 & -78.575 & 168.5 & 21.12 & 0.000\end{array}$

$\begin{array}{lllll}7 & -76.124 & 168.9 & 21.52 & 0.000\end{array}$

$\begin{array}{llllll}6 & -78.454 & 170.9 & 23.47 & 0.000\end{array}$

$+8-76.235172 .024 .590 .000$ 
(c)

Global model call: Imer(formula = Lac $~$ Treatment * Time + Mass + Length + (1 | Fish), na.action = "na.fail")

Model selection table

(Int) Lng Mss Tim Trt Tim:Trt df logLik AICc delta weight

53.458

133.136

293.057

13.004

92.682

$146.953-0.011610$

$6 \quad 6.084-0.007860$

$30 \quad 6.874-0.011610$

154.513

$7 \quad 4.470$

$-0.002761$

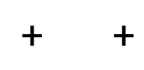

$+\quad+$

$\begin{array}{llll}4 & -96.501 & 201.9 & 0.00\end{array}$

$\begin{array}{llll}5 & -95.435 & 202.2 & 0.32\end{array}$

0.411

314.434

$106.499-0.011610$

$-0.001906$

$-0.002761$

$+$

$\begin{array}{llllll}6 & -94.870 & 203.6 & 1.75 & 0.171\end{array}$

$\begin{array}{lllll}3 & -100.369 & 207.2 & 5.38 & 0.028\end{array}$

$2 \quad 5.630-0.007860$

114.059

34.016

$16 \quad 2.831$

$8 \quad 2.892$

$32 \quad 2.752$

$12 \quad 2.377$

0.006822

$-0.002761$

$-0.001906$

$-0.003887$

$0.006401-0.002960$

$0.006822-0.003887$

$0.006822-0.003887$

$\begin{array}{lllll}4 & 2.439 & 0.006401 & -0.002960\end{array}$

$\begin{array}{lllll}4 & -99.303 & 207.5 & 5.60 & 0.025\end{array}$

$\begin{array}{lllll}6 & -98.460 & 210.8 & 8.93 & 0.005\end{array}$

$\begin{array}{lllll}5 & -99.754 & 210.8 & 8.96 & 0.005\end{array}$

$+\quad+$

$+\quad+$

$+\quad+$

$+7-97.895212 .310 .480 .002$

$\begin{array}{lllll}6 & -99.888 & 213.6 & 11.79 & 0.001\end{array}$

$\begin{array}{llll}5 & -101.307 & 213.9 & 12.06\end{array}$

$+7-99.323215 .213 .34$

0.001

$\begin{array}{lllll}5 & -102.328 & 216.0 & 14.11 & 0.000\end{array}$

$\begin{array}{lllll}4 & -103.622 & 216.1 & 14.24 & 0.000\end{array}$

$\begin{array}{llllll}5 & -103.756 & 218.8 & 16.96 & 0.000\end{array}$

$\begin{array}{lllll}4 & -105.175 & 219.2 & 17.35 & 0.000\end{array}$

$\begin{array}{lllll}7 & -102.518 & 221.6 & 19.73 & 0.000\end{array}$

$\begin{array}{llllll}6 & -103.924 & 221.7 & 19.86 & 0.000\end{array}$

$+\quad 8-101.953223 .321 .400 .000$

$\begin{array}{lllll}6 & -106.386 & 226.6 & 24.78 & 0.000\end{array}$

$\begin{array}{lllll}5 & -107.792 & 226.9 & 25.03 & 0.000\end{array}$

Models ranked by $\operatorname{AICc}(x)$ 
(d)

Global model call: 1 mer(formula $=$ 0sm Treatment $*$ Time + Mass $+(1 \mid$ Fish $)$, na.action $=$ "na.fail")

Model selection table

(Int) Mss Tim Trt Tim:Trt df logLik AICc delta weight

$15320.8++\quad+\quad 6-189.545393 .10 .00 \quad 0.963$

$\begin{array}{lllllll}7316.8+5 & +194.877 & 401.2 & 8.06 & 0.017\end{array}$

$16313.20 .01522++\quad+7-192.285401 .38 .210 .016$

$\begin{array}{llllllll}3 & 315.4 & + & -197.572 & 404.1 & 10.96 & 0.004\end{array}$

$8309.00 .01580++\quad 6-197.589409 .216 .090 .000$

$4309.40 .01123+5 \quad 5-200.502412 .419 .310 .000$

$5310.1+$

1308.5

$6301.20 .01809+$

$2 \quad 301.60 .01303$

$\begin{array}{lllll}4 & -201.971 & 412.9 & 19.76 & 0.000\end{array}$

$\begin{array}{lllll}3 & -204.701 & 415.9 & 22.84 & 0.000\end{array}$

$\begin{array}{lllll}5 & -204.565 & 420.5 & 27.43 & 0.000\end{array}$

Models ranked by $\operatorname{AICC}(x)$

$\begin{array}{lllll}4 & -207.553 & 424.0 & 30.92 & 0.000\end{array}$ 
(e)

Global model call: lmer (formula = Hae $~$ Treatment $*$ Time + Mass + Length + $(1$ | Fish), na.action = "na.fail")

Model selection table

(Int) Lng

10.2236

$5 \quad 0.2367$

90.2363

130.2489

$20.4408-0.0006449$

290.2593

$3 \quad 0.2887$

$6 \quad 0.4597-0.0006613$

$10 \quad 0.4104-0.0005261$

$\begin{array}{ll}7 & 0.3037\end{array}$

110.2847

$140.4309-0.0005492$

150.2999

$30 \quad 0.4489-0.0005713$

$4 \quad 0.3643-0.0003012$

310.3128

$8 \quad 0.3809-0.0003071$

$-1.046 e-04$

$.417 \mathrm{e}-05$

$\begin{array}{lllll}12 & 0.3625 & -0.0003097 & -4.669 e-05\end{array}$

$160.3791-0.0003152-5.049 e-05$

$320.3934-0.0003205-5.411 \mathrm{e}-05$

Models ranked by $\operatorname{AICc}(x)$
Mss Tim Trt Tim:Trt df logLik AICc delta weight

$\begin{array}{lllll}3 & 72.307 & -138.1 & 0.00 & 0.839\end{array}$

$\begin{array}{lllll}4 & 71.460 & -134.0 & 4.09 & 0.109\end{array}$

$\begin{array}{lllll}4 & 70.565 & -132.2 & 5.88 & 0.044\end{array}$

$\begin{array}{lllll}5 & 69.619 & -127.8 & 10.28 & 0.005\end{array}$

$\begin{array}{lllll}4 & 67.084 & -125.2 & 12.84 & 0.001\end{array}$

$+\quad 669.111-124.113 .930 .001$

$\begin{array}{lllll}4 & 65.456 & -122.0 & 16.10 & 0.000\end{array}$

$\begin{array}{lllll}5 & 66.328 & -121.2 & 16.86 & 0.000\end{array}$

$\begin{array}{lllll}5 & 64.713 & -118.0 & 20.09 & 0.000\end{array}$

$\begin{array}{lllll}5 & 64.707 & -118.0 & 20.11 & 0.000\end{array}$

$\begin{array}{lllll}5 & 62.983 & -114.5 & 23.55 & 0.000\end{array}$

$\begin{array}{lllll}6 & 63.869 & -113.6 & 24.42 & 0.000\end{array}$

$\begin{array}{lllll}6 & 62.149 & -110.2 & 27.86 & 0.000\end{array}$

$+763.457-110.028 .010 .000$

$\begin{array}{lllll}5 & 59.151 & -106.8 & 31.22 & 0.000\end{array}$

$+761.745-106.631 .440 .000$

$\begin{array}{lllll}6 & 58.407 & -102.7 & 35.34 & 0.000\end{array}$

$\begin{array}{lllll}6 & 56.674 & -99.2 & 38.81 & 0.000\end{array}$

$\begin{array}{lllll}7 & 55.847 & -94.8 & 43.23 & 0.000\end{array}$

$+855.453-91.146 .940 .000$ 
Table S9. Model selection outputs for haematological responses of SEH vs. SE fish, showing models for (a) plasma cortisol, (b) blood glucose, (c) blood lactate, (d) plasma osmolality, and (e) haematocrit.

(a)

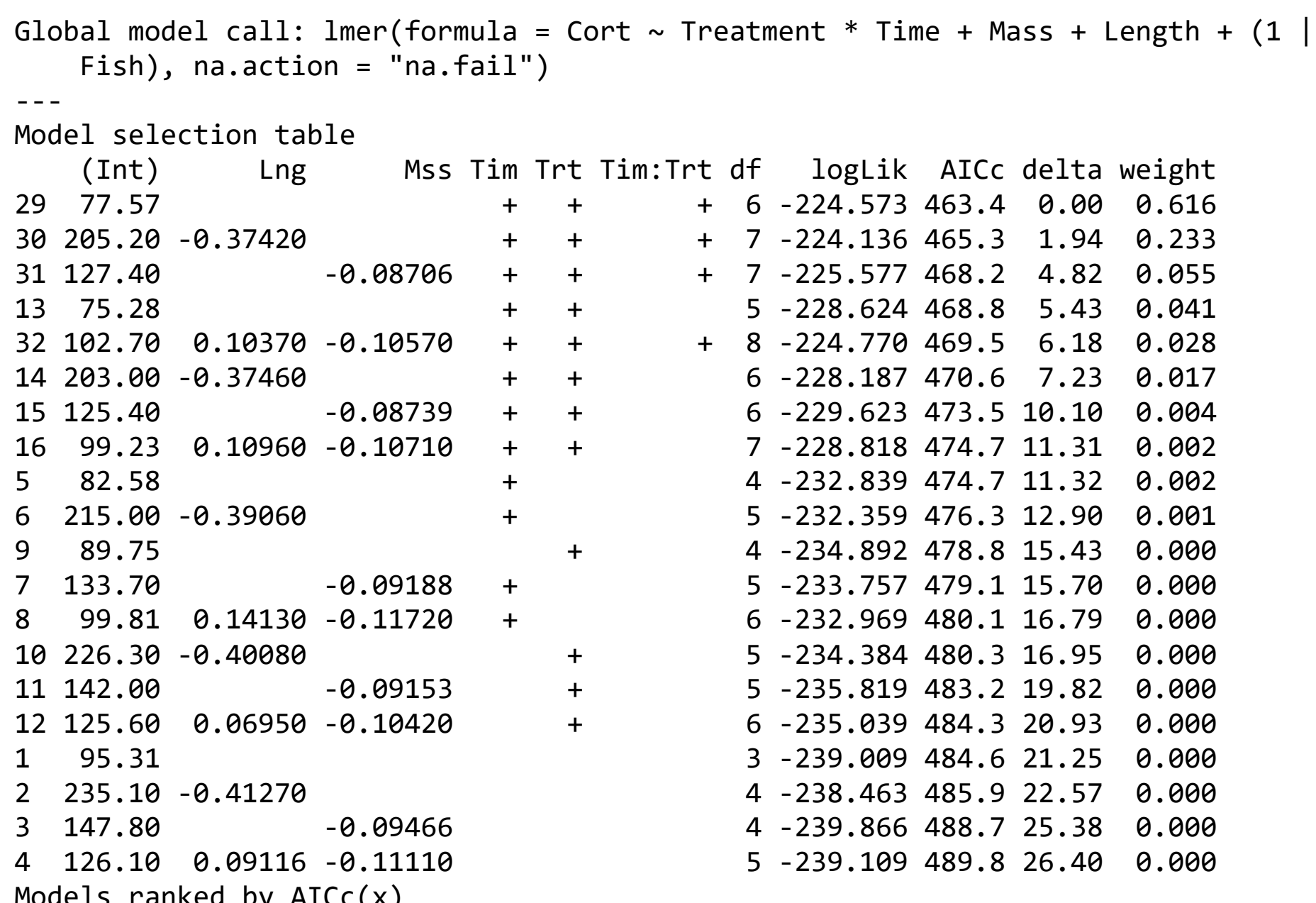


(b)

Global model call: lmer(formula = Glu Treatment * Time + Mass + Length + (1 | Fish), na.action = "na.fail")

Model selection table

(Int) Lng

54.463

14.247

134.230

94.019

$29 \quad 4.233$

$6 \quad 3.908 \quad 0.001637$

$2 \quad 3.8140 .001278$

$14 \quad 3.480 \quad 0.002200$

$10 \quad 3.396 \quad 0.001831$

$7 \quad 4.863 \quad-0.0007213$

$34.686 \quad-0.0007900$

$\begin{array}{llll}30 & 3.478 & 0.002221\end{array}$

$15 \quad 4.541$

$11 \quad 4.374$

314.542

$\begin{array}{lll}8 & -1.229 & 0.025350\end{array}$

$\begin{array}{lllll}4 & -1.345 & 0.025090 & -0.0052360\end{array}$

$\begin{array}{lllll}16 & -1.216 & 0.024090 & -0.0048330\end{array}$

$\begin{array}{lllll}12 & -1.335 & 0.023890 & -0.0048690\end{array}$

$\begin{array}{llll}32 & -1.216 & 0.024100 & -0.0048310\end{array}$

Models ranked by $\operatorname{AICc}(x)$

Mss Tim Trt Tim:Trt df logLik AICc delta weight

$+$

$+\quad+$

$+$

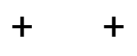

$+$

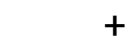

$+$

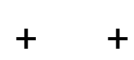

$+\quad+$

$+$

$+$

$+\quad+$

$+$

$+\quad+$ $\begin{array}{lllll}4 & -68.107 & 145.2 & 0.00 & 0.382\end{array}$

$\begin{array}{lllll}3 & -69.850 & 146.3 & 1.09 & 0.221\end{array}$

$\begin{array}{lllll}5 & -67.451 & 146.4 & 1.20 & 0.210\end{array}$

$\begin{array}{lllll}4 & -69.226 & 147.4 & 2.24 & 0.125\end{array}$

$\begin{array}{lllll}6 & -67.460 & 149.0 & 3.85 & 0.056\end{array}$

$\begin{array}{lllll}5 & -71.976 & 155.4 & 10.25 & 0.002\end{array}$

$\begin{array}{lllll}4 & -73.722 & 156.4 & 11.23 & 0.001\end{array}$

$\begin{array}{lllll}6 & -71.303 & 156.7 & 11.54 & 0.001\end{array}$

$\begin{array}{lllll}5 & -73.083 & 157.6 & 12.46 & 0.001\end{array}$

$\begin{array}{lllll}5 & -73.519 & 158.5 & 13.34 & 0.000\end{array}$

$\begin{array}{lllll}4 & -75.239 & 159.4 & 14.26 & 0.000\end{array}$

$+\quad 7-71.311159 .514 .330 .000$

$\begin{array}{lllll}6 & -72.902 & 159.9 & 14.74 & 0.000\end{array}$

$\begin{array}{lllll}5 & -74.655 & 160.8 & 15.61 & 0.000\end{array}$

$+\quad 7-72.911162 .717 .530 .000$

$\begin{array}{lllll}6 & -75.651 & 165.4 & 20.24 & 0.000\end{array}$

$\begin{array}{lllll}5 & -77.393 & 166.2 & 21.08 & 0.000\end{array}$

$\begin{array}{lllll}7 & -75.128 & 167.1 & 21.96 & 0.000\end{array}$

$\begin{array}{lllll}6 & -76.899 & 167.9 & 22.73 & 0.000\end{array}$

$+\quad 8-75.137170 .124 .900 .000$ 
(c)

Global model call: lmer(formula = Lac $~$ Treatment * Time + Mass + Length + (1 | Fish), na.action = "na.fail")

Model selection table

\begin{tabular}{|c|c|c|c|c|c|c|c|c|c|c|}
\hline (Int) & Lng & Mss & Tim & Trt & 1:Trt & $d f$ & $\log L i k$ & AICC & delta & weight \\
\hline 3.7000 & & & + & & & 4 & -92.506 & 193.9 & 0.00 & 0.493 \\
\hline 3.8690 & & & + & + & & 5 & -91.830 & 195.1 & 1.15 & 0.278 \\
\hline 3.9250 & & & + & + & + & 6 & -91.226 & 196.5 & 2.56 & 0.137 \\
\hline 3.2100 & & & & & & 3 & -95.990 & 198.5 & 4.58 & 0.050 \\
\hline 3.3790 & & & & + & & 4 & -95.314 & 199.6 & 5.61 & 0.030 \\
\hline 0.7316 & 0.008766 & & + & & & 5 & -95.731 & 202.9 & 8.95 & 0.006 \\
\hline 0.9936 & 0.008450 & & + & + & & 6 & -95.062 & 204.2 & 10.23 & 0.003 \\
\hline 1.0500 & 0.008450 & & + & + & + & 7 & -94.458 & 205.7 & 11.77 & 0.001 \\
\hline 3.7080 & & $-1.471 e-05$ & + & & & 5 & -97. & 206.6 & 2.69 & .001 \\
\hline 0.2421 & 0.008766 & & & & & 4 & -99.214 & 207.4 & 13.42 & 0.001 \\
\hline 3.9470 & & $-1.382 e-04$ & + & + & & 6 & -96.899 & 207.8 & 13.90 & 0.000 \\
\hline 0.5040 & 0.008450 & & & + & & 5 & -98.545 & 208.5 & 14.58 & 0.000 \\
\hline 4.0040 & & $-1.382 e-04$ & + & + & + & 7 & -96.295 & 209.4 & 15.45 & 0.000 \\
\hline 3.2190 & & $-1.471 e-05$ & & & & 4 & -101.083 & 211.1 & 17.15 & 0.000 \\
\hline-7.3410 & 0.046020 & $-8.189 e-03$ & + & & & 6 & -98.909 & 211.9 & 17.92 & 0.000 \\
\hline 3.4580 & & $-1.382 e-04$ & & + & & 5 & -100.383 & 212.2 & 18.25 & 0.000 \\
\hline-7.3770 & 0.047450 & $-8.600 e-03$ & + & + & & 7 & -98.159 & 213.1 & 19.18 & 0.000 \\
\hline-7.3210 & 0.047450 & $-8.600 e-03$ & + & + & + & 8 & -97.555 & 214.8 & 20.86 & 0.000 \\
\hline-7.8310 & 0.046020 & $-8.189 e-03$ & & & & 5 & -102.393 & 216.2 & 22.27 & 0.000 \\
\hline-7.8670 & 0.047450 & $-8.600 e-03$ & & + & & 6 & -101.643 & 217.3 & 23.39 & 0.000 \\
\hline
\end{tabular}


(d)

Global model call: Imer(formula = Osm Treatment * Time + Mass + Length + (1 | Fish), na.action = "na.fail")

Model selection table

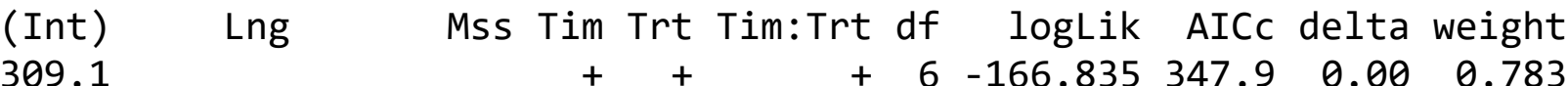

29309.1

13310.9

$\begin{array}{lll}30 & 276.8 & 0.09432\end{array}$

31301.6

$\begin{array}{lll}14 & 279.2 & 0.09276\end{array}$

0.012990

$\begin{array}{llllll}5 & -170.233 & 352.0 & 4.10 & 0.101\end{array}$

$+7-167.751352 .64 .670 .076$

$+7-169.711356 .58 .590 .011$

$\begin{array}{lllll}6 & -171.170 & 356.6 & 8.67 & 0.010\end{array}$

$5 \quad 314.5$

9306.8

$\begin{array}{lll}32 & 257.4 & 0.18560\end{array}$

15303.6

$\begin{array}{llll}6 & 288.7 & 0.07640\end{array}$

$-0.020580$

$\begin{array}{lllll}4 & -173.950 & 356.9 & 8.99 & 0.009\end{array}$

$\begin{array}{lllll}4 & -174.500 & 358.0 & 10.09 & 0.005\end{array}$

$+8-169.976360 .112 .130 .002$

$\begin{array}{lllll}6 & -173.125 & 360.5 & 12.58 & 0.001\end{array}$

$\begin{array}{llllll}5 & -175.095 & 361.8 & 13.83 & 0.001\end{array}$

$\begin{array}{lllll}5 & -175.391 & 362.4 & 14.42 & 0.001\end{array}$

$\begin{array}{lllll}3 & -178.352 & 363.3 & 15.36 & 0.000\end{array}$

$\begin{array}{llllll}7 & -173.394 & 363.9 & 15.96 & 0.000\end{array}$

$\begin{array}{llllll}5 & -177.005 & 365.6 & 17.65 & 0.000\end{array}$

$\begin{array}{llllll}5 & -177.377 & 366.3 & 18.39 & 0.000\end{array}$

$\begin{array}{lllll}4 & -179.470 & 368.0 & 20.03 & 0.000\end{array}$

$\begin{array}{llllll}6 & -177.138 & 368.5 & 20.61 & 0.000\end{array}$

$\begin{array}{llllll}6 & -177.591 & 369.5 & 21.51 & 0.000\end{array}$

$\begin{array}{lllll}4 & -181.401 & 371.8 & 23.89 & 0.000\end{array}$

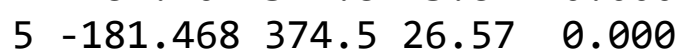


(e)

Global model call: lmer (formula = Hae $~$ Treatment $*$ Time + Mass + Length + $(1$ | Fish), na.action = "na.fail")

Model selection table

$$
\text { (Int) Lng }
$$

10.2251

$5 \quad 0.2345$

90.2090

130.2184

290.2100

$20.3540-3.774 \mathrm{e}-04$

30.2772

$6 \quad 0.3634-3.774 \mathrm{e}-04$

$100.3240-3.346 \mathrm{e}-04$

$7 \quad 0.2867$

110.2543

$140.3334-3.346 \mathrm{e}-04$

$300.3250-3.346 \mathrm{e}-04$

$15 \quad 0.2637$

310.2553

$4 \quad 0.2378$

$8 \quad 0.2472$

$12 \quad 0.2441$

$16 \quad 0.2535$

320.2451

Models ranked by $\operatorname{AICC}(x)$
Mss Tim Trt Tim:Trt df logLik AICc delta weight

$\begin{array}{lllll}3 & 78.214 & -149.8 & 0.00 & 0.769\end{array}$

$\begin{array}{lllll}4 & 77.824 & -146.6 & 3.21 & 0.155\end{array}$

$\begin{array}{lllll}4 & 76.865 & -144.7 & 5.12 & 0.059\end{array}$

$\begin{array}{lllll}5 & 76.475 & -141.4 & 8.46 & 0.011\end{array}$

$+\quad 676.928-139.610 .240 .005$

$\begin{array}{lllll}4 & 71.790 & -134.6 & 15.27 & 0.000\end{array}$

$\begin{array}{lllll}4 & 70.553 & -132.1 & 17.75 & 0.000\end{array}$

$571.400-131.2 \quad 18.610 .000$

$\begin{array}{lllll}5 & 70.299 & -129.0 & 20.81 & 0.000\end{array}$

$\begin{array}{lllll}5 & 70.163 & -128.7 & 21.08 & 0.000\end{array}$

$\begin{array}{lllll}5 & 68.904 & -126.2 & 23.60 & 0.000\end{array}$

$\begin{array}{lllll}6 & 69.909 & -125.5 & 24.28 & 0.000\end{array}$

$+\quad 770.362-123.626 .220 .000$

$\begin{array}{lllll}6 & 68.514 & -122.8 & 27.07 & 0.000\end{array}$

$+768.967-120.829 .010 .000$

$\begin{array}{lllll}5 & 64.193 & -116.8 & 33.02 & 0.000\end{array}$

$\begin{array}{lllll}6 & 63.803 & -113.3 & 36.49 & 0.000\end{array}$

$\begin{array}{lllll}6 & 62.471 & -110.7 & 39.16 & 0.000\end{array}$

$\begin{array}{lllll}7 & 62.081 & -107.1 & 42.78 & 0.000\end{array}$

$+862.534-105.044 .870 .000$ 
Table S10. Model selection outputs for haematological responses of SEL vs. SEH fish, showing models for (a) plasma cortisol, (b) blood glucose, (c) blood lactate, (d) plasma osmolality, and (e) haematocrit.

(a)

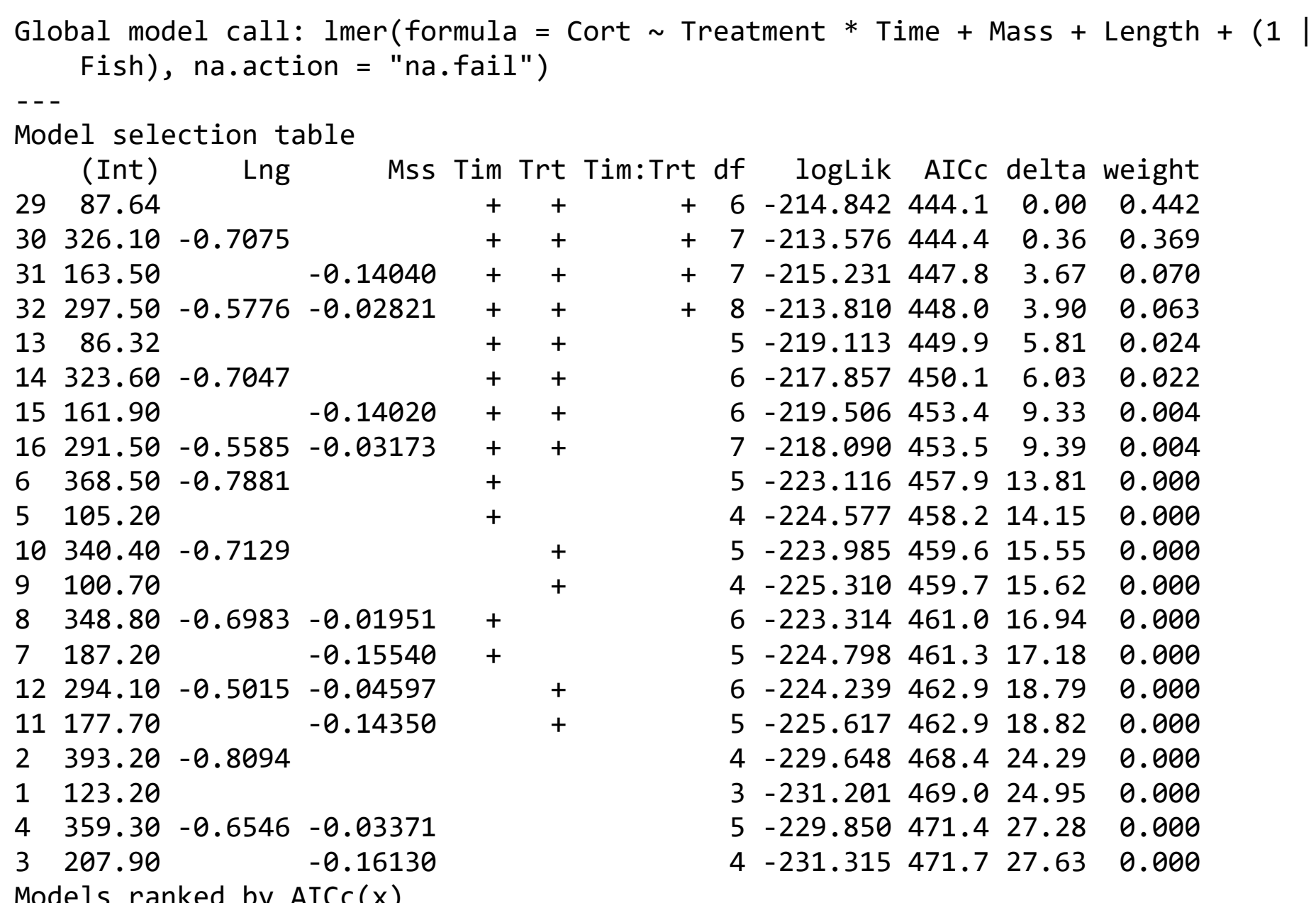


(b)

Global model call: lmer(formula = Glu Treatment * Time + Mass + Length + (1 | Fish), na.action = "na.fail")

Model selection table

(Int) Lng

$9 \quad 4.471$

$13 \quad 4.684$

15.123

$5 \quad 5.330$

$29 \quad 4.692$

$1010.200-0.0169900$

$1410.350-0.0168100$

$211.790-0.0199500$

$6 \quad 11.920-0.0197300$

116.500

$3010.360-0.0168200$

$15 \quad 6.694$

37.393

$7 \quad 7.578$

$31 \quad 6.703$

125.362

$16 \quad 5.507$

$4 \quad 7.203$

87.326

$32 \quad 5.518$

Models ranked by $\operatorname{AICc}(x)$
Mss Tim Trt Tim:Trt df logLik AICc delta weight

$\begin{array}{lllll}4 & -82.093 & 173.2 & 0.00 & 0.355\end{array}$

$\begin{array}{lllll}5 & -81.127 & 173.8 & 0.61 & 0.262\end{array}$

$\begin{array}{lllll}3 & -84.161 & 174.9 & 1.72 & 0.150\end{array}$

$\begin{array}{lllll}4 & -83.160 & 175.3 & 2.13 & 0.122\end{array}$

$+\quad 6-80.892176 .02 .810 .087$

$\begin{array}{llllll}5 & -84.748 & 181.0 & 7.85 & 0.007\end{array}$

$\begin{array}{lllll}6 & -83.794 & 181.8 & 8.61 & 0.005\end{array}$

$\begin{array}{lllll}4 & -86.626 & 182.3 & 9.07 & 0.004\end{array}$

$\begin{array}{lllll}5 & -85.640 & 182.8 & 9.63 & 0.003\end{array}$

$\begin{array}{lllll}5 & -86.243 & 184.0 & 10.84 & 0.002\end{array}$

$+7-83.558184 .110 .960 .001$

$\begin{array}{lllll}6 & -85.289 & 184.8 & 11.60 & 0.001\end{array}$

$\begin{array}{lllll}4 & -88.130 & 185.3 & 12.07 & 0.001\end{array}$

$\begin{array}{lllll}5 & -87.143 & 185.8 & 12.64 & 0.001\end{array}$

$+\quad 7-85.053187 .113 .950 .000$

$\begin{array}{lllll}6 & -88.289 & 190.8 & 17.60 & 0.000\end{array}$

$\begin{array}{lllll}7 & -87.332 & 191.7 & 18.51 & 0.000\end{array}$

$\begin{array}{lllll}5 & -90.150 & 191.8 & 18.65 & 0.000\end{array}$

$\begin{array}{lllll}6 & -89.164 & 192.5 & 19.35 & 0.000\end{array}$

$+\quad 8-87.097194 .221 .010 .000$ 
(c)

Global model call: lmer(formula = Lac $~$ Treatment * Time + Mass + Length + (1 | Fish), na.action = "na.fail")

Model selection table

(Int) Lng

$13 \quad 3.505$

$5 \quad 3.922$

293.475

93.042

13.459

$14-3.920 \quad 0.02203$

$\begin{array}{llll}6 & -2.636 & 0.01963\end{array}$

$30-3.9490 .02203$

151.500

$7 \quad 2.192$

$10-4.3830 .02203$

$\begin{array}{llll}2 & -3.099 & 0.01963\end{array}$

$31 \quad 1.471$

$11 \quad 1.037$

31.729

$16-9.1720 .04580-0.005104$

$\begin{array}{lllll}8 & -7.688 & 0.04251 & -0.004917\end{array}$

$\begin{array}{lllll}32 & -9.202 & 0.04580 & -0.005104\end{array}$

$\begin{array}{lllll}12 & -9.635 & 0.04580 & -0.005104\end{array}$

$\begin{array}{lllll} & 4 & -8.151 & 0.04251 & -0.004917\end{array}$

Models ranked by $\operatorname{AICc}(x)$
Mss Tim Trt Tim:Trt df logLik AICc delta weight

$\begin{array}{lllll}5 & -87.854 & 187.2 & 0.00 & 0.385\end{array}$

$\begin{array}{lllll}4 & -89.136 & 187.2 & 0.04 & 0.378\end{array}$

$+\quad 6-87.424189 .01 .80 \quad 0.157$

$\begin{array}{lllll}4 & -91.770 & 192.5 & 5.31 & 0.027\end{array}$

$\begin{array}{lllll}3 & -93.053 & 192.7 & 5.47 & 0.025\end{array}$

$\begin{array}{lllll}6 & -90.167 & 194.5 & 7.28 & 0.010\end{array}$

$\begin{array}{lllll}5 & -91.623 & 194.7 & 7.54 & 0.009\end{array}$

$+\quad 7-89.738196 .4 \quad 9.22 \quad 0.004$

$\begin{array}{lllll}6 & -92.026 & 198.2 & 11.00 & 0.002\end{array}$

$\begin{array}{lllll}5 & -93.433 & 198.4 & 11.16 & 0.001\end{array}$

$\begin{array}{lllll}5 & -94.084 & 199.7 & 12.46 & 0.001\end{array}$

$\begin{array}{lllll}4 & -95.540 & 200.1 & 12.85 & 0.001\end{array}$

$+\quad 7-91.597200 .112 .930 .001$

$\begin{array}{lllll}5 & -95.943 & 203.4 & 16.18 & 0.000\end{array}$

$\begin{array}{llllll}4 & -97.350 & 203.7 & 16.47 & 0.000\end{array}$

$\begin{array}{llllll}7 & -93.671 & 204.3 & 17.08 & 0.000\end{array}$

$\begin{array}{lllll}6 & -95.128 & 204.4 & 17.20 & 0.000\end{array}$

$+8-93.242206 .419 .170 .000$

$\begin{array}{lllll}6 & -97.588 & 209.3 & 22.12 & 0.000\end{array}$

$\begin{array}{lllll}5 & -99.045 & 209.6 & 22.38 & 0.000\end{array}$ 
(d)

Global model call: Imer(formula = Osm Treatment * Time + Mass + Length + (1 I Fish), na.action = "na.fail")

Model selection table

(Int) Lng Mss Tim Trt Tim:Trt df logLik AICc delta weight

29320.

$\begin{array}{lll}30 & 247.3 & 0.2175\end{array}$

31287.4

0.21750 .06253

13318.3

$32434.4-0.6383 \quad 0.18970$

$\begin{array}{lll}14 & 245.4 & 0.2179\end{array}$

$15285.6 \quad 0.06257$

$\begin{array}{llll}16 & 432.1 & -0.6359 & 0.18930\end{array}$

$5 \quad 314.6$

9314.6

$6 \quad 239.0$

$7 \quad 281.6$

0.2274

$418.2-0.5950 \quad 0.18260$

$\begin{array}{lll}10 & 242.1 & 0.2169\end{array}$

11282.3

$12423.2-0.6123 \quad 0.18380$

1310.6

$\begin{array}{lll}2 & 235.1 & 0.2272\end{array}$

$3 \quad 277.9 \quad 0.06324$

$\begin{array}{llll}4 & 408.3 & -0.5687 & 0.17670\end{array}$

Models ranked by $\operatorname{AICc}(x)$

$+6-167.075348 .6 \quad 0.00 \quad 0.573$

$+7-166.983351 .3 \quad 2.710 .148$

$+7-167.511352 .3 \quad 3.770 .087$

$\begin{array}{lllll}5 & -170.544 & 352.8 & 4.21 & 0.070\end{array}$

$+\quad 8-166.320353 .04 .450 .062$

$\begin{array}{lllll}6 & -170.447 & 355.3 & 6.74 & 0.020\end{array}$

$\begin{array}{lllll}6 & -170.975 & 356.3 & 7.80 & 0.012\end{array}$

$\begin{array}{lllll}7 & -169.792 & 356.9 & 8.33 & 0.009\end{array}$

$\begin{array}{lllll}4 & -173.965 & 357.0 & 8.46 & 0.008\end{array}$

$\begin{array}{llllll}4 & -174.831 & 358.7 & 10.19 & 0.004\end{array}$

$\begin{array}{llllll}5 & -173.763 & 359.2 & 10.64 & 0.003\end{array}$

$\begin{array}{lllll}5 & -174.298 & 360.3 & 11.71 & 0.002\end{array}$

$\begin{array}{llllll}6 & -173.254 & 360.9 & 12.36 & 0.001\end{array}$

$\begin{array}{lllll}5 & -174.745 & 361.2 & 12.61 & 0.001\end{array}$

$\begin{array}{lllll}5 & -175.321 & 362.3 & 13.76 & 0.001\end{array}$

$\begin{array}{lllll}6 & -174.225 & 362.9 & 14.30 & 0.000\end{array}$

$\begin{array}{llllll}3 & -178.331 & 363.3 & 14.74 & 0.000\end{array}$

$\begin{array}{lllll}4 & -178.137 & 365.4 & 16.80 & 0.000\end{array}$

$\begin{array}{lllll}4 & -178.726 & 366.5 & 17.98 & 0.000\end{array}$

$\begin{array}{lllll}5 & -177.774 & 367.2 & 18.66 & 0.000\end{array}$ 
(e)

Global model call: lmer (formula = Hae $~$ Treatment $*$ Time + Mass + Length + $(1$ | Fish), na.action = "na.fail")

Model selection table

$$
\text { (Int) Lng }
$$

50.2637

10.2455

$13 \quad 0.2594$

90.2412

$6 \quad 0.4221-0.0004745$

290.2590

70.3046

$20.4040-0.0004745$

$140.4146-0.0004574$

30.2865

$15 \quad 0.2998$

$10 \quad 0.3964-0.0004574$

$8 \quad 0.5421-0.0010130$

$\begin{array}{lll}11 & 0.2817\end{array}$

$\begin{array}{lll}30 & 0.4143 & -0.0004574\end{array}$

310.2995

$4 \quad 0.5240-0.0010130$

$160.5330-0.0009860$

$120.5148-0.0009860$

$320.5326-0.0009860$

Models ranked by $\operatorname{AICC}(\mathrm{x})$

Random terms (all models):

'1 | Fish'
Mss Tim Trt Tim:Trt df logLik AICc delta weight

$\begin{array}{lllll}4 & 73.947 & -138.8 & 0.00 & 0.932\end{array}$

$\begin{array}{lllll}3 & 69.888 & -133.1 & 5.67 & 0.055\end{array}$

$\begin{array}{lllll}5 & 70.885 & -130.1 & 8.71 & 0.012\end{array}$

$\begin{array}{lllll}4 & 66.825 & -124.6 & 14.24 & 0.001\end{array}$

$\begin{array}{lllll}5 & 67.984 & -124.3 & 14.51 & 0.001\end{array}$

$+667.631-120.917 .950 .000$

$\begin{array}{lllll}5 & 65.970 & -120.3 & 18.54 & 0.000\end{array}$

$\begin{array}{lllll}4 & 63.925 & -118.8 & 20.05 & 0.000\end{array}$

$\begin{array}{lllll}6 & 64.781 & -115.2 & 23.65 & 0.000\end{array}$

$\begin{array}{lllll}4 & 61.911 & -114.7 & 24.07 & 0.000\end{array}$

$\begin{array}{lllll}6 & 62.810 & -111.2 & 27.59 & 0.000\end{array}$

$\begin{array}{lllll}5 & 60.722 & -109.8 & 29.04 & 0.000\end{array}$

$\begin{array}{lllll}6 & 60.501 & -106.6 & 32.21 & 0.000\end{array}$

$\begin{array}{lllll}5 & 58.751 & -105.8 & 32.98 & 0.000\end{array}$

$+761.527-105.833 .050 .000$

$+759.556-101.836 .990 .000$

$\begin{array}{lllll}5 & 56.442 & -101.2 & 37.60 & 0.000\end{array}$

$\begin{array}{llllll}7 & 57.308 & -97.3 & 41.49 & 0.000\end{array}$

$\begin{array}{lllll}6 & 53.248 & -92.1 & 46.72 & 0.000\end{array}$

$+854.054-87.751 .07 \quad 0.000$ 
Table S11. Model selection outputs for surgery responses of E vs. HC fish, showing models for (a) thrash count and (b) ventilation rate.

(a)

Global model call: glm(formula = Thrash Treatment + Mass + Stemp, family = "poisson", na.action = "na.fail")

$--$

Model selection table

(Intrc) Mass Stemp Trtmn df logLik AICc delta weight

$8-8.517000 .0014820 .2768+4-62.224133 .30 .00 \quad 0.639$

$7-8.41700 \quad 0.3094+3-64.321135 .11 .850 .253$

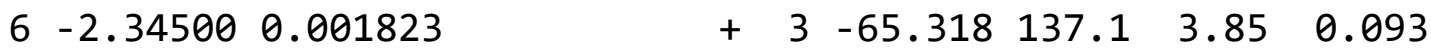

$5-1.31200+2-68.345140 .97 .650 .014$

$\begin{array}{llllllllll}4 & -8.74100 & 0.001427 & 0.3373 & 3 & -73.261 & 153.0 & 19.73 & 0.000\end{array}$

$\begin{array}{llllllll}3 & -8.89700 & 0.3792 & 2 & -75.169 & 154.6 & 21.30 & 0.000\end{array}$

$\begin{array}{lllllllll}2 & -1.23600 & 0.001980 & 2 & -77.693 & 159.6 & 26.35 & 0.000\end{array}$

$1-0.09909$

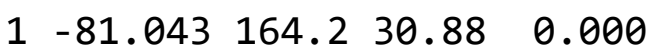

Models ranked by $\operatorname{AICC}(x)$

(b)

Global model call: $\operatorname{lm}($ formula $=$ VR Treatment + Mass + Stemp, na.action = "na.fail")

- - -

Model selection table

(Intrc) Mass Stemp Trtmn df logLik AICc delta weight

$\begin{array}{lllllllll}4 & -0.9026 & -0.0005538 & 0.10060 & 4 & -21.807 & 52.6 & 0.00 & 0.320\end{array}$

$\begin{array}{llllllll}3-0.9020 & 0.08746 & 3 & -23.077 & 52.7 & 0.15 & 0.297\end{array}$

$8-0.8732-0.00055360 .09809+5-21.72054 .92 .340 .099$

$7-0.8725 \quad 0.08496$

$+\quad 4-22.99454 .92 .370 .098$

11.0940

$\begin{array}{lllll}2 & -25.458 & 55.2 & 2.62 & 0.086\end{array}$

$2 \quad 1.2920-0.0003684$

$\begin{array}{lllll}3 & -24.936 & 56.4 & 3.86 & 0.046\end{array}$

51.0430

$6 \quad 1.2450-0.0003770$

$+\quad 3-25.20257 .04 .400 .035$

Models ranked by AICC $(x)$ 
Table S12. Model selection outputs for surgery responses of SE vs. E fish, showing models for (a) thrash count and (b) ventilation rate.

(a)

Global model call: glm(formula = Thrash Treatment + Mass + Stemp, family = "poisson", na.action = "na.fail")

$$
\text { - - - }
$$

Model selection table

\begin{tabular}{|c|c|c|c|c|c|c|c|c|}
\hline (Intrc) & Mass & Stemp & Trtmn & $d f$ & logLik & $\mathrm{AICC}$ & delta & weight \\
\hline-3.682 & 0.004181 & & & 2 & -37.858 & 80.0 & 0.00 & 0.524 \\
\hline-3.792 & 0.004103 & & + & 3 & -37.691 & 81.9 & 1.91 & 0.202 \\
\hline-5.242 & 0.003971 & 0.07369 & & 3 & -37.756 & 82.0 & 2.04 & 0.189 \\
\hline-5.384 & 0.003903 & 0.07473 & + & 4 & -37.582 & 84.0 & 4.03 & 0.070 \\
\hline-1.045 & & & & 1 & -43.411 & 88.9 & 8.95 & 0.006 \\
\hline-5.255 & & 0.18280 & & 2 & -42.727 & 89.7 & 9.74 & 0.004 \\
\hline-1.312 & & & + & 2 & -42.917 & 90.1 & 10.12 & 0.003 \\
\hline-5.065 & & 0.16430 & + & 3 & -42.352 & 91.2 & 11.23 & 0.002 \\
\hline
\end{tabular}

Models ranked by $\operatorname{AICC}(x)$

(b)

Global model call: $\operatorname{lm}($ formula $=$ VR Treatment + Mass + Stemp, na.action = "na.fail")

- - -

Model selection table

(Intrc) Mass Stemp Trtmn df logLik AICc delta weight

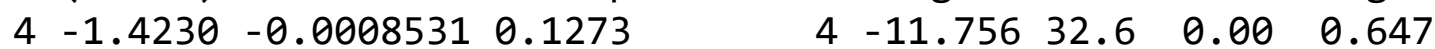

$8-1.4570-0.00081530 .1302+5-11.27634 .21 .610 .289$

$\begin{array}{llllllll}3-1.6420 & 0.1160 & 3 & -15.830 & 38.3 & 5.71 & 0.037\end{array}$

$7-1.6760 \quad 0.1206+4-15.04039 .16 .57 \quad 0.024$

$2 \quad 1.3880-0.0007005 \quad 3-19.25145 .1 \quad 12.55 \quad 0.001$

$\begin{array}{lllllll}1 & 0.9953 & 2 & -21.317 & 46.9 & 14.37 & 0.000\end{array}$

$61.4050-0.0006768+4-19.13847 .314 .770 .000$

$51.0430+3-21.04348 .716 .140 .000$

Models ranked by $\operatorname{AICc}(x)$ 
Table S13. Model selection outputs for surgery responses of SEH vs. SE fish, showing models for (a) thrash count and (b) ventilation rate.

(a)

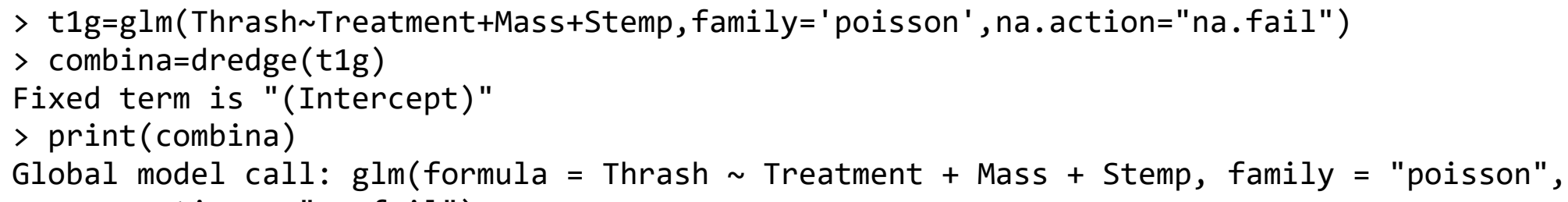


(b)

Global model call: $\operatorname{lm}($ formula $=$ VR Treatment + Mass + Stemp, na.action = "na.fail") --

Model selection table

(Intrc) Mass Stemp Trtmn df logLik AICc delta weight

$\begin{array}{llll}8 & -0.04778 & -0.0009588 & 0.06814\end{array}$

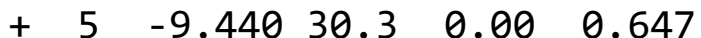

$\begin{array}{lllll}4 & -0.49950 & -0.0007959 & 0.07973\end{array}$

$\begin{array}{lrl}6 & 1.50400 & -0.0009413\end{array}$

$\begin{array}{lll}3-0.81000 & 0.07433\end{array}$

$\begin{array}{lll}7-0.56950 & 0.06646\end{array}$

$2 \quad 1.25100-0.0007182$

50.95360

10.86110

$\begin{array}{lllll}4 & -11.707 & 32.3 & 2.03 & 0.234\end{array}$

$+4-13.07735 .14 .770 .059$

$\begin{array}{lllll}3 & -15.030 & 36.6 & 6.30 & 0.028\end{array}$

$+\quad 4-14.24437 .47 .110 .018$

$\begin{array}{lllll}3 & -16.361 & 39.3 & 8.96 & 0.007\end{array}$

$+\quad 3-17.12340 .810 .480 .003$

Models ranked by $\operatorname{AICC}(x)$ 
Table S14. Model selection outputs for surgery responses of SEL vs. SEH fish, showing models for (a) thrash count and (b) ventilation rate.

(a)

Global model call: glm(formula = Thrash Treatment + Mass + Stemp, family = "poisson", na.action = "na.fail") $--$

Model selection table

(Intrc) Mass Stemp Trtmn df logLik AICc delta weight

$\begin{array}{llllllll}3 & -9.3440 & 0.3799 & 2 & -47.430 & 99.1 & 0.00 & 0.454\end{array}$

$7-9.0000+0.3735+3-46.811100 .11 .010 .274$

$\begin{array}{lllllllll}4 & -9.6560 & 0.0004839 & 0.3829 & 3 & -47.388 & 101.3 & 2.17 & 0.154\end{array}$

$8-9.26000 .00042320 .3754+4-46.780102 .43 .290 .088$

$1-0.7122$

$5-0.5232$

$2-0.77910 .0001317$

$6-0.5826 \quad 0.0001166$

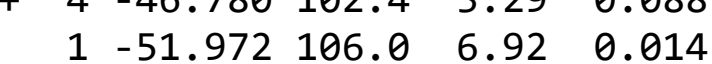

$+\quad 2-51.382107 .07 .900 .009$

Models ranked by $\operatorname{AICC}(x)$

(b)

Global model call: $\operatorname{lm}($ formula $=$ VR $~$ Treatment + Mass + Stemp, na.action = "na.fail")

- - -

Model selection table

(Intrc) Mass Stemp Trtmn df logLik AICc delta weight

$\begin{array}{llllllll}5 & 0.77600+3 & -12.66431 .9 & 0.00 & 0.232\end{array}$

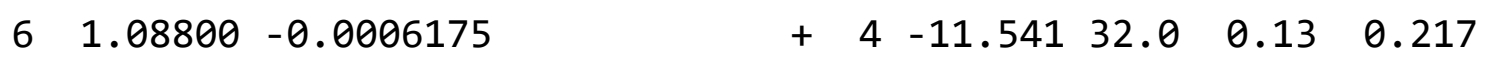

$7-0.05835 \quad 0.03778+4-11.65632 .20 .360 .193$

$80.25020-0.00062060 .03799+5-10.47232 .30 .480 .182$

$\begin{array}{llllllll}3 & -0.07653 & 0.04311 & 3 & -14.218 & 35.0 & 3.11 & 0.049\end{array}$

$\begin{array}{lllllll}1 & 0.88160 & 2 & -15.405 & 35.1 & 3.21 & 0.047\end{array}$

$\begin{array}{lllllllll}4 & 0.22620 & -0.0006091 & 0.04336 & 4 & -13.195 & 35.3 & 3.44 & 0.041\end{array}$

$21.18800-0.0006048$

$\begin{array}{lllll}3 & -14.445 & 35.4 & 3.56 & 0.039\end{array}$

Models ranked by $\operatorname{AICC}(x)$ 
Table S15. Model selection outputs for behaviour-track cooler responses of HC vs. BB fish, showing models for (a) VR 1 , (b) $\mathrm{VR}_{2}$, (c) $\triangle \mathrm{VR}$, (d) opercular twitch count, (e) RAMP 1, and (f) RAMP 2.

(a)

Global model call: $\operatorname{lm}($ formula $=\mathrm{V} 1 \sim$ Treatment + Mass + Ttemp, na.action = "na.fail") - - -

Model selection table

\begin{tabular}{|c|c|c|c|c|c|c|c|c|}
\hline (Intrc) & Mass & Trtmn & Ttemp & $d f$ & logLik & $\mathrm{AICC}$ & delta & weight \\
\hline 0.9667 & & & & 2 & 8.302 & -12.1 & 0.00 & 0.237 \\
\hline 1.1490 & -0.0003711 & & & 3 & 9.546 & -12.1 & 0.01 & 0.236 \\
\hline 0.1802 & & & 0.03384 & 3 & 9.159 & -11.4 & 0.79 & 0.160 \\
\hline 0.4101 & -0.0003529 & & 0.03140 & 4 & 10.345 & -11.0 & 1.12 & 0.13 \\
\hline 1.1470 & -0.0004193 & + & & 4 & 9.828 & -10.0 & 2.15 & 0.081 \\
\hline 0.9571 & & + & & 3 & 8.339 & -9.7 & 2.42 & 0.071 \\
\hline 0.1829 & & + & 0.03347 & 4 & 9.173 & -8.7 & 3.46 & 0.04 \\
\hline 0.4472 & -0.0003940 & + & 0.02974 & 5 & 10.548 & -8.5 & 3.65 & 0.03 \\
\hline
\end{tabular}

Models ranked by $\operatorname{AICc}(x)$

(b)

Global model call: $\operatorname{lm}($ formula = V2 Treatment + Mass + Ttemp, na.action = "na.fail") - - -

Model selection table

(Intrc) Mass Trtmn Ttemp df logLik AICc delta weight

$\begin{array}{llllllll}5 & -0.28870 & 0.06059 & 3 & 0.420 & 6.1 & 0.00 & 0.214\end{array}$

$\begin{array}{lllllll}1 & 1.12000 & 2 & -1.051 & 6.6 & 0.44 & 0.171\end{array}$

$\begin{array}{lllllllll}6 & -0.02256 & -0.0004085 & 0.05777 & 4 & 1.280 & 7.1 & 0.99 & 0.131\end{array}$

$\begin{array}{llllllll}2 & 1.33700 & -0.0004420 & 3 & -0.136 & 7.2 & 1.11 & 0.123\end{array}$

$41.33000-0.0005776+4 \quad 4 \quad 1.047 \quad 7.6 \quad 1.450 .103$

$\begin{array}{llllllll}7-0.26760 & + & 0.05779 & 4 & 0.884 & 7.9 & 1.78 & 0.088\end{array}$

$\begin{array}{llllllll}3 & 1.06900+ & 3 & -0.492 & 7.9 & 1.82 & 0.086\end{array}$

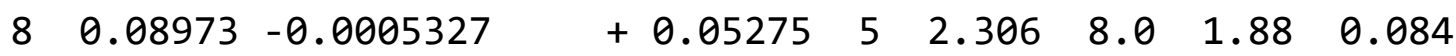

Models ranked by $\operatorname{AICC}(x)$ 
(c)

Global model call: $1 \mathrm{~m}($ formula $=$ VD Treatment + Mass + Ttemp, na.action = "na.fail")

$--$

Model selection table

(Intrc) Mass Trtmn Ttemp df logLik AICc delta weight

\begin{tabular}{|c|c|c|c|c|c|c|c|}
\hline 0.1529 & & & 2 & 3.325 & -2.2 & 0.00 & 0.378 \\
\hline 0.1119 & & + & 3 & 3.821 & -0.7 & 1.51 & 0.178 \\
\hline-0.4688 & & 0.02675 & 3 & 3.698 & -0.4 & 1.75 & 0 \\
\hline 0.1876 & $-7.082 e-05$ & & 3 & 3.355 & 0.2 & 2.44 & 0 \\
\hline-0.4505 & & +0.02432 & 4 & 4.137 & 1.4 & 3.58 & \\
\hline 0.1834 & $-1.583 e-04$ & + & $v^{\circ}$ & 3.969 & 1.7 & 3.92 & g. \\
\hline-0.4327 & $-5.555 e-05$ & 0.02637 & 4 & 3.717 & 2.2 & 4.42 & \\
\hline-0.3574 & $-1.388 e-04$ & +0.02300 & & 4.253 & 4.1 & 6.29 & \\
\hline
\end{tabular}

Models ranked by $\operatorname{AICC}(x)$

(d)

Global model call: glm(formula = Twitch Treatment + Mass + Ttemp, family = "poisson", na.action = "na.fail")

Model selection table

(Intrc) Mass Trtmn Ttemp df logLik AICc delta weight

$\begin{array}{lllllll}3-0.45200 & + & 2 & -28.985 & 62.6 & 0.00 & 0.316\end{array}$

$\begin{array}{llrllll}1 & 0.04256 & 1 & -30.721 & 63.6 & 1.06 & 0.186\end{array}$

$\begin{array}{lllllllll}7 & 3.83300+ & + & -0.1877 & 3 & -28.213 & 63.7 & 1.12 & 0.180\end{array}$

53.06400

$4-0.57500 \quad 0.0002667$

$2-0.473100 .0009862$ $\begin{array}{llllll}-0.1306 & 2 & -30.280 & 65.2 & 2.59 & 0.087\end{array}$

$83.79200 \quad 0.0000500$

$+\quad 3-28.96365 .2 \quad 2.620 .085$

2.497000 .0009234

$\begin{array}{lllll}2 & -30.415 & 65.4 & 2.86 & 0.076\end{array}$

Models ranked by $\operatorname{AICC}(x)$ 
(e)

Global model call: glm(formula = RAMP1 Treatment + Mass + Ttemp, family = "poisson", na.action = "na.fail")

Model selection table

\begin{tabular}{|c|c|c|c|c|c|c|c|c|}
\hline (Intrc) & Mass & Trtmn & Ttemp & $d f$ & $\log L i k$ & AICC & delta & weight \\
\hline 1.5160 & & & & 1 & -49.868 & 101.9 & 0.00 & 0.439 \\
\hline 0.9641 & & & 0.02371 & 2 & -49.807 & 104.1 & 2.19 & 0.147 \\
\hline 1.5040 & & + & & 2 & -49.860 & 104.2 & 2.30 & 0.139 \\
\hline 1.5440 & $-5.764 e-05$ & & & 2 & -49.863 & 104.2 & 2.30 & 0.139 \\
\hline 0.9671 & & + & 0.02319 & 3 & -49.802 & 106.6 & 4.68 & 0.042 \\
\hline 0.9929 & $-4.378 e-05$ & & 0.02339 & 3 & -49.805 & 106.6 & 4.69 & 0.042 \\
\hline 1.5420 & $-8.448 e-05$ & + & & 3 & -49.851 & 106.7 & 4.78 & 0.040 \\
\hline 1.0110 & $-6.532 e-05$ & + & 0.02257 & 4 & -49.797 & 109.3 & 7.38 & 0.011 \\
\hline
\end{tabular}

(f)

Global model call: glm(formula = RAMP2 Treatment + Mass + Ttemp, family = "poisson", na.action = "na.fail") $--$

Model selection table

\begin{tabular}{|c|c|c|c|c|c|c|c|c|}
\hline (Intrc) & Mass & Trtmn & Ttemp & $d f$ & logLik & $\mathrm{AICC}$ & delta & weight \\
\hline 1.5310 & & & & 1 & -50.041 & 102.2 & 0.00 & 0.434 \\
\hline 1.0070 & & & 0.02251 & 2 & -49.985 & 104.4 & 2.20 & 0.144 \\
\hline 1.5040 & & + & - & 2 & -49.998 & 104.5 & 2.23 & 0.143 \\
\hline 1.4620 & 0.0001386 & & & 2 & -50.015 & 104.5 & 2.26 & 0.140 \\
\hline 1.0150 & & + & -0.02113 & 3 & -49.950 & 106.9 & 4.63 & 0.04 \\
\hline 0.9060 & 0.0001523 & & 0.02363 & 3 & -49.954 & 106.9 & 4.64 & 0.04 \\
\hline 1.4600 & 0.0000972 & + & - & 3 & -49.986 & 106.9 & 4.70 & 0.04 \\
\hline 0.9363 & 0.0001159 & + & -0.02226 & 4 & -49.933 & 109.5 & 7.30 & 0.01 \\
\hline
\end{tabular}


Table S16. Model selection outputs for behaviour-track cooler responses of E vs. HC fish, showing models for (a) VR 1 , (b) VR 2 , (c) $\triangle \mathrm{VR}$, (d) opercular twitch count, (e) RAMP 1, and (f) RAMP 2.

(a)

Global model call: $\operatorname{lm}($ formula = V1 Treatment + Mass + Ttemp, na.action = "na.fail")$$
\text { -- }
$$

Model selection table

$$
\text { (Intrc) Mass Trtmn Ttemp df logLik AICc delta weight }
$$

$\begin{array}{lllllllll}6 & -0.1234 & -0.0002737 & 0.05238 & 4 & 16.385 & -23.0 & 0.00 & 0.484\end{array}$

$\begin{array}{llllllll}5-0.3810 & 0.05683 & 3 & 14.020 & -21.0 & 1.99 & 0.179\end{array}$

$\begin{array}{lllllllll}8 & -0.1224 & -0.0002549 & +0.05082 & 5 & 16.776 & -20.8 & 2.21 & 0.160\end{array}$

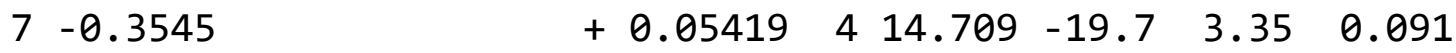

$\begin{array}{llllllll}2 & 1.1130 & -0.0003128 & 3 & 12.613 & -18.2 & 4.80 & 0.044\end{array}$

$41.0660-0.0002864+\quad+\quad 413.142-16.5 \quad 6.49 \quad 0.019$

$\begin{array}{lllllll}1 & 0.9369 & 2 & 10.227 & -16.0 & 7.06 & 0.014\end{array}$

$\begin{array}{lllllll}3 & 0.8923+311.110 & -15.2 & 7.81 & 0.010\end{array}$

Models ranked by $\operatorname{AICc}(x)$

(b)

Global model call: $\operatorname{lm}($ formula = V2 Treatment + Mass + Ttemp, na.action = "na.fail")

-- -

Model selection table

(Intrc) Mass Trtmn Ttemp df logLik AICc delta weight

$\begin{array}{lllllllll}6 & 0.2045 & -0.0007280 & 0.05961 & 4 & -1.109 & 12.0 & 0.00 & 0.375\end{array}$

$\begin{array}{llllllll}2 & 1.6120 & -0.0007725 & 3 & -2.631 & 12.3 & 0.30 & 0.322\end{array}$

$\begin{array}{lllllllll}8 & 0.2023 & -0.0007701 & +0.06311 & 5 & -0.543 & 13.8 & 1.86 & 0.148\end{array}$

$\begin{array}{lllllllll}4 & 1.6780 & -0.0008092+4 & -2.287 & 14.3 & 2.36 & 0.116\end{array}$

$\begin{array}{llllllll}5 & -0.4808 & 0.07145 & 3 & -5.549 & 18.1 & 6.14 & 0.017\end{array}$

$\begin{array}{lllllll}1 & 1.1760 & 2 & -7.155 & 18.8 & 6.83 & 0.012\end{array}$

$\begin{array}{llllllll}7 & -0.4992+0.07330 & 4 & -5.467 & 20.7 & 8.72 & 0.005\end{array}$

$\begin{array}{llllllll}3 & 1.1870+3 & -7.140 & 21.3 & 9.32 & 0.004\end{array}$

Models ranked by $\operatorname{AICC}(x)$ 
(c)

Global model call: $\operatorname{lm}($ formula $=$ VD Treatment + Mass + Ttemp, na.action = "na.fail")

-.-

Model selection table

(Intrc) Mass Trtmn Ttemp df logLik AICc delta weight

$\begin{array}{lllllllll}4 & 0.61200 & -0.0005229 & 4 & 4.628 & 0.5 & 0.00 & 0.370\end{array}$

$\begin{array}{llllllll}2 & 0.49870 & -0.0004597 & 3 & 3.039 & 0.9 & 0.44 & 0.297\end{array}$

$\begin{array}{lllllllll}8 & 0.32460 & -0.0005152 & +0.012290 & 5 & 4.730 & 3.3 & 2.78 & 0.092\end{array}$

$\begin{array}{lllllll}1 & 0.23930 & 2 & 0.457 & 3.6 & 3.08 & 0.079\end{array}$

$\begin{array}{lllllllll}6 & 0.32790 & -0.0004543 & 0.007233 & 4 & 3.071 & 3.6 & 3.11 & 0.078\end{array}$

$\begin{array}{llllllll}30.29490+3 & 3.134 & 4.7 & 4.25 & 0.044\end{array}$

$\begin{array}{llllllll}5 & -0.09978 & 0.014620 & 3 & 0.567 & 5.9 & 5.38 & 0.025\end{array}$

$\begin{array}{llllllll}7 & -0.14470+0.019110 & 4 & 1.329 & 7.1 & 6.60 & 0.014\end{array}$

Models ranked by $\operatorname{AICC}(x)$

(d)

Global model call: glm(formula = Twitch Treatment + Mass + Ttemp, family = "poisson", na.action = "na.fail")

Model selection table

\begin{tabular}{|c|c|c|c|c|c|c|c|c|}
\hline (Intrc) & Mass & Trtmn & Ttemp & $d f$ & $\operatorname{logLik}$ & $\mathrm{AICC}$ & delta & weight \\
\hline 0.5281 & & & & 1 & -36.311 & 74.8 & 0.00 & 0.316 \\
\hline 0.6931 & & + & & 2 & -35.735 & 76.1 & 1.26 & 0.169 \\
\hline-1.9490 & & & 0.1065 & 2 & -35.849 & 76.3 & 1.49 & 0.150 \\
\hline 0.1482 & 0.0006173 & & & 2 & -35.947 & 76.5 & 1.68 & 0.136 \\
\hline-2.2340 & & + & 0.1271 & 3 & -35.063 & 77.4 & 2.58 & 0.087 \\
\hline-2.5740 & 0.0006829 & & 0.1153 & 3 & -35.407 & 78.1 & 3.26 & 0.062 \\
\hline 0.3863 & 0.0004640 & + & & 3 & -35.534 & 78.3 & 3.52 & 0.054 \\
\hline-2.6180 & 0.0004936 & + & 0.1296 & 4 & -34.836 & 79.9 & 5.08 & 0.025 \\
\hline
\end{tabular}


(e)

Global model call: glm(formula = RAMP1 Treatment + Mass + Ttemp, family = "poisson", na.action = "na.fail")

Model selection table

\begin{tabular}{|c|c|c|c|c|c|c|c|c|}
\hline $\begin{array}{r}\text { Intrc) } \\
1.551\end{array}$ & Mass & Trtmn & Ttemp & $\begin{array}{r}d f \\
1\end{array}$ & $\begin{array}{r}\text { logLik } \\
-48.495\end{array}$ & $\begin{array}{l}\text { AICC } \\
99.1\end{array}$ & $\begin{array}{r}\text { delta } \\
0.00\end{array}$ & $\begin{array}{r}\text { weight } \\
0.436\end{array}$ \\
\hline 1.638 & -0.0001565 & & & 2 & -48.424 & 101.3 & 2.18 & 0.146 \\
\hline 1.578 & & + & & 2 & -48.451 & 101.4 & 24 & \\
\hline 1.396 & & & 0.006661 & 2 & -48.489 & 101.5 & 2.31 & 0.137 \\
\hline 1.689 & -0.0001843 & + & & 3 & -48.354 & 103.7 & 4.56 & 0.045 \\
\hline 1.539 & -0.0001534 & & $0 . e$ & 3 & -48.421 & 103.8 & 70 & 0.042 \\
\hline 1.375 & & + & 0.008814 & 3 & -48.440 & 103.9 & 4.74 & 0.041 \\
\hline 1.538 & -0.0001803 & + & 0.006455 & 4 & -48.348 & 106.4 & 7.29 & 0.01 \\
\hline
\end{tabular}

Models ranked by $\operatorname{AICC}(x)$

(f)

Global model call: glm(formula = RAMP2 Treatment + Mass + Ttemp, family = "poisson", na.action = "na.fail")

Model selection table

\begin{tabular}{|c|c|c|c|c|c|c|c|}
\hline (Intrc) & Mass & Trtmn & $d f$ & $\log L i k$ & AICC & delta & weight \\
\hline 1.580 & & & 1 & -48.671 & 99.5 & 0.00 & 0.443 \\
\hline 1.609 & & + & 2 & -48.620 & 101.7 & 2.22 & 0.146 \\
\hline 1.551 & $5.200 \mathrm{e}-05$ & & 2 & -48.662 & 101.8 & 2.31 & 0.140 \\
\hline 1.535 & & 0.001979 & 2 & -48.670 & 101.8 & 2.33 & 0.139 \\
\hline 1.592 & $2.903 e-05$ & + & 3 & -48.617 & 104.2 & 4.74 & 0.041 \\
\hline 1.512 & & +0.004224 & 3 & -48.617 & 104.2 & 4.74 & 0.041 \\
\hline 1.483 & $5.413 e-05$ & 0.002862 & 3 & -48.661 & 104.3 & 4.83 & 0.040 \\
\hline 1.483 & $3.189 e-05$ & +0.004644 & 4 & -48.614 & 107.0 & 7.47 & 0.011 \\
\hline
\end{tabular}


Table S17. Model selection outputs for behaviour-track cooler responses of SE vs. E fish, showing models for (a) VR 1 , (b) VR 2 , (c) $\Delta \mathrm{VR}$, (d) opercular twitch count, (e) RAMP 1, and (f) RAMP 2.

(a)

Global model call: $\operatorname{lm}($ formula = V1 Treatment + Mass + Ttemp, na.action = "na.fail")

Model selection table

$$
\text { (Intrc) Mass Trtmn Ttemp df logLik AICc delta weight }
$$

$0.05103 \quad 3 \quad 11.731-16.5 \quad 0.00 \quad 0.458$

$\begin{array}{lllllllll}6 & -0.1842 & -0.0001467 & 0.04925 & 4 & 12.295 & -14.9 & 1.58 & 0.208\end{array}$

$\begin{array}{llllllll}7 & -0.2993+0.05179 & 4 & 12.187 & -14.7 & 1.79 & 0.187\end{array}$

$8-0.1670-0.0001500+0.05000 \quad 5 \quad 12.797-13.0 \quad 3.520 .079$

$\begin{array}{lllllll}1 & 0.8655 & 2 & 7.823 & -11.2 & 5.32 & 0.032\end{array}$

$\begin{array}{llllllll}2 & 0.9773 & -0.0001864 & 3 & 8.528 & -10.1 & 6.41 & 0.019\end{array}$

$\begin{array}{lllllll}30.8923 & + & 3 & 8.073 & -9.2 & 7.32 & 0.012\end{array}$

$\begin{array}{lllllllll}4 & 1.0070 & -0.0001897+ & 4 & 8.817 & -8.0 & 8.53 & 0.006\end{array}$

Models ranked by $\operatorname{AICc}(x)$

(b)

Global model call: $\operatorname{lm}($ formula = V2 Treatment + Mass + Ttemp, na.action = "na.fail")

$$
---
$$

Model selection table

$$
\text { (Intrc) Mass Trtmn Ttemp df logLik AICc delta weight }
$$

$3-4.97616 .90 .00 \quad 0.346$

$\begin{array}{lllllllll}6 & 0.43720 & -0.0006164 & 0.04723 & 4 & -3.720 & 17.1 & 0.20 & 0.314\end{array}$

$\begin{array}{lllllllll}4 & 1.58700 & -0.0006584 & + & -4.818 & 19.3 & 2.39 & 0.105\end{array}$

$\begin{array}{lllllllll}8 & 0.45690 & -0.0006202 & +0.04809 & 5 & -3.503 & 19.6 & 2.70 & 0.090\end{array}$

$5-0.10500$

11.15900

$7-0.09015$

31.18700

$\begin{array}{llllll}0.05470 & 3 & -6.746 & 20.5 & 3.54 & 0.059\end{array}$

$\begin{array}{lllll}2 & -8.120 & 20.7 & 3.79 & 0.052\end{array}$

Models ranked by $\operatorname{AICC}(x)$ 
(c)

Global model call: $\operatorname{lm}($ formula $=$ VD Treatment + Mass + Ttemp, na.action = "na.fail") $--$

Model selection table

(Intrc) Mass Trtmn Ttemp df logLik AICc delta weight

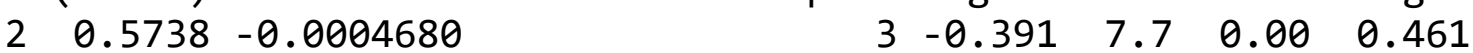

$\begin{array}{lllllll}1 & 0.2931 & 2 & -2.667 & 9.8 & 2.05 & 0.165\end{array}$

$\begin{array}{lllllllll}4 & 0.5791 & -0.0004686 & + & -0.386 & 10.4 & 2.70 & 0.120\end{array}$

$\begin{array}{lllllllll}6 & 0.6213 & -0.0004697 & -0.002017 & 4 & -0.388 & 10.4 & 2.70 & 0.119\end{array}$

$\begin{array}{llllllll}5 & 0.2082 & 0.003674 & 3 & -2.659 & 12.3 & 4.53 & 0.048\end{array}$

$\begin{array}{llllllll}30.2949+3 & -2.667 & 12.3 & 4.55 & 0.047\end{array}$

$\begin{array}{llllllllll}8 & 0.6239 & -0.0004702 & + & -0.001906 & 5 & -0.384 & 13.4 & 5.63 & 0.028\end{array}$

$\begin{array}{lllllllll}7 & 0.2092+0.003725 & 4 & -2.658 & 15.0 & 7.24 & 0.012\end{array}$

Models ranked by $\operatorname{AICC}(x)$

(d)

Global model call: glm(formula = Twitch Treatment + Mass + Ttemp, family = "poisson", na.action = "na.fail") $---$

Model selection table

(Intrc) Mass Trtmn Ttemp df logLik AICc delta weight

$\begin{array}{llllllll}5 & -4.53700 & 0.2226 & 2 & -39.640 & 83.8 & 0.00 & 0.353\end{array}$

$\begin{array}{lllllllll}6 & -5.38700 & 0.0010590 & 0.2302 & 3 & -38.399 & 83.9 & 0.12 & 0.333\end{array}$

$\begin{array}{llllllll}7-4.57500+0.2275 & 3 & -39.525 & 86.2 & 2.37 & 0.108\end{array}$

$\begin{array}{lllllllll}8 & -5.37400 & 0.0010310 \quad+0.2317 & 4 & -38.383 & 86.8 & 2.94 & 0.081\end{array}$

$\begin{array}{lllllll}1 & 0.65230 & 1 & -42.741 & 87.7 & 3.83 & 0.052\end{array}$

$\begin{array}{llllllll}2 & 0.01782 & 0.0009963 & 2 & -41.704 & 88.0 & 4.13 & 0.045\end{array}$

$\begin{array}{llllllll}30.69310 & + & 2 & -42.709 & 90.0 & 6.14 & 0.016\end{array}$

$\begin{array}{lllllllll}4 & 0.01983 & 0.0009952 & + & 3 & -41.704 & 90.5 & 6.72 & 0.012\end{array}$

Models ranked by $\operatorname{AICC}(x)$ 
(e)

Global model call: glm(formula = RAMP1 Treatment + Mass + Ttemp, family = "poisson", na.action = "na.fail")

Model selection table

\begin{tabular}{|c|c|c|c|c|c|c|c|c|}
\hline c) & Mass & Trtmn & Ttemp & $d f$ & logLik & AICC & delta & weight \\
\hline 1.595 & & & & 1 & -48.714 & 99.6 & 0.00 & 0.443 \\
\hline 1.664 & -0.0001 & & & 2 & -48.671 & 101.8 & 2.24 & 0.145 \\
\hline 1.578 & & + & + & 2 & -48 & 9 & & \\
\hline 1.535 & & & 0.0 & 2 & -48 & 101.9 & 2.32 & 0 . \\
\hline 1.646 & -0.0001132 & + & + & 3 & -48 & 104.3 & 73 & 0.042 \\
\hline 1.643 & -0.0001162 & & 0. & 3 & -48 & 104.3 & 76 & 0.041 \\
\hline 1.525 & & + & 0.0023210 & 3 & -48.696 & 104.4 & 4.81 & 0.040 \\
\hline 1.631 & -0.0001125 & + & 0.0006733 & 4 & -48.657 & 107.1 & 7.47 & 0.01 \\
\hline
\end{tabular}

Models ranked by $\operatorname{AICC}(x)$

(f)

Global model call: glm(formula = RAMP2 Treatment + Mass + Ttemp, family = "poisson", na.action = "na.fail")

Model selection table

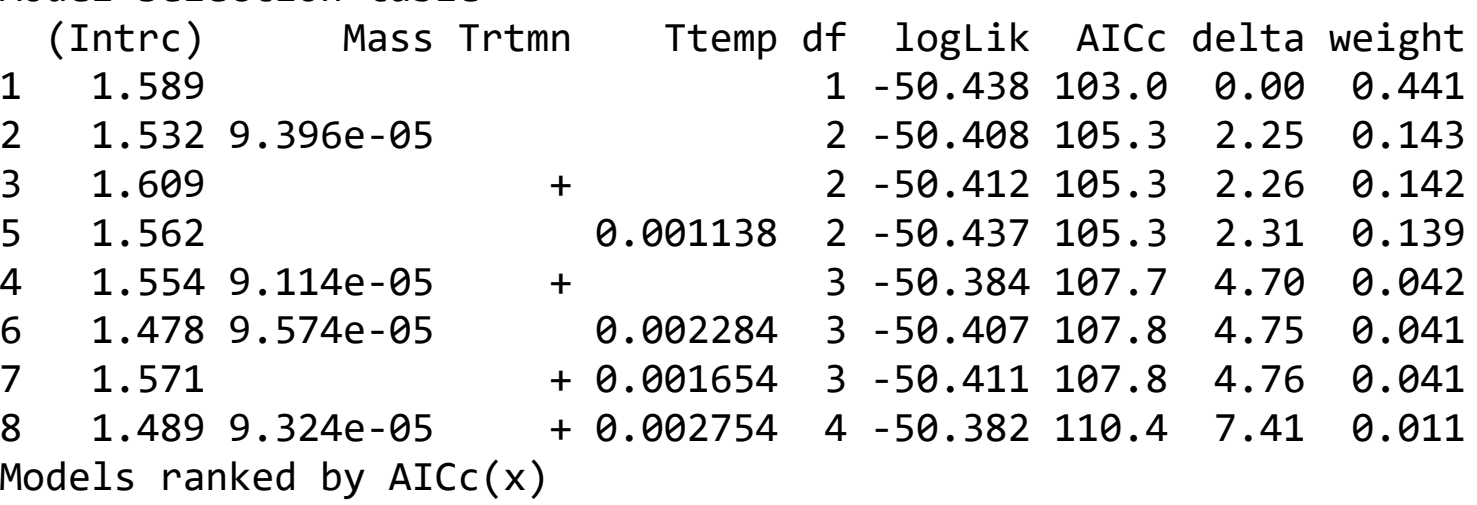


Table S18. Model selection outputs for behaviour-track cooler responses of SEH vs. SE fish, showing models for (a) VR 1 , (b) VR 2 , (c) $\triangle \mathrm{VR}$, (d) opercular twitch count, (e) RAMP 1, and (f) RAMP 2.

(a)

Global model call: $\operatorname{lm}($ formula $=\mathrm{V} 1$ Treatment + Mass + Ttemp, na.action = "na.fail")

$$
---
$$

Model selection table

$$
\text { (Intrc) Mass Trtmn Ttemp df logLik AICc delta weight }
$$

$\begin{array}{llllllll}7 & -0.33760+0.05098 & 4 & 7.068 & -4.5 & 0.00 & 0.442\end{array}$

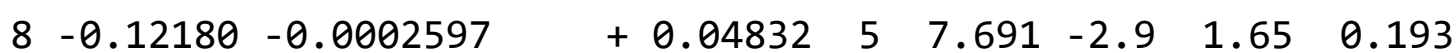

$\begin{array}{llllllll}30.84370+ & + & 3 & 4.256 & -1.6 & 2.95 & 0.101\end{array}$

$\begin{array}{lllllllll}4 & 1.03600 & -0.0003239+4 & + & 5.076 & -0.6 & 3.98 & 0.060\end{array}$

$\begin{array}{lllllllll}6 & 0.32350 & -0.0004371 & 0.03670 & 4 & 5.074 & -0.5 & 3.99 & 0.060\end{array}$

$2 \quad 1.17100-0.0004545 \quad 3 \quad 3.672 \quad-0.4 \quad 4.12 \quad 0.056$

50.04507

10.92110

$\begin{array}{llllll}0.03838 & 3 & 3.474 & 0.0 & 4.51 & 0.046\end{array}$

Models ranked by $\operatorname{AICc}(x)$

(b)

Global model call: $\operatorname{lm}($ formula = V2 Treatment + Mass + Ttemp, na.action = "na.fail")

$$
\text { - - }
$$

Model selection table

$$
\text { (Intrc) Mass Trtmn Ttemp df logLik AICc delta weight }
$$

$\begin{array}{lllllllll}2 & 1.3950-0.0004256 & & 3 & 3.430 & 0.1 & 0.00 & 0.307 \\ 1 & 1.1610 & & & 2 & 2.058 & 0.3 & 0.26 & 0.269 \\ 3 & 1.1350 & + & 3 & 2.281 & 2.4 & 2.30 & 0.097 \\ 6 & 1.1050-0.0004196 & 0.01257 & 4 & 3.585 & 2.4 & 2.37 & 0.094 \\ 5 & 0.8374 & & 0.01418 & 3 & 2.239 & 2.4 & 2.38 & 0.093 \\ 4 & 1.3790 & -0.0004104 & + & 4 & 3.448 & 2.7 & 2.64 & 0.082 \\ 7 & 0.7082 & & +0.01843 & 4 & 2.578 & 4.4 & 4.38 & 0.034 \\ 8 & 1.0330-0.0003912 & +0.01443 & 5 & 3.641 & 5.2 & 5.15 & 0.023\end{array}$

Models ranked by $\operatorname{AICc}(x)$ 
(c)

Global model call: $\operatorname{lm}($ formula $=$ VD Treatment + Mass + Ttemp, na.action = "na.fail") - -

Model selection table

(Intrc) Mass Trtmn Ttemp df logLik AICc delta weight

10.2400

$\begin{array}{lllll}2 & -0.955 & 6.4 & 0.00 & 0.324\end{array}$

$3 \quad 0.2917$

$5 \quad 0.7924$

71.0460

$20.2241 \quad 2.894 \mathrm{e}-05$

$+\quad 3-0.2037 .30 .970 .199$

$4 \quad 0.3430-8.645 e-05$

$6 \quad 0.7812 \quad 1.749 \mathrm{e}-05$

$81.1550-1.315 \mathrm{e}-04$

$\begin{array}{llllll}-0.02420 & 3 & -0.521 & 8.0 & 1.61 & 0.145\end{array}$

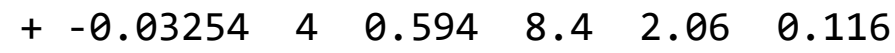

$\begin{array}{lllll}3 & -0.950 & 8.8 & 2.47 & 0.094\end{array}$

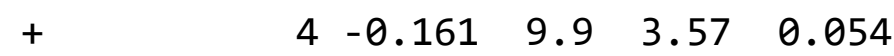

$\begin{array}{llllll}-0.02413 & 4 & -0.519 & 10.6 & 4.28 & 0.038\end{array}$

Models ranked by $\operatorname{AICC}(x)$

(d)

Global model call: glm(formula = Twitch Treatment + Mass + Ttemp, family = "poisson", na.action = "na.fail")

Model selection table

(Intrc) Mass Trtmn Ttemp df logLik AICc delta weight

$\begin{array}{llllllll}5 & -2.67800 & 0.1434 & 2 & -43.797 & 92.1 & 0.00 & 0.262\end{array}$

$\begin{array}{lllllll}1 & 0.61310 & 1 & -45.317 & 92.8 & 0.69 & 0.186\end{array}$

$\begin{array}{lllllllll}6 & -3.43400 & 0.001222 & 0.1468 & 3 & -42.908 & 92.9 & 0.79 & 0.177\end{array}$

$\begin{array}{llllllll}2 & -0.05583 & 0.001205 & 2 & -44.519 & 93.6 & 1.44 & 0.128\end{array}$

$\begin{array}{llllllll}7 & -2.91800+0.1516 & 3 & -43.725 & 94.5 & 2.43 & 0.078\end{array}$

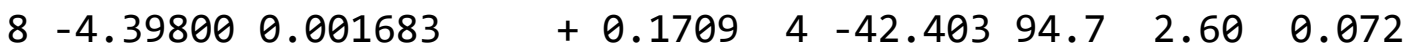

$\begin{array}{llllllll}30.61900+ & + & -45.316 & 95.2 & 3.04 & 0.057\end{array}$

$\begin{array}{llllllll}4-0.25900 & 0.001437+3 & -44.395 & 95.9 & 3.77 & 0.040\end{array}$

Models ranked by $\operatorname{AICc}(x)$ 
(e)

Global model call: glm(formula = RAMP1 Treatment + Mass + Ttemp, family = "poisson", na.action = "na.fail")

Model selection table

\begin{tabular}{|c|c|c|c|c|c|c|c|c|}
\hline (Intrc) & Mass & Trtmn & Ttemp & $d f$ & $\log L i k$ & $\mathrm{AICC}$ & delta & weight \\
\hline 1.596 & & & & 1 & -50.678 & 103.5 & 0.00 & 0.445 \\
\hline 1.609 & & + & & 2 & -50.663 & 105.8 & 2.28 & 0.142 \\
\hline 1.5 & & & 0.003089 & 2 & -50.676 & 105.8 & 2.31 & 0.140 \\
\hline 1.585 & $1.915 e-05$ & & & 2 & -50 & 105.8 & 2.31 & 0 \\
\hline 1.575 & & + & 0.001510 & 3 & -50 & 108.3 & 4.78 & 0 . \\
\hline 1.613 & $-6.844 e-06$ & + & & 3 & -5 & 10 & 4.78 & 41 \\
\hline 1.509 & $2.251 e-05$ & & 0.003260 & 3 & -50.675 & 108.3 & 4.81 & $0.04 t$ \\
\hline 1.578 & $-4.240 e-06$ & + & 0.001456 & 4 & -50.663 & 111.0 & 7.49 & 0.0 \\
\hline
\end{tabular}

Models ranked by $\operatorname{AICC}(x)$

(f)

Global model call: glm(formula = RAMP2 Treatment + Mass + Ttemp, family = "poisson", na.action = "na.fail")

Model selection table

\begin{tabular}{|c|c|c|c|c|c|c|c|c|}
\hline (Intrc) & Mass & Trtmn & Ttemp & $d f$ & logLik & AICC & delta & weight \\
\hline 1.555 & & & & 1 & -52.215 & 106.6 & 0.00 & 0.432 \\
\hline 1.438 & 0.0002108 & & & 2 & -52.136 & 108.7 & 2.14 & 0.148 \\
\hline 1.807 & & & -0.01108 & 2 & -52.188 & 108.8 & 2.25 & 0.140 \\
\hline 1.571 & & + & & 2 & -52.192 & 108.8 & 2.26 & 0.140 \\
\hline 1.677 & 0.0002071 & & -0.01036 & 3 & -52.113 & 111.1 & 4.58 & 0.044 \\
\hline 1.455 & 0.0001940 & + & & 3 & -52.132 & 111.2 & 4.61 & 0.043 \\
\hline 1.892 & & + & -0.01387 & 3 & -52.152 & 111.2 & 4.65 & 0.042 \\
\hline 1.744 & 001789 & + & -0.01207 & 4 & -52.101 & 113.8 & 7.23 & 0.012 \\
\hline
\end{tabular}


Table S19. Model selection outputs for behaviour-track cooler responses of SEL vs. SEH fish, showing models for (a) VR 1 , (b) VR 2 , (c) $\triangle \mathrm{VR}$, (d) opercular twitch count, (e) RAMP 1, and (f) RAMP 2.

(a)

Global model call: $\operatorname{lm}($ formula = V1 Treatment + Mass + Ttemp, na.action = "na.fail")

$$
\text { - - - }
$$

Model selection table

$$
\text { (Intrc) Mass Trtmn Ttemp df logLik AICc delta weight }
$$

$\begin{array}{lllllllll}6 & 0.09631 & -0.001182 & 0.06700 & 4 & 7.624 & -5.6 & 0.00 & 0.744\end{array}$

$\begin{array}{lllllllll}8 & 0.09630 & -0.001182 & +0.06700 & 5 & 7.624 & -2.6 & 2.94 & 0.171\end{array}$

$\begin{array}{llllllll}5 & -0.53500 & 0.06863 & 3 & 3.143 & 0.7 & 6.25 & 0.033\end{array}$

$\begin{array}{llllllll}2 & 1.61800 & -0.001211 & 3 & 3.120 & 0.7 & 6.30 & 0.032\end{array}$

$\begin{array}{llllllll}7 & -0.53260+0.06878 & 4 & 3.153 & 3.4 & 8.94 & 0.009\end{array}$

$41.61400-0.001214+4 \quad 4 \quad 3.128 \quad 3.4 \quad 8.99 \quad 0.008$

$\begin{array}{llllllll}1 & 1.00900 & 2 & -0.445 & 5.4 & 10.93 & 0.003\end{array}$

$\begin{array}{llllllll}31.01000 & + & -0.445 & 7.9 & 13.43 & 0.001\end{array}$

Models ranked by $\operatorname{AICc}(x)$

(b)

Global model call: $\operatorname{lm}($ formula = V2 Treatment + Mass + Ttemp, na.action = "na.fail")

Model selection table

(Intrc) Mass Trtmn Ttemp df logLik AICc delta weight

$\begin{array}{lllllllll}2 & 1.7360 & -0.001075 & & 3 & 7.214 & -7.5 & 0.00 & 0.465 \\ 6 & 1.1440 & -0.001063 & 0.02606 & 4 & 8.012 & -6.4 & 1.11 & 0.267 \\ 4 & 1.7280 & -0.001080 & + & 4 & 7.252 & -4.8 & 2.63 & 0.125 \\ 8 & 1.1430 & -0.001067 & +0.02584 & 5 & 8.038 & -3.5 & 4.00 & 0.063 \\ 1 & 1.1950 & & 2 & 3.512 & -2.6 & 4.91 & 0.040 \\ 5 & 0.5761 & & 0.02753 & 3 & 4.200 & -1.4 & 6.03 & 0.023 \\ 3 & 1.1900 & + & 3 & 3.519 & -0.1 & 7.39 & 0.012 \\ 7 & 0.5749 & +0.02745 & 4 & 4.202 & 1.3 & 8.73 & 0.006\end{array}$

Models ranked by $\operatorname{AICc}(x)$ 
(c)

Global model call: $\operatorname{lm}($ formula $=$ VD Treatment + Mass + Ttemp, na.action = "na.fail") - -

Model selection table

\begin{tabular}{|c|c|c|c|c|c|c|c|c|}
\hline (Intrc) & Mass & Trtmn & Ttemp & $d f$ & $\operatorname{logLik}$ & AICC & delta & weight \\
\hline 1.1110 & & & -0.04110 & 3 & 4.491 & -2.0 & 0.00 & 0.348 \\
\hline 0.1862 & & & & 2 & 2.971 & -1.5 & 0.54 & 0.266 \\
\hline 1.0470 & 0.0001191 & & -0.04094 & 4 & 4.534 & 0.6 & 2.62 & 0.094 \\
\hline 1.1080 & & + & -0.04133 & 4 & 4.514 & 0.6 & 2.66 & 0.092 \\
\hline 0.1174 & 0.0001368 & & & 3 & 3.022 & 0.9 & 2.94 & 0.080 \\
\hline 0.1810 & & + & & 3 & 2.979 & 1.0 & 3.02 & 0.077 \\
\hline 1.0460 & 0.0001151 & + & -0.04115 & 5 & 4.554 & 3.5 & 5.52 & 0.022 \\
\hline 0.1139 & 0.0001345 & + & & 4 & 3.028 & 3.6 & 5.63 & 0.021 \\
\hline
\end{tabular}

Models ranked by $\operatorname{AICc}(x)$

(d)

Global model call: glm(formula = Twitch Treatment + Mass + Ttemp, family = "poisson", na.action = "na.fail")

Model selection table

\begin{tabular}{|c|c|c|c|c|c|c|c|c|}
\hline (Intrc) & Mass & Trtmn & Ttemp & $d f$ & logLik & AICC & delta & weight \\
\hline 0.6729 & & & & 1 & -39.999 & 82.2 & 0.00 & 0.300 \\
\hline-2.0950 & & & 0.1226 & 2 & -38.884 & 82.3 & 0.14 & 0.279 \\
\hline 1.0900 & -0.0008606 & & & 2 & -39.854 & 84.3 & 2.08 & 0.106 \\
\hline 0.6061 & & + & & 2 & -39.905 & 84.4 & 2.18 & 0.10 \\
\hline-2.1040 & & + & 0.1207 & 3 & -38.825 & 84.8 & 2.62 & 0.081 \\
\hline-1.7490 & -0.0005221 & & 0.1185 & 3 & -38.828 & 84.8 & 2.63 & 0.08 \\
\hline 1.0200 & -0.0008540 & + & & 3 & -39.757 & 86.7 & 4.49 & 0.03 \\
\hline-1.7520 & -0.0005353 & + & 0.1165 & 4 & -38.764 & 87.5 & 5.36 & 0.02 \\
\hline
\end{tabular}


(e)

Global model call: glm(formula = RAMP1 Treatment + Mass + Ttemp, family = "poisson", na.action = "na.fail")

Model selection table

\begin{tabular}{|c|c|c|c|c|c|c|c|c|}
\hline (Intrc) & Mass & Trtmn & Ttemp & $d f$ & $\log \mathrm{Lik}$ & AICC & delta & weight \\
\hline 1.553 & & & & 1 & -50.467 & 103.1 & 0.00 & 0.433 \\
\hline 1.087 & & & 0.02065 & 2 & -50.386 & 105.2 & 2.15 & 0.148 \\
\hline 1.580 & & + & - & 2 & -50.416 & 105.3 & 2.21 & 0.143 \\
\hline 1.531 & $4.348 e-05$ & & & 2 & -50.466 & 105.4 & 2.31 & 0.136 \\
\hline 1.099 & & + & -0.02147 & 3 & -50.329 & 107.6 & 4.54 & 0.04 \\
\hline 1.059 & $5.321 e-05$ & & 0.02074 & 3 & -50.384 & 107.7 & 4.65 & 0.042 \\
\hline 1.552 & $5.806 e-05$ & + & - & 3 & -50.414 & 107.8 & 4.71 & 0.04 \\
\hline 1.061 & $6.984 e-05$ & + & -0.02161 & 4 & -50.326 & 110.3 & 7.24 & 0.01 \\
\hline
\end{tabular}

(f)

Global model call: glm(formula = RAMP2 Treatment + Mass + Ttemp, family = "poisson", na.action = "na.fail")

Model selection table

\begin{tabular}{|c|c|c|c|c|c|c|c|c|c|}
\hline & Intrc) & Mass & Trtmn & Ttemp & $d f$ & $\log L i k$ & $\mathrm{AICC}$ & delta & weight \\
\hline 1 & 1.560 & & & & 1 & -50.520 & 103.2 & 0.00 & 0.432 \\
\hline 5 & 2.072 & & & -0.02280 & 2 & -50.418 & 105.3 & 2.11 & 0.150 \\
\hline 3 & 1.535 & & + & & 2 & -50.482 & 105.4 & 2.24 & 0.141 \\
\hline 2 & 1.582 & $-4.437 e-05$ & & & 2 & -50.519 & 105.5 & 2.31 & 0.136 \\
\hline 7 & 2.060 & & + & -0.02345 & 3 & -50.375 & 107.7 & 4.52 & 0.045 \\
\hline 6 & 2.100 & $-5.330 e-05$ & & -0.02285 & 3 & -50.417 & 107.8 & 4.61 & 0.043 \\
\hline 4 & 1.563 & $-5.603 e-05$ & + & & 3 & -50.480 & 107.9 & 4.73 & 0.041 \\
\hline 8 & 2.094 & $-6.535 e-05$ & + & -0.02351 & 4 & -50.372 & 110.4 & 7.22 & 0.012 \\
\hline
\end{tabular}


Table S20. Model selection outputs for behaviour-track arena responses of HC vs. BB fish, showing models for (a) refuge emergence, (b) refuge emergence time, (c) threat perception of lifting refuge, (d) line cross counts, (e) number of refuge re-entries, and (f) time spent in the re-entered refuge.

(a)

Global model call: glm(formula = EM Treatment + Length + Ttemp, family = "binomial", na.action = "na.fail") $--$

Model selection table

(Intrc) Lngth Trtmn Ttemp df logLik AICc delta weight

$1-0.6931$

$2 \quad 6.1580-0.02125$

52.2960

$3-0.8109$

$4 \quad 6.6990-0.02373$

$\begin{array}{lll}6 & 9.4720 & -0.02152\end{array}$

$7 \quad 2.4330$

$8 \quad 10.7800-0.02444$

$\begin{array}{lllll}1 & -17.186 & 36.5 & 0.00 & 0.356\end{array}$

$\begin{array}{lllll}2 & -16.520 & 37.5 & 1.01 & 0.215\end{array}$

$\begin{array}{llllll}-0.1290 & 2 & -17.098 & 38.7 & 2.16 & 0.121\end{array}$

$\begin{array}{lllll}+ & 2-17.14938 .8 & 2.27 & 0.115\end{array}$

$+\quad 3-16.34939 .7 \quad 3.210 .071$

$\begin{array}{llllll}-0.1392 & 3 & -16.420 & 39.9 & 3.35 & 0.067\end{array}$

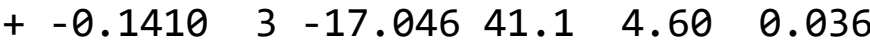

Models ranked by $\operatorname{AICc}(x)$

$+\begin{array}{llllll}-0.1676 & 4 & -16.209 & 42.2 & 5.70 & 0.021\end{array}$ 
(b)

Global model call: $\operatorname{lm}($ formula $=\mathrm{ET} \sim$ Treatment + Length + Ttemp, na.action = "na.fail")

-..

Model selection table

(Intrc) Lngth Trtmn Ttemp df logLik AICc delta weight

$\begin{array}{lllllllll}6 & 3919.0 & -4.512 & -97.41 & 4 & -46.417 & 110.8 & 0.00 & 0.946\end{array}$

$83870.0-3.961+-101.305-43.586117 .26 .340 .040$

$\begin{array}{lllllllll}2 & 1780.0 & -4.851 & 3 & -54.754 & 120.3 & 9.47 & 0.008\end{array}$

$\begin{array}{llllllll}5 & 2720.0 & -107.50 & 3 & -56.017 & 122.8 & 12.00 & 0.002\end{array}$

$\begin{array}{llllllll}1 & 240.7 & 2 & -58.617 & 123.2 & 12.40 & 0.002\end{array}$

$72953.0+-113.90 \quad 4 \quad-53.809125 .6 \quad 14.78 \quad 0.001$

$\begin{array}{llllllll}3 & 315.2+3 & -57.793 & 126.4 & 15.55 & 0.000\end{array}$

$4 \quad 1710.0-4.568+4 \quad 4-54.660127 .3 \quad 16.490 .000$

Models ranked by $\operatorname{AICC}(x)$

(c)

Global model call: glm(formula = Threat Treatment + Length + Ttemp, family = "binomial", na.action = "na.fail")

Model selection table

(Intrc) Lngth Trtmn Ttemp df logLik AICc delta weight

$\begin{array}{llllllllll}8 & -8.7210 & 0.09647 & + & -0.9708 & 4 & -4.487 & 20.1 & 0.00 & 0.296\end{array}$

$4-31.75000 .09950+3 \quad-6.26320 .2 \quad 0.190 .270$

$\begin{array}{lllllllll}6 & -11.6800 & 0.11120 & -1.0980 & 3 & -6.280 & 20.3 & 0.22 & 0.265\end{array}$

$\begin{array}{llllllll}2 & -23.0100 & 0.06871 & 2 & -9.151 & 23.1 & 3.05 & 0.064\end{array}$

$\begin{array}{llllllll}5 & 21.3500 & -0.9402 & 2 & -9.363 & 23.5 & 3.47 & 0.052\end{array}$

$\begin{array}{llllllll}7 & 23.3100+ & -0.9925 & 3 & -8.508 & 24.7 & 4.68 & 0.029\end{array}$

$\begin{array}{lllllll}1 & -0.4520 & 1 & -12.028 & 26.3 & 6.26 & 0.013\end{array}$

$\begin{array}{llllllll}3 & 0.2231 & + & -10.950 & 26.7 & 6.65 & 0.011\end{array}$

Models ranked by $\operatorname{AICc}(x)$ 
(d)

Global model call: glm(formula = Lines Treatment + Length + Ttemp + Threat, family = "poisson",

$$
\text { na.action = "na.fail") }
$$

Model selection table

\begin{tabular}{|c|c|c|c|c|c|c|c|c|c|}
\hline (Intrc) & Lngth & Thret & Trtmn & Ttemp & $d f$ & $\log$ Lik & AICC & delta & weight \\
\hline 5.577 & -0.0049620 & + & + & & 4 & -164.865 & 340.8 & 0.00 & 0.801 \\
\hline 5.313 & -0.0053990 & + & + & 0.016540 & 5 & -164.629 & 344.3 & 3.45 & 0.143 \\
\hline 4.083 & & + & + & & 3 & -169.574 & 346.9 & 6.05 & 0.039 \\
\hline 4.314 & & + & + & -0.009686 & 4 & -169.480 & 350.0 & 9.23 & 0.008 \\
\hline 4.986 & & & + & -0.034940 & 3 & -172.042 & 351.8 & 10.99 & 0.003 \\
\hline 4.183 & & & + & & 2 & -173.622 & 352.0 & 11.24 & 0.003 \\
\hline 5.232 & -0.0006573 & & + & -0.036410 & 4 & -171.891 & 354.9 & 14.05 & 0.001 \\
\hline 4.298 & -0.0003564 & & + & & 3 & -173.577 & 354.9 & 14.06 & 0.001 \\
\hline 4.218 & & + & & & 2 & -175.451 & 355.7 & 14.89 & 0.000 \\
\hline 4.259 & & & & & 1 & -177.022 & 356.3 & 15.49 & 0.000 \\
\hline 4.831 & & & & -0.024590 & 2 & -176.197 & 357.2 & 16.39 & 0.000 \\
\hline 4.527 & -0.0009690 & + & & & 3 & -175.195 & 358.1 & 17.30 & 0.000 \\
\hline 4.446 & & + & & -0.009538 & 3 & -175.359 & 358.4 & 17.63 & 0.000 \\
\hline 4.143 & 0.0003 & & & & 2 & -176.976 & 358.8 & 17.95 & 0.000 \\
\hline 4.748 & 0.0002308 & & & -0.024290 & 3 & -176.178 & 360.1 & 19.26 & 0.000 \\
\hline 4.635 & -0.0008768 & + & & -0.005738 & 4 & -175.164 & 361.4 & 20.60 & 0.000 \\
\hline
\end{tabular}


(e)

Global model call: glm(formula = Re.enter Treatment + Length + Ttemp, family = "poisson", na.action = "na.fail")

Model selection table

(Intrc) Lngth Trtmn Ttemp df logLik AICc delta weight

$\begin{array}{llllllll}5 & 1.714 \mathrm{e}+01 & -0.7545 & 2 & -9.028 & 24.1 & 0.00 & 0.434\end{array}$

$14.332 \mathrm{e}-13 \quad 1-11.07924 .7 \quad 0.68 \quad 0.309$

$\begin{array}{llllllll}3-2.877 e-01+2 & -10.849 & 27.7 & 3.64 & 0.070\end{array}$

$\begin{array}{lllllllll}6 & 1.748 \mathrm{e}+01 & 0.014770 & -0.9787 & 3 & -8.489 & 27.8 & 3.72 & 0.067\end{array}$

$\begin{array}{llllllll}2 & -1.709 \mathrm{e}+00 & 0.005354 & 2 & -10.986 & 28.0 & 3.92 & 0.061\end{array}$

$\begin{array}{lllllllll}7 & 1.712 \mathrm{e}+01+ & +0.7666 & 3 & -8.796 & 28.4 & 4.34 & 0.050\end{array}$

$4-9.247 \mathrm{e}-010.002087+3-10.83632 .5 \quad 8.420 .006$

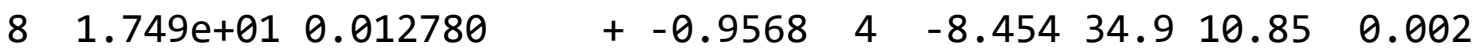

Models ranked by $\operatorname{AICC}(x)$

(f)

Global model call: $\operatorname{lm}($ formula = RefT Treatment + Length + Ttemp, na.action = "na.fail")

Model selection table

(Intrc) Lngth Trtmn Ttemp df logLik AICc delta weight

182.22

51290.00

$\begin{array}{llll}2 & -355.70 & 1.379\end{array}$

$3 \quad 86.25$

$6 \quad 872.10 \quad 1.574$

71315.00

$\begin{array}{llll}4 & -451.50 & 1.762\end{array}$

$\begin{array}{lll}8 & 823.90 & 2.120\end{array}$

Models ranked by $\operatorname{AICC}(x)$

$\begin{array}{rrrrrr} & 2 & -54.975 & 116.0 & 0.00 & 0.635 \\ -52.40 & 3 & -53.775 & 118.3 & 2.40 & 0.191 \\ & 3 & -54.477 & 119.8 & 3.80 & 0.095 \\ & 3 & -54.970 & 120.7 & 4.79 & 0.058 \\ -55.93 & 4 & -52.901 & 123.8 & 7.85 & 0.013 \\ -53.08 & 4 & -53.742 & 125.5 & 9.53 & 0.005 \\ & 4 & -54.293 & 126.6 & 10.64 & 0.003 \\ -59.82 & 5 & -52.384 & 134.8 & 18.82 & 0.000\end{array}$

$$
\text { (n) }
$$


Table S21. Model selection outputs for behaviour-track arena responses of E vs. HC fish, showing models for (a) threat perception of lifting refuge and (b) line cross counts.

(a)

Global model call: glm(formula = Threat Treatment + Length + Ttemp, family = "binomial", na.action = "na.fail") $--$

Model selection table

(Intrc) Lngth Trtmn Ttemp df logLik AICc delta weight

$\begin{array}{llllllll}2 & -15.4600 & 0.04283 & 2 & -9.108 & 22.9 & 0.00 & 0.558\end{array}$

$\begin{array}{lllllllll}4 & -14.2200 & 0.04024 & + & 3 & -8.911 & 25.3 & 2.40 & 0.168\end{array}$

$\begin{array}{lllllllll}6 & -11.5000 & 0.04274 & -0.1706 & 3 & -9.004 & 25.5 & 2.59 & 0.153\end{array}$

$\begin{array}{lllllll}1 & -0.6190 & 1 & -12.949 & 28.1 & 5.20 & 0.042\end{array}$

$\begin{array}{llllllllll}8 & -11.3600 & 0.04044 & + & -0.1293 & 4 & -8.853 & 28.4 & 5.45 & 0.037\end{array}$

$\begin{array}{llllllll}3 & -0.1823+ & 2 & -12.346 & 29.4 & 6.48 & 0.022\end{array}$

$\begin{array}{llllllll}5 & 3.2920 & -0.1692 & 2 & -12.777 & 30.3 & 7.34 & 0.014\end{array}$

$\begin{array}{llllllll}7 & 2.3900+ & -0.1125 & 3 & -12.275 & 32.0 & 9.13 & 0.006\end{array}$

Models ranked by $\operatorname{AICc}(x)$ 
(b)

Global model call: glm(formula = Lines Treatment + Length + Ttemp + Threat, family = "poisson",

$$
\text { na.action = "na.fail") }
$$

Model selection table

(Intrc) Lngth Thret Trtmn Ttemp df logLik AICc delta weight

$160.011350 .005974++\quad+0.084445-214.032442 .3 \quad 0.00 \quad 0.999$

$8 \quad 1.86000 \quad 0.006304$

$140.65790 \quad 0.002613$

151.88700

$\begin{array}{lllll}4 & -222.772 & 456.2 & 13.86 & 0.001\end{array}$

131.69300

$\begin{array}{lll}6 & 3.06600 & 0.002272\end{array}$

$120.00880 \quad 0.005086$

$\begin{array}{ll}7 & 3.92800\end{array}$

53.85400

111.68500

$\begin{array}{lll}4 & 2.49700 & 0.005175\end{array}$

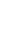

$+0.099374-226.282463 .2$

$+$

$+0.08792$

$\begin{array}{lll}4 & -229.319 & 469.3\end{array}$

20.88

$+0.09381$

$+$

$3-231.215469 .9$

26.95

0.000

$3-238.695484 .9$

27.58

0.000

$+$ $\begin{array}{lllll}0.10730 & 4 & -237.229 & 485.1\end{array}$

42.54

0.000

$3-238.974 \quad 485.4$

$\begin{array}{llll}0.10660 & 2 & -242.391 & 489.5 \\ 0 & -250.204 & 507.9\end{array}$

$+$

42.78

0.000

$+\quad+$

$+$

$\begin{array}{lll}10 & 0.73970 & 0.001580\end{array}$

$3-252.947513 .4$

47.14

65.56

0.000

0.12080

0.11700

$3-255.104517 .7$

91.36800

$2-257.078 \quad 518.9$

$2-265.868 \quad 536.4$

0.000

34.18600

$\begin{array}{llll}1 & -276.109 & 554.4 & 112.09\end{array}$

$\begin{array}{lllll}2 & -275.170 & 555.0 & 112.70\end{array}$

0.000

0.000

0.000

$23.72200 \quad 0.001097$

Models ranked by $\operatorname{AICC}(x)$ 
Table S22. Model selection outputs for behaviour-track arena responses of SE vs. E fish, showing models for (a) threat perception of lifting refuge and (b) line cross counts.

(a)

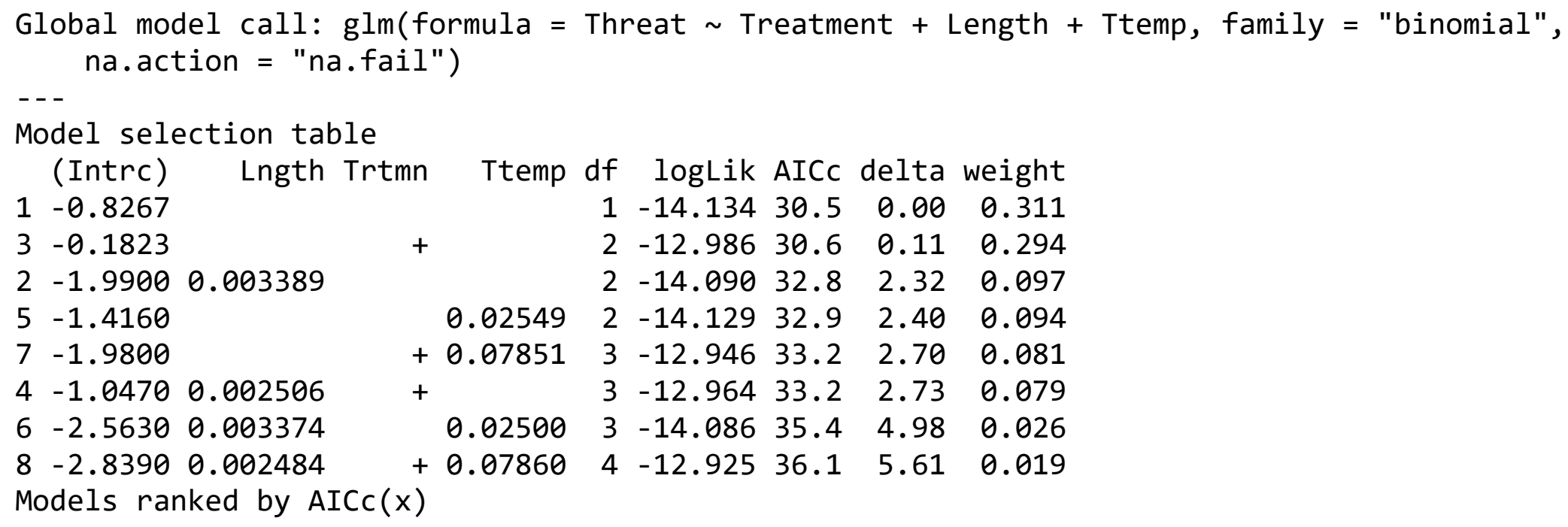


(b)

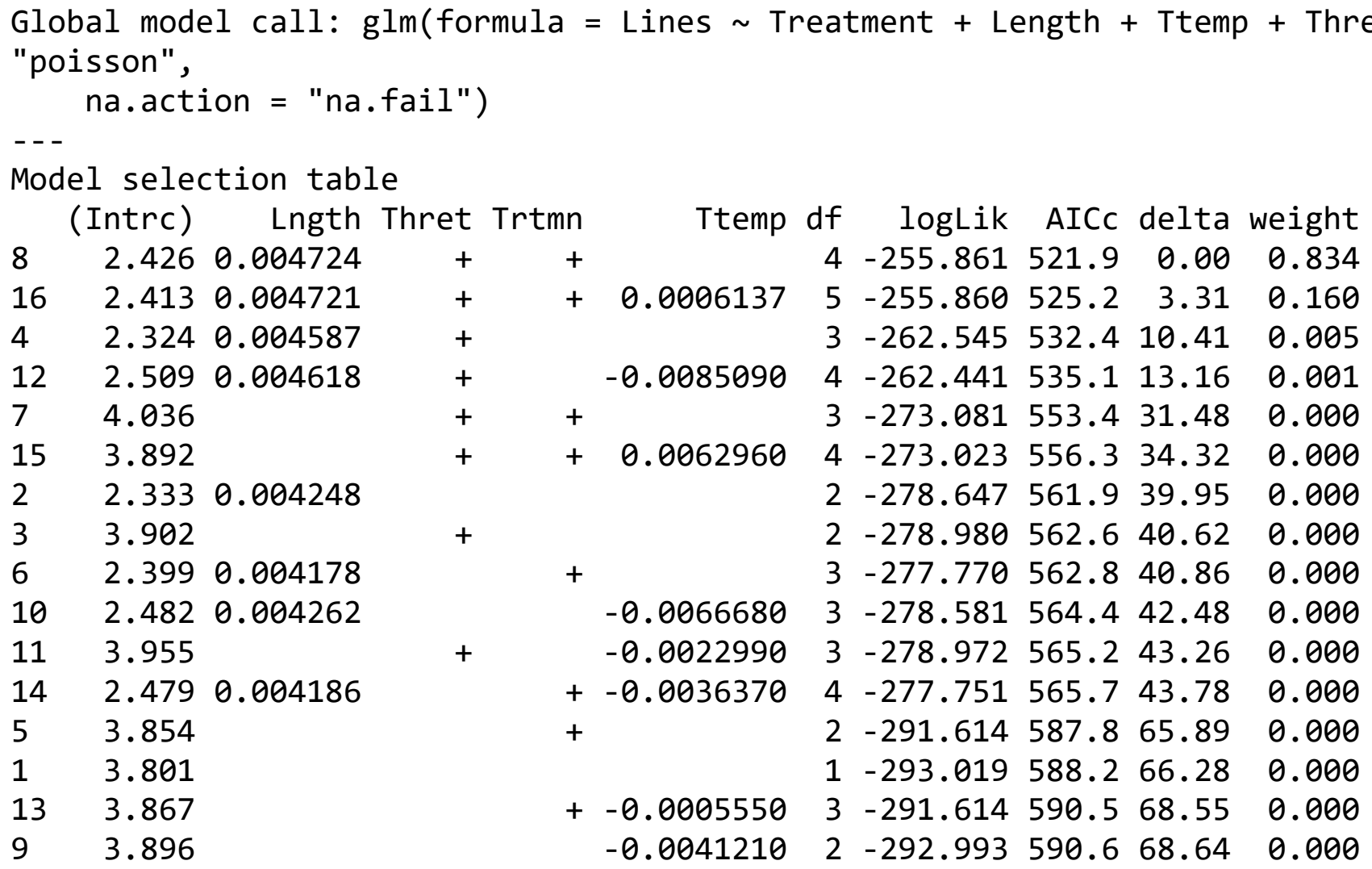

Models ranked by $\operatorname{AICc}(x)$ 
Table S23. Model selection outputs for behaviour-track arena responses of SEH vs. SE fish, showing models for (a) threat perception of lifting refuge and (b) line cross counts.

(a)

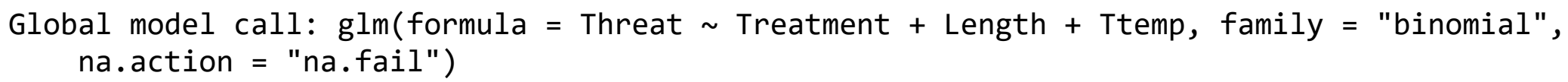


(b)

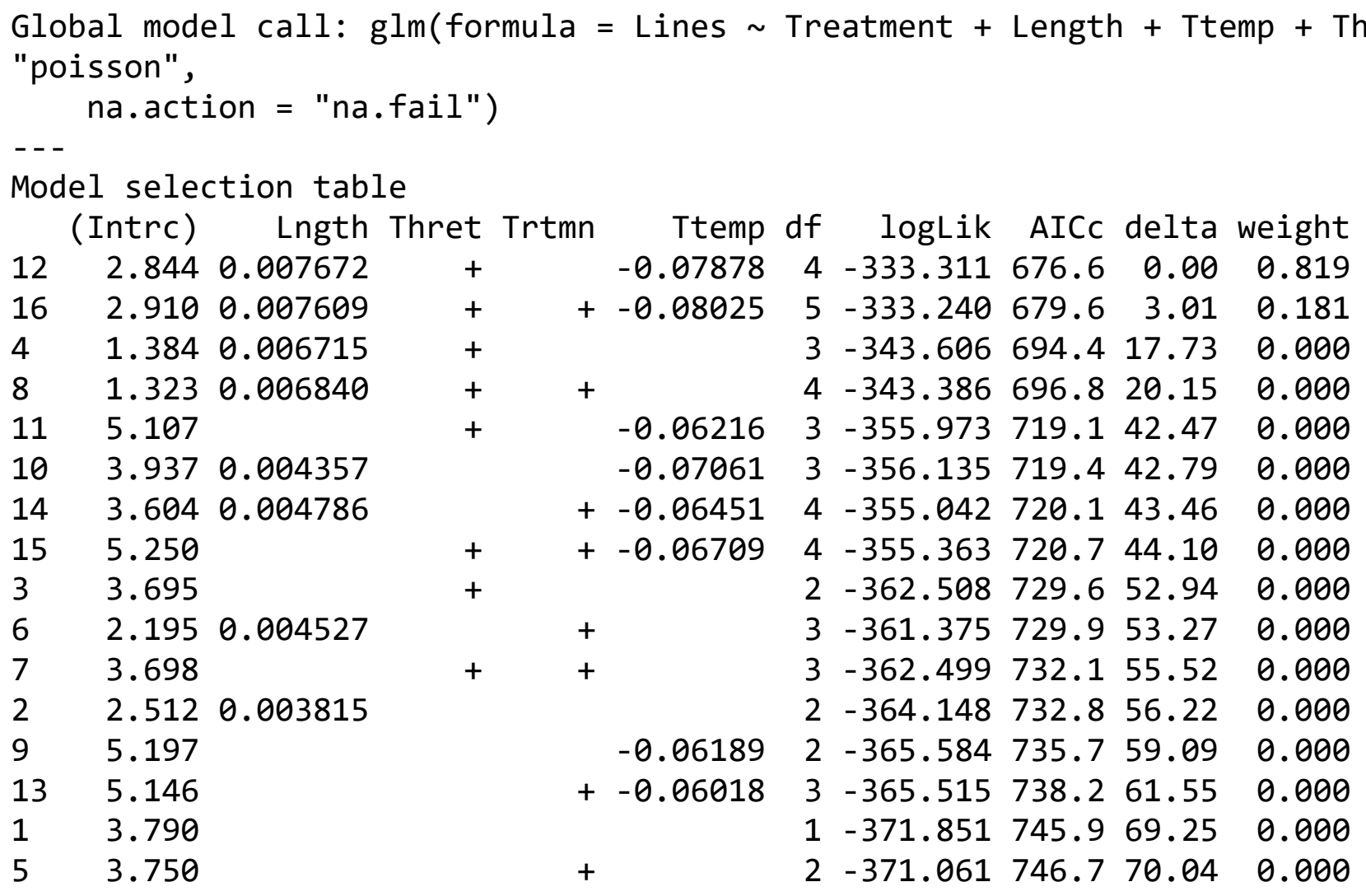


Table S24. Model selection outputs for behaviour-track arena responses of SEL vs. SEH fish, showing models for (a) threat perception of lifting refuge and (b) line cross counts.

(a)

Global model call: glm(formula = Threat Treatment + Length + Ttemp, family = "binomial", na.action = "na.fail")

$$
\text { - - - }
$$

Model selection table

(Intrc) Lngth Trtmn Ttemp df logLik AICc delta weight

10.0000

$\begin{array}{lllll}1 & -16.636 & 35.5 & 0.00 & 0.396\end{array}$

$5-5.1670$

0.2287

$2-3.26300 .01000$

$3-0.1542$

$\begin{array}{lll}6 & -8.7200 & 0.01061\end{array}$

$7-5.1190$

$4-3.5360 \quad 0.01035$

$8-8.7480 \quad 0.01089$

$\begin{array}{lllll}2 & -16.224 & 37.0 & 1.57 & 0.181\end{array}$

$\begin{array}{lllll}2 & -16.526 & 37.6 & 2.17 & 0.134\end{array}$

$+\quad 2-16.55237 .7 \quad 2.220 .130$

$\begin{array}{llllll}0.2328 & 3 & -16.103 & 39.4 & 3.95 & 0.055\end{array}$

$\begin{array}{llllll}+0.2211 & 3 & -16.173 & 39.5 & 4.09 & 0.051\end{array}$

$+\quad 3-16.43640 .14 .620 .039$

Models ranked by $\operatorname{AICC}(x)$ 
(b)

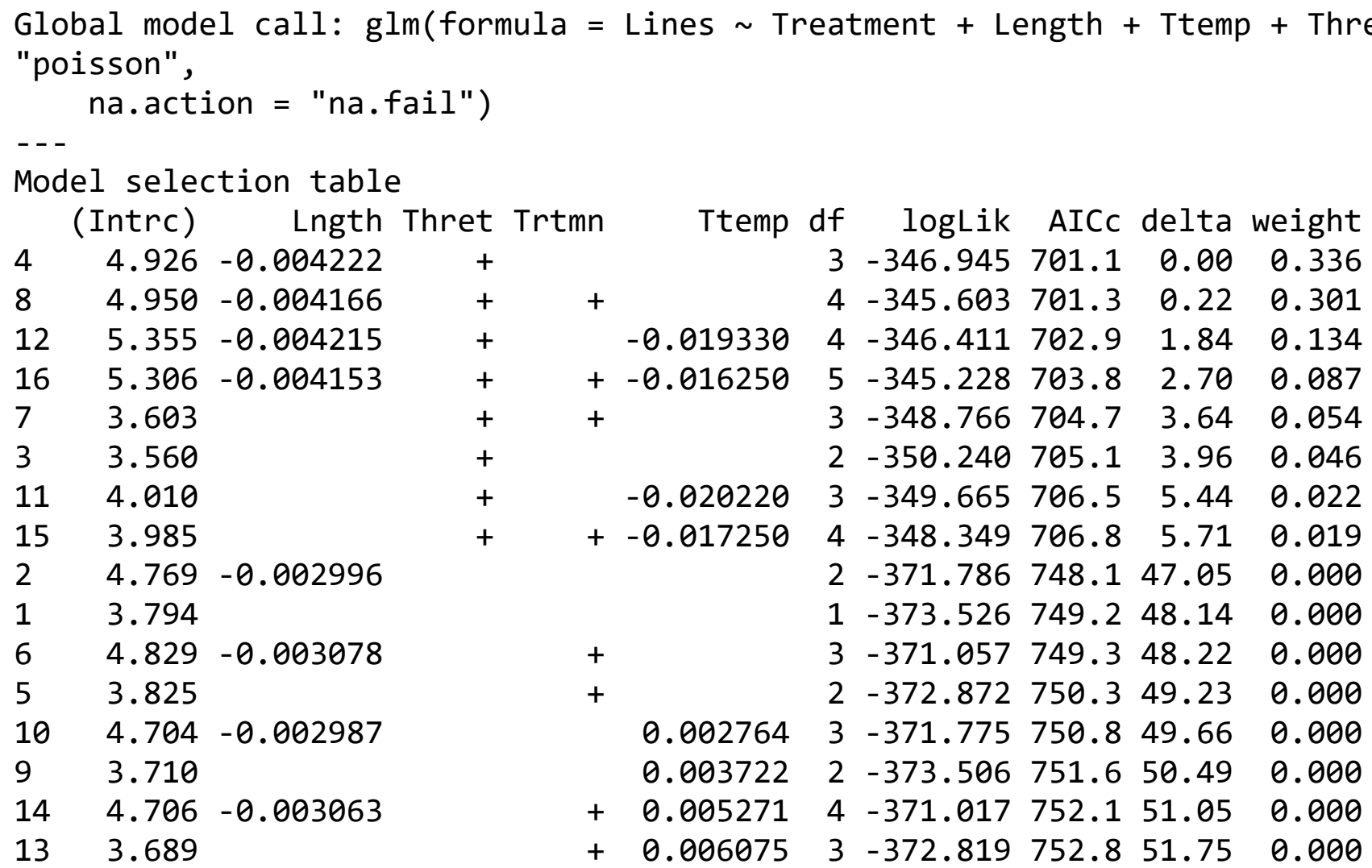

